\section{Pacific Northwest}

National Laboratory

Operated by Battelle for the

U.S. Department of Energy

\title{
300 Area Uranium Leach and Adsorption Project
}

\author{
R.J. Serne \\ C.F. Brown \\ H.T. Schaef \\ E.M. Pierce \\ J. Lindberg \\ Z. Wang \\ P. Gassman \\ J. Catalano
}

November 25, 2002

Prepared for Bechtel Hanford Company, Inc., and for the U.S. Department of Energy under Contract DE-AC06-76RL01830 


\title{
DISCLAIMER
}

This report was prepared as an account of work sponsored by an agency of the United States Government. Neither the United States Government nor any agency thereof, nor Battelle Memorial Institute, nor any of their employees, makes any warranty, express or implied, or assumes any legal liability or responsibility for the accuracy, completeness, or usefulness of any information, apparatus, product, or process disclosed, or represents that its use would not infringe privately owned rights. Reference herein to any specific commercial product, process, or service by trade name, trademark, manufacturer, or otherwise does not necessarily constitute or imply its endorsement, recommendation, or favoring by the United States Government or any agency thereof, or Battelle Memorial Institute. The views and opinions of authors expressed herein do not necessarily state or reflect those of the United States Government or any agency thereof.

\author{
PACIFIC NORTHWEST NATIONAL LABORATORY \\ operated by \\ BATTELLE \\ for the \\ UNITED STATES DEPARTMENT OF ENERGY \\ under Contract DE-AC06-76RL01830
}

Printed in the United States of America

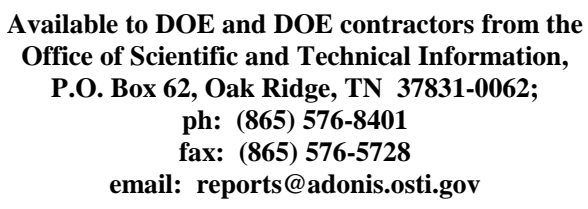

Available to the public from the National Technical Information Service, U.S. Department of Commerce, 5285 Port Royal Rd., Springfield, VA 22161 ph: (800) 553-6847 fax: $(703) 605-6900$

email: orders@ntis.fedworld.gov

online ordering: http://www.ntis.gov/ordering.htm 


\title{
300 Area Uranium Leach and Adsorption Project
}

\author{
R. Jeff Serne \\ Chris F. Brown \\ H. Todd Schaef \\ Eric M. Pierce \\ Mike J. Lindberg \\ Zheming Wang ${ }^{(1)}$ \\ Paul Gassman ${ }^{(1)}$ \\ Jeff Catalano $^{(2)}$
}

November 25, 2002

Prepared for Bechtel Hanford Company, Inc., and

the U.S. D epartment of Energy

under Contract DE-AC06-76RL01830

Applied Geology and Geochemistry Group

Pacific Northwest National Laboratory

Richland, Washington 99352-0999

${ }^{(1)}$ Environmental Molecular Sciences Laboratory

Pacific Northwest National Laboratory

Richland, Washington 99352-0999

${ }^{(2)}$ Surface and Aqueous Geochemistry Group

Stanford University

Stanford, California 994305 


\section{Executive Summary}

The objective of the 300 Area $\mathrm{K}_{\mathrm{d}}$ /leach study was to perform controlled laboratory experiments to measure the leaching and adsorption characteristics of uranium in near-surface sediment samples collected from the 300 Area of the Hanford Site. The Environmental Restoration Contractor (ERC) will use the results of this research to model uranium mobility for the 300-FF1 and 300-FF-2 operable unit (OU) waste sites.

Eight near-surface sediment samples were collected by the ERC between December of 2000 and February 2001. The samples consisted of three uncontaminated background sediment samples (B11491, B11492, and B11493), two uranium-contaminated samples collected from the 300 Area North Process Pond (B11494 and B11495), and three uranium-contaminated samples collected in the vicinity of the 303-K building (B11BY4, B11BY5, and B11BY6).

Once received by the Applied Geology and Geochemistry Group at Pacific Northwest National Laboratory, the sediment samples were subjected to a series of mineralogical and geochemical measurements. The samples were found to be composed primarily of coarse-grained sand $\mathrm{s}$ with some gravel (sample B11494 contained slightly more silt and fine-grained material than all others). The organic carbon content of the samples was typical for Hanford soils $(<1 \%)$, with the exception of sample B11BY5, which contained almost $3 \%$ by weight organic carbon. Scanning electron micrographs (Appendix T) of the 53 to $75 \mu \mathrm{m}$ and the $<53 \mu \mathrm{m}$ size fractions from sample B11BY6 showed that the uranium contamination in the sediments is most likely present as co-precipitates and/or discrete uranium particles. State-of-the-art molecular probe techniques (Appendix U) also confirm the presence of crystalline discrete uranium bearing phases in the sediments from around the $303-\mathrm{K}$ building. The nature of the uranium in the sediments from the 300 Area N Process Pond is less certain. One technique used on sample B11494 from the N Process Pond suggests the presence of the same crystalline compounds found in samples from around $303-\mathrm{K}$ but, another technique suggests that the uranium in sample B11494 is less crystalline and predominately amorphous. In all cases, the uranium is present as oxidized uranium (uranyl [U(VI)]). Semi-selective extraction analysis of six near-surface sediment samples showed that the bulk of the extractable uranium in the contaminated sediments was associated with weak acid dissolvable phases (perhaps discrete uranyl compounds or associated with alkaline earth carbonates) and with amorphous hydrous iron and aluminum oxides, and that very little (a few percent or less) of the uranium is readily water-soluble or ion-exchangeable.

Results from large column leach tests showed that uranium leaching did not follow a constant solubility paradigm. Four of the five near-surface sediments showed a large near instantaneous release of a few percent of the total uranium in the first few pore volumes followed by a slower continual release that continued for many more pore volumes (months). Steady-state uranium leachate concentrations were never attained and leaching characteristics and trends were not consistent among the samples. Dissolution kinetics were slow, and the measured leach curves most likely represent a slow, kinetically-controlled desorption or dissolution paradigm. Results from the preliminary column and batch adsorption experiments showed that uranium sorption onto the uncontaminated sediment was highly variable, and that sorption was dependent on the solution concentrations of inorganic carbon, $\mathrm{pH}$, and to a lesser extent total dissolved solids. 
The laboratory work performed during fiscal year (FY) 2002 was changed from the original sampling and analysis plan (SAP) after analysis of the FY 2001 results. The SAP was amended to enable a more accurate prediction of uranium partition coefficients $\left(\mathrm{K}_{\mathrm{d}}\right)$ based on the range of water chemistry expected in the 300 Area vadose zone and unconfined aquifer. The amendment to the SAP included long-term batch leach tests (to provide equilibrium desorption $\mathrm{K}_{\mathrm{d}}$ values) and numerous batch uranium adsorption studies (to investigate the sensitivity of the adsorption $\mathrm{K}_{\mathrm{d}}$ to key variables such as $\mathrm{pH}$, carbonate, and uranium solution concentrations and total ionic strength). These FY 2002 batch adsorption tests were used to bound the chemical environment expected in two longer-term column flow-through adsorption/desorption tests.

Long-term static batch leach tests were used to investigate whether steady state uranium concentrations could be attained; ultimately enabling the determination of a desorption $\mathrm{K}_{\mathrm{d}}$ for the slowly leaching fraction observed in the large column leach tests. Aliquots of sediment taken from the large leach columns after they were stopped was subjected to three leaching solutions (deionized water, uncontaminated groundwater, and simulated vadose zone porewater) to determine how much of the recalcitrant uranium could be removed over a six-month period. Results from the batch leach test showed that less than four percent of the remaining uranium mass was removed by deionized water. The groundwater solution was slightly more effective, leaching as much as $10 \%$ of the recalcitrant uranium. The simulated vadose zone porewater solution was the most effective at leaching uranium, removing almost $30 \%$ of the residual total uranium mass in two out of the five contaminated samples.

Three batch adsorption experiments were performed to investigate the effect of uranium solution concentration, $\mathrm{pH}$, and dissolved inorganic carbon solution concentration on uranium adsorption onto the uncontaminated sediment. Uranium adsorption $\mathrm{K}_{\mathrm{d}}$ values ranged from $0 \mathrm{~mL} / \mathrm{g}$ to more than $100 \mathrm{~mL} / \mathrm{g}$ depending on which solution parameter was being adjusted. Results of the experiments showed that total inorganic carbon solution concentration had the greatest impact on uranium adsorption onto the uncontaminated 300 Area sediment. Solution $\mathrm{pH}$ was shown to be important in laboratory tests; however, the sediment in the field dominates the $\mathrm{pH}$ (i.e., buffers $\mathrm{pH}$ to a nearly constant value) thus minimizing its overall effect in the 300 Area sediments. Results from the batch adsorption tests also showed that uranium sorption onto the background sediment is linear up to uranium concentrations of $3 \mathrm{mg} / \mathrm{L}$ (holding all other parameters constant), which is well above the values found in the upper unconfined aquifer. Thus, the linear isotherm assumption holds for uranium in the 300 Area sediment/porewater environment. The natural vadose zone porewater and groundwater chemical compositions in the 300 Area are not constant. Carbonate, $\mathrm{pH}$, and other constituents vary in space and time because of evapotranspiration, transient rain fall/snow events, and the fluctuations of the Columbia River. River stage fluctuation causes groundwater and river water to mix at different proportions at different times of year and even different times of day when the dams are dominating the River flow. Therefore, the $\mathrm{K}_{\mathrm{d}}$ for uranium(VI) is not a constant even though the adsorption of uranium(VI) from a fixed composition solution onto the background sediment follows the linear isotherm. Therefore, the linear $\mathrm{K}_{\mathrm{d}}$ model, but not the constant $\mathrm{K}_{\mathrm{d}}$ model, is defensible in predicting the fate of uranium in the 300 Area aquifer plume.

Column adsorption tests were performed to assess the sorption, or loading, of uranium onto the background, or uncontaminated sediment. This test most closely predicts the fate of uranium 
contaminated solutions once they come into contact with "clean" or uncontaminated sediment. Uranium adsorption $\mathrm{K}_{\mathrm{d}}$ values ranged from $1.85 \mathrm{~mL} / \mathrm{g}$ in the low ionic strength solution matrix to $0.86 \mathrm{~mL} / \mathrm{g}$ in the high ionic strength solution matrix.

Less than $4 \%$ of the existing uranium in the contaminated near-surface sediments readily leaches into "simulated" rainwater over a period of 6 months. Uranium sorption onto uncontaminated 300 Area sediment has been shown to be highly variable and dependent upon solution conditions. Therefore, predicted $\mathrm{K}_{\mathrm{d}}$ values based on site specific conditions expected in the 300 Area range from a low of 0 to $1 \mathrm{~mL} / \mathrm{g}$ in the near-surface vadose zone that is influenced by evapotranspiration to 2 to $4 \mathrm{~mL} / \mathrm{g}$ in the unconfined aquifer sediments not influenced by dilution with Columbia River water. Although not studied in detail, adsorption $\mathrm{K}_{\mathrm{d}}$ values in the saturated aquifer where dilution due to River water is present (lower total carbonate solution concentration) could create adsorption $\mathrm{K}_{\mathrm{d}}$ values in excess of $7 \mathrm{~mL} / \mathrm{g}$. 


\section{Table of Contents}

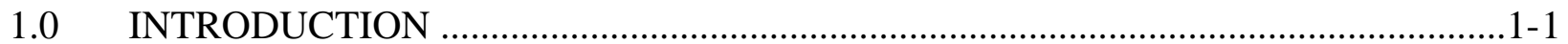

1.1. Statement of the Problem................................................................................. $1-1$

1.2. Organization of Report ………......................................................................... 1-1

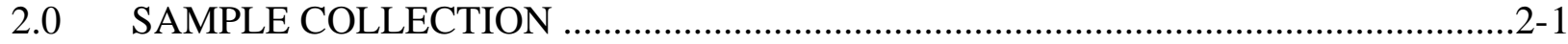

2.1. Description of Pond and 303-K Facility ................................................................ 2-1

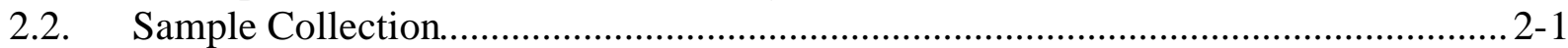

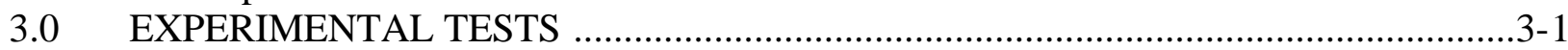

3.1. Sediment Characterization..................................................................................

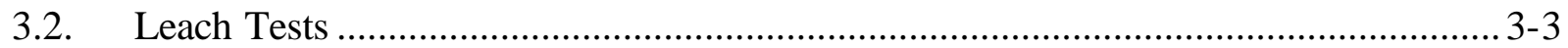

3.3. Scouting Adsorption Tests ............................................................................ 3-4

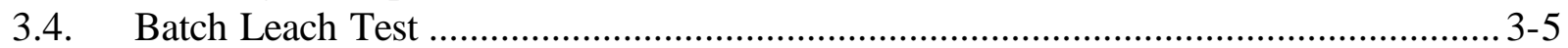

3.5. Batch Adsorption Test: Variable Uranium Concentration .......................................... 3-5

3.6. Batch Adsorption Test: Variable Solution pH........................................................ 3-6

3.7. Batch Adsorption Test: Variable Bicarbonate Solution Concentration.........................3-7

3.8. Column Flow-Through Test: Adsorption/Desorption Study...................................... 3-7

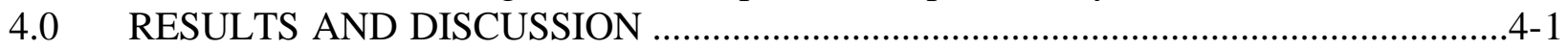

4.1. Sediment Characterization Results ................................................................... 4

4.1.1. Moisture Content ....................................................................................... 4-1

4.1.2. 1:1 Sediment to Water Extracts ....................................................................... 4-2

4.1.3. Total Carbon, $\mathrm{CaCO}_{3}$ and Organic Carbon Content of Sediment Samples......... 4-5

4.1.4. Sediment Uranium Concentration .............................................................. 4-6

4.1.5. Sediment Total Oxide Composition ................................................................. 4-6

4.1.6. Particle Size Measurements on 300 Area Vadose Zone Sediments .................... 4-9

4.1.7. Selective Extraction Results ..................................................................... 4-11

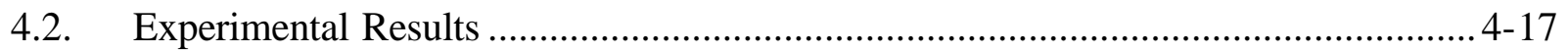

4.2.1. Flow Through Column Leach Tests ............................................................... 4-17

4.2.2. Scouting Adsorption Studies ............................................................ 4-22

4.2.3. Batch Leach Test ............................................................................... 4-23

4.2.4. Batch Adsorption Test: Variable Uranium Solution Concentration.................. 4-29

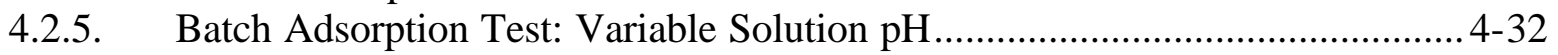

4.2.6. Batch Adsorption Test: Variable Bicarbonate Solution Concentration.............. 4-35

4.2.7. Column Flow-through Test: Adsorption/Desorption Study ............................ 4-38

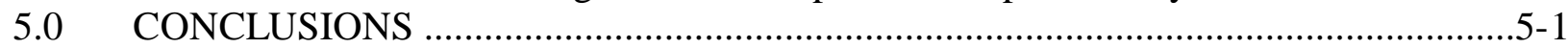

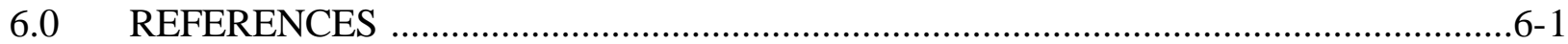

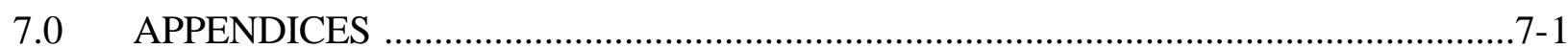

A. Leach Column Set-up ...................................................................................

B. FY01 Batch and Column Ads $\mathrm{K}_{\mathrm{d}}$ Set-up ............................................................

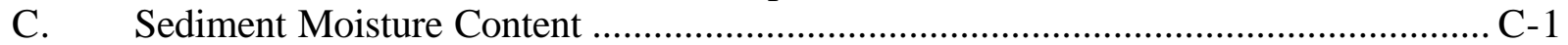

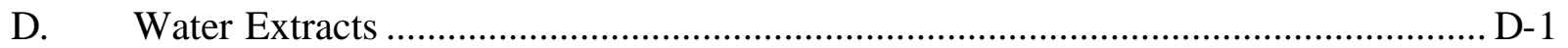

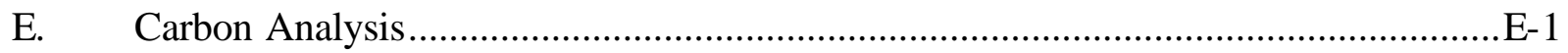

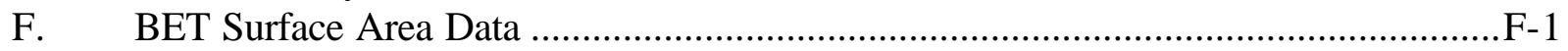

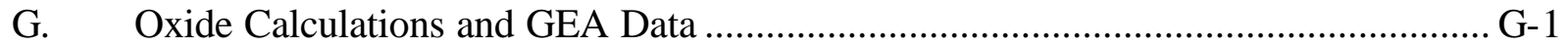

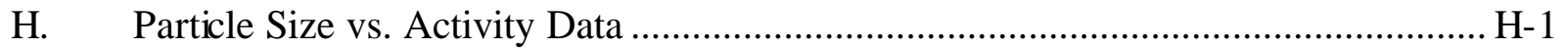

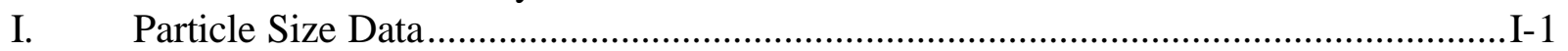

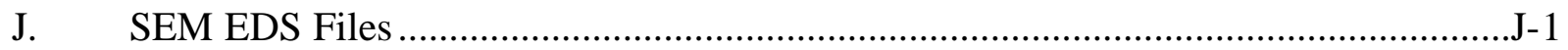




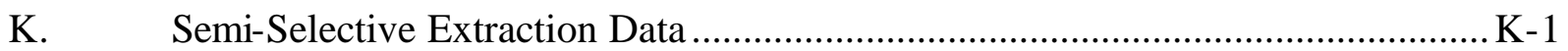

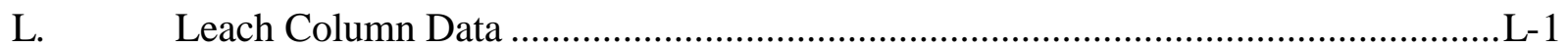

M. Batch Leach Test Set-up and Data...................................................................

N. Batch Adsorption Test Variable Uranium ..................................................... N-1

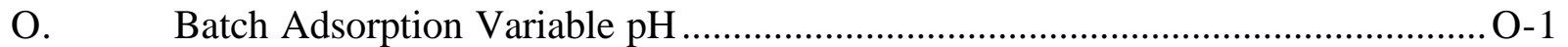

P. Batch Adsorption Variable Carbonate .................................................................

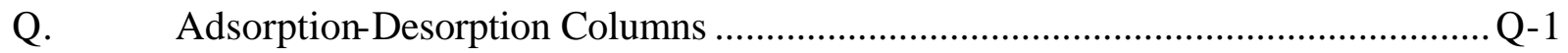

R. Experiment Key .....................................................................................

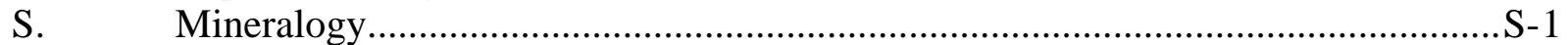

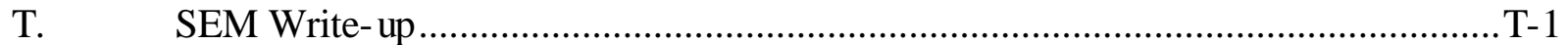

U. $\quad$ Molecular Probe Write-up ................................................................................... U-1

V. Scouting Column Adsorption Write-up ............................................................... V-1

W. Activity vs. Grain Size Write-up .................................................................... 
PNNL-14022 300 Area U Leach/Adsorption Study for ERC Final Report

Front Material

\section{List of Tables}

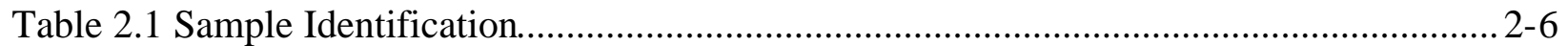

Table 3.1 Semi-Selective Extraction Reagents And Details ................................................ 3-2

Table 3.2 Leach Column Parameters ............................................................................. 3-4

Table 3.3 Details for Batch Adsorption Test ................................................................... 3-5

Table 3.4 Details of the Synthetic Porewater Solution (High Ionic Strength) ......................... 3-6

Table 3.5 Adsorption/Desorption Column Details ................................................................... 3-8

Table 4.1 Air-Dried Moisture Content of Sediments from 300 Area .......................................4-1

Table 4.2 Water Extract pH and EC Values ............................................................................ 4-2

Table 4.3 Anion Composition of the 1:1 Sediment to Water Extract......................................4-3

Table 4.4 Cation Composition of the 1:1 Sediment to Water Extracts ..................................4-4

Table 4.5 Trace Metal Composition of the 1:1 Sediment to Water Extracts .............................4-4

Table 4.6 Carbon Content in Near-Surface Vadose Sediments from 300 Area .........................4-5

Table 4.7 Comparison of the U Content of the Bulk Sediments Using Two Analytical

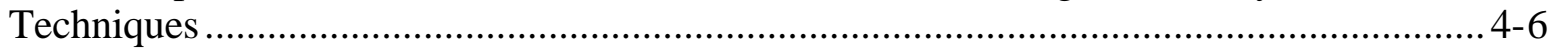

Table 4.8 Total Composition of the Vadose Zone Sediments from the 300 Area..................... 4-7

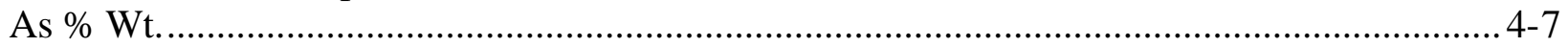

Table 4.9 Other Trace Constituents Found in the Bulk Sediments From Near-Surface Sediments

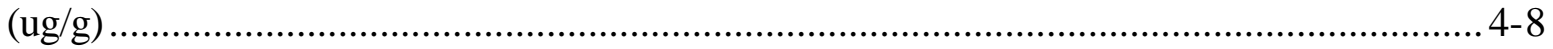

Table 4.10 Particle Size Distribution (\% Wt.) Measured by Wet Sieve/Hydrometer Method..4-10

Table 4.11. Cumulative Percent Finer Than Particle Size Distribution (\% Wt.) After Gravel

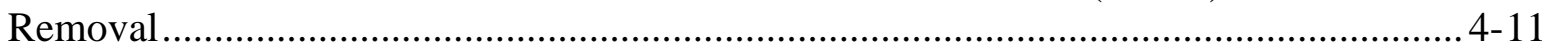

Table 4.12 Selective Extraction Results for U in the Six Near-surface Sediment Samples \% of

Total U Removed by Each Extractant .................................................................... 42

Table 4.13 Calculated $\mathrm{K}_{\mathrm{d}}$ Value From Batch Adsorption Experiments .................................4-22

Table 4.14 Batch Leach Test Data: Deionized Water .......................................................... 4-24

Table 4.15 Batch Leach Test Data: Groundwater ............................................................... 4-26

Table 4.16 Batch Leach Test Data: Simulated Porewater ................................................... 4-28

Table 4.17 Batch Adsorption Data for the Low Ionic Strength Solution................................4-30

Table 4.18 Batch Adsorption Data for the High Ionic Strength Solution ...............................4-31

Table 4.19 Batch pH Adsorption Data for the Low Ionic Strength Solution.......................... 4-33

Table 4.20 Batch pH Adsorption Data for the High Ionic Strength Solution........................... 4-33

Table 4.21 Batch Carbonate Adsorption Data for the Low Ionic Strength Solution.................4-36

Table 4.22 Batch Carbonate Adsorption Data for the High Ionic Strength Solution................4-36 


\section{List of Figures}

Figure 2.1 Map of the Sampling Locations

Figure 2.2 Location Where the Background (Uncontaminated) Sediment Was Obtained 2-3

Figure 2.3 Close-up Picture of the Background Sediment Used in the Tests......................2-3

Figure 2.4 Location Where Sample B11494 was Collected............................................. 2-4

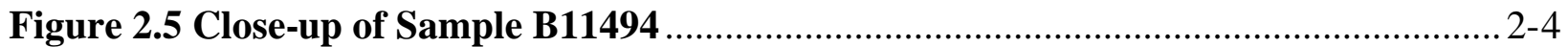

Figure 2.6 Location Where Sample B11495 was Collected......................................... 2-5

Figure 2.7 Close-up of Sample B11495

Figure 3.1 Flow-Through Column Leach Test........................................................... 3-3

Figure 4.1: Particle Size Distribution of 300 Area Sediments After Removal of Gravel.. 4-10

Figure 4.2: Plot of the \% Uranium Released in the Respective Leaching Solutions ......... 4-13

Figure 4.3: Plot of the \% Aluminum Released in the Respective Leaching Solutions ...... 4-14

Figure 4.4: Plot of the \% Silica Released in the Respective Leaching Solutions ............... 4-15

Figure 4.5: Plot of the \% Iron Released in the Respective Leaching Solutions ................. 4-16

Figure 4.6: Plot of the \% Manganese Released in the Respective Leaching Solutions ..... 4-16

Figure 4.7: Leach Test Data for the 300 Area North Process Pond Samples.................... 4-18

Figure 4.8: Leach Test Data for the 303-K Environ Samples......................................... 4-19

Figure 4.9: Leach Test Data for the Background Material and Sample B11BY5 ............ 4-20

Figure 4.10: Percentage of Total Uranium in the Sediment That Leaches vs. Pore Volumes

Figure 4.11 Uranium Leach $K_{d}$ as a Function of Time for the Five Contaminated Near-

Surface Sediment Samples in Deionized Water. $4-25$

Figure 4.12 Uranium Leach $K_{d}$ as a Function of Time for the Five Contaminated Near-

Surface Sediment Samples in Ground water .......................................................... 4-27

Figure 4.13 Uranium Leach $K_{d}$ Data as a Function of Time for the Five Contaminated

Near-Surface Sediment Samples in Simulated Porewater.......................................... 4-29

Figure 4.14: Plot of $C_{A}$ vs. $C_{L}$ for the Low Ionic Strength Solution................................. 4-30

Figure 4.15: Plot of $\mathbf{C}_{\mathbf{A}}$ vs. $\mathbf{C}_{\mathbf{L}}$ for the High Ionic Strength Solution............................... 4-31

Figure 4.16: Uranium Adsorption as a Function of pH.............................................. 4-34

Figure 4.17: Uranium $\mathbf{K}_{\mathbf{d}}$ as a Function of $\mathbf{p H}$........................................................ 4-34

Figure 4.18: Uranium Adsorption as a Function of Bicarbonate Concentration.............. 4-37

Figure 4.19: Uranium Kd as a Function of Bicarbonate Concentration........................... 4-37

Figure 4.20 Adsorption Column Data: Low Ionic Strength Solution............................... 4-39

Figure 4.21 Adsorption Column Data: High Ionic Strength Solution .............................. 4-41 


\section{Acronyms}

$\begin{array}{ll}\text { ASTM } & \text { American Society for Testing and Materials } \\ \text { DI water } & \text { Deionized water } \\ \text { DOE } & \text { Department of Energy } \\ \text { EPA } & \text { Environmental Protection Agency } \\ \text { ERC } & \text { Environmental Restoration Contractor } \\ \text { EXAFS } & \text { Extended X-ray absorption fine structure } \\ \text { FY } & \text { Fiscal Year } \\ \text { HDPE } & \text { High density polyethylene } \\ \text { HIS } & \text { High ionic strength } \\ \text { K }_{\mathrm{d}} & \text { Partition or distribution coefficient } \\ \text { LIS } & \text { Low ionic strength } \\ \text { OU } & \text { Operable unit } \\ \text { PNNL } & \text { Pacific Northwest National Laboratory } \\ \text { ppb } & \text { Parts per billion } \\ \text { ppm } & \text { Parts per million } \\ \text { QA/QC } & \text { Quality assurance/quality control } \\ \text { RCF } & \text { Radiological counting facility } \\ \text { REDOX } & \text { Oxidation-reduction } \\ \text { PUREX } & \text { Plutonium uranium extraction process } \\ \text { SAP } & \text { Sampling and analysis plan } \\ \text { SEM } & \text { Scanning electron microscope } \\ \text { TEM } & \text { Transmission electron microscope } \\ \text { XAS } & \text { X-ray absorption spectroscopy } \\ \text { XANES } & \text { X-ray absorption near edge spectroscopy } \\ \text { XRF } & \text { X-ray fluorescence } \\ & \end{array}$

Terms in equations

$\mathrm{C}_{\mathrm{A}} \quad$ Adsorbed concentration of chemical in weight/weight of soil

$\mathrm{C}_{\mathrm{L}} \quad$ Solution concentration of chemical in weight/volume of solution 
PNNL-14022 300 Area U Leach/Adsorption Study for ERC Final Report

Chapter 1. Introduction

\subsection{INTRODUCTION}

The objective of this study was to perform controlled laboratory experiments to measure the leaching and adsorption characteristics of uranium in near-surface sediments collected from the 300 Area of the Hanford Site. The scope of the laboratory tests, including quality assurance and quality control (QA/QC) objectives, was outlined in Appendix B of the "Sampling and Analysis Plan for the 300 Area Uranium Leach/K $\mathrm{d}_{\mathrm{d}}$ Study" (DOE-RL, 2000b). The laboratory work was conducted over the course of two fiscal years (FY) (FY 2001 and FY 2002). Results from the FY 2001 experiments necessitated a revision to the original sampling and analysis plan (SAP). The work scope and experiments were revised in order to keep the project on-line with the study objective. Specifically, more batch adsorption experiments were added to further investigate the effect of solution parameters on uranium sorption onto the uncontaminated or background sediment. The results of this study will be used by the Environmental Restoration Contractor to determine if the soil cleanup level of $350 \mathrm{pCi}$ total uranium (U)/g at the 300-FF-1 and 300-FF-2 Operable Unit (OU) waste sites is protective of groundwater in the 300 Area.

\subsection{Statement of the Problem}

Uranium is the principal contaminant of concern in the 300 Area of the Hanford Site. Currently, uranium in several monitoring wells exceeds the maximum contaminant level for drinking water of $30 \mu \mathrm{g} / \mathrm{L}$. Uranium leach rate and partition/distribution coefficient $\left(\mathrm{K}_{\mathrm{d}}\right)$ values are key input parameters for modeling contaminant mobility and predicting future impacts to groundwater. Partition coefficients are an empirical measure of the ability of a soil or sediment material to sorb a contaminant and retard the contaminants migration through soil/sediment horizons. In its most simplistic form, a linear adsorption isotherm, $\mathrm{K}_{\mathrm{d}}$ (volume/weight) is calculated as the adsorbed concentration $\left(\mathrm{C}_{\mathrm{A}}\right.$ in weight/weight of soil) divided by the concentration in solution $\left(\mathrm{C}_{\mathrm{L}}\right.$ in weight/volume of solution) (Jury et al., 1991). Some contaminants, such as oxidized technetium $(\mathrm{Tc}(\mathrm{VI}))$, are considered conservative in that they readily travel at nearly the same rate as the groundwater and thus, have a low or zero $K_{d}$ value. Non-conservative contaminants, such as cesium (Cs), tend to sorb to soil particles and thus have higher $\mathrm{K}_{\mathrm{d}}$ values. Literature values for uranium partition coefficients vary by as much as four orders of magnitude (EPA, 1999a,and b). This variability is a function of environmental parameters, including: soil grain size and distribution, $\mathrm{pH}$, ionic strength, moisture content, organic matter, and mineralogy (Waite et al., 1994; Kaplan et al., 1998; Hsi and Langmuir, 1985). Due to this large variability in uranium $\mathrm{K}_{\mathrm{d}}$ values reported in the literature, site-specific studies were performed with sediments from the near-surface in Hanford's 300 Area.

\subsection{Organization of Report}

This report is divided into 7 sections that describe the sample collection locations and brief history of the facilities, sediment characterization methods, the laboratory testing methodologies used to develop information that quantifies uranium leaching from the near-surface sediment and subsequent adsorption onto uncontaminated sediments, the results of the lab testing, discussion, and conclusions. There are also 23 appendices that document the important primary data 
PNNL-14022 300 Area U Leach/Adsorption Study for ERC Final Report Chapter 1. Introduction

generated in the project that support the report interpretations and conclusions as well as supplemental sections not included in the formal report that provide data used to more fully explore the controlling mechanisms and to identify the uranium solid-phase speciation. 
PNNL-14022 300 Area U Leach/Adsorption Study for ERC Final Report

Chapter 2. Sample Collection

\subsection{SAMPLE COLLECTION}

\subsection{Description of Pond and 303-K Facility}

Construction of the 300 Area North Process Pond began in 1948. Once completed, the Pond received industrial waste from the 300 Area process sewer system through an underground network of pipes. During its twenty-six years of operation, the 300 Area North Process Pond received waste from reactor fuel fabrication processes, separations process chemicals, and solutions from the 3706 building, as well as waste from the 321 building, where tests of the bismuth phosphate, Metal Recovery, reduction-oxidation (REDOX), and plutonium uranium extraction (PUREX) processes were performed.

The 303K building was constructed in 1943 and served primarily as a storage facility for radioactive and mixed waste generated by 300 Area operations. The building was used to store uranium and aluminum canned uranium from 1943 to 1953. In 1953, newly constructed asphalt and concrete storage pads were used in support of aluminum reactor spacer decontamination. From 1953 to 2001, the outdoor pads were used to store radioactive and mixed waste. Concrete billets of uranium were cured and stored in the facility from 1977 to 1982 . From 1986 to 2001, the building served as a storage unit for low-level radioactive waste and radioactive mixed waste. The building was demolished in September of 2001.

\subsection{Sample Collection}

Eight near-surface sediment samples were collected by an ERC field crew between December 2000 and February 2001 from three general locations that represented an uncontaminated site, one of the past liquid disposal sites (300 Area North Process Pond), and a waste storage facility (303-K building). A map of the sampling locations is shown in Figure 2.1.

Three 5-gallon buckets of representative uncontaminated background sediment were collected from the north-south face of an excavated pit (Pit 6) located west of the 300 Area. The three samples were labeled B11491, B11492, and B11493. Photographs of the site where the background sediment was collected from the near surface are shown in Figures 2.2 and 2.3. As shown in Figure 2.3, the samples were screened in the field to remove gravel particles larger than $6.35 \mathrm{~mm}$ using a standard $1 / 4$-inch sieve. Although three background sediment samples were collected, only sample B11493 was used in most laboratory tests.

One 5-gallon bucket of sediment was collected from each of two locations associated with the 300 Area North Process Pond (B11494 and B11495). Sample B11494 (Figures 2.4 and 2.5) consisted of scrapings taken from an excavated trench along the southern border of the 300 Area North Process Pond. Sample B11495 (Figures 2.6 and 2.7) was collected from the pond wall in the northeast corner of the Process Pond.

Three 5-gallon buckets were collected at locations around the 303-K building. Two of the 303-K samples (B11BY4 and B11BY6) were collected next to an asphalt pad located directly behind (north) the $303 \mathrm{~K}$ building. The third sample (B11BY5) was collected adjacent to a downspout 
located on the east side of the facility. As with the background sediment, all contaminated sediment samples were sieved in the field with a standard 1/4-inch sieve to remove material larger than $6.35 \mathrm{~mm}$. A sample identification reference table (Table 2.1) is included at the end of this section.

No photographs were taken when the three samples from around the $303-\mathrm{K}$ building were obtained, but the physical appearances of the three sediment samples are similar to B11495 and the background sediment. However, the photographs presented in this report highlight the geological (grain size) variability among the site-specific soil samples collected for this study.

\section{Figure 2.1 Map of the Sampling Locations}

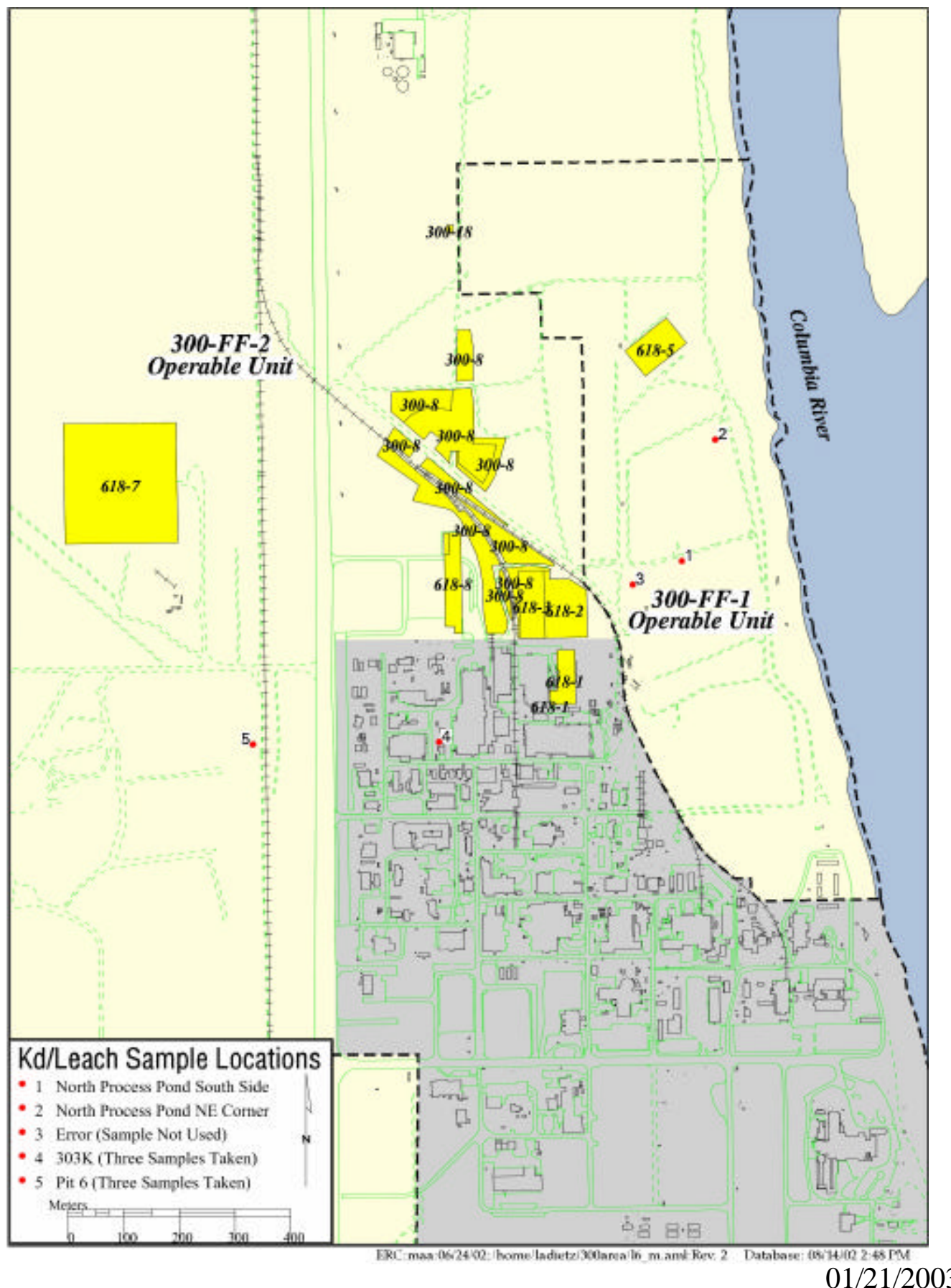


Figure 2.2 Location Where the Background (Uncontaminated) Sediment Was Obtained

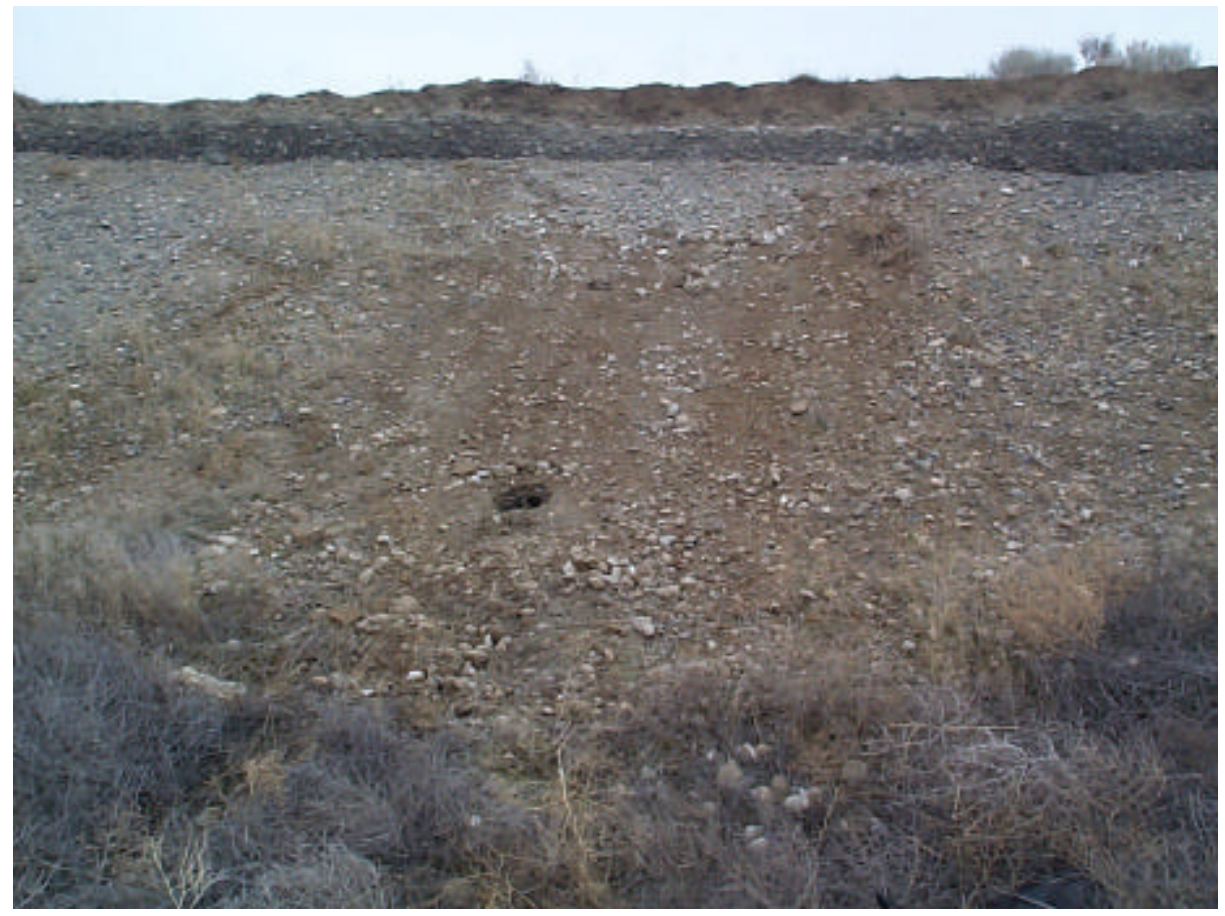

Figure 2.3 Close-up Picture of the Background Sediment Used in the Tests

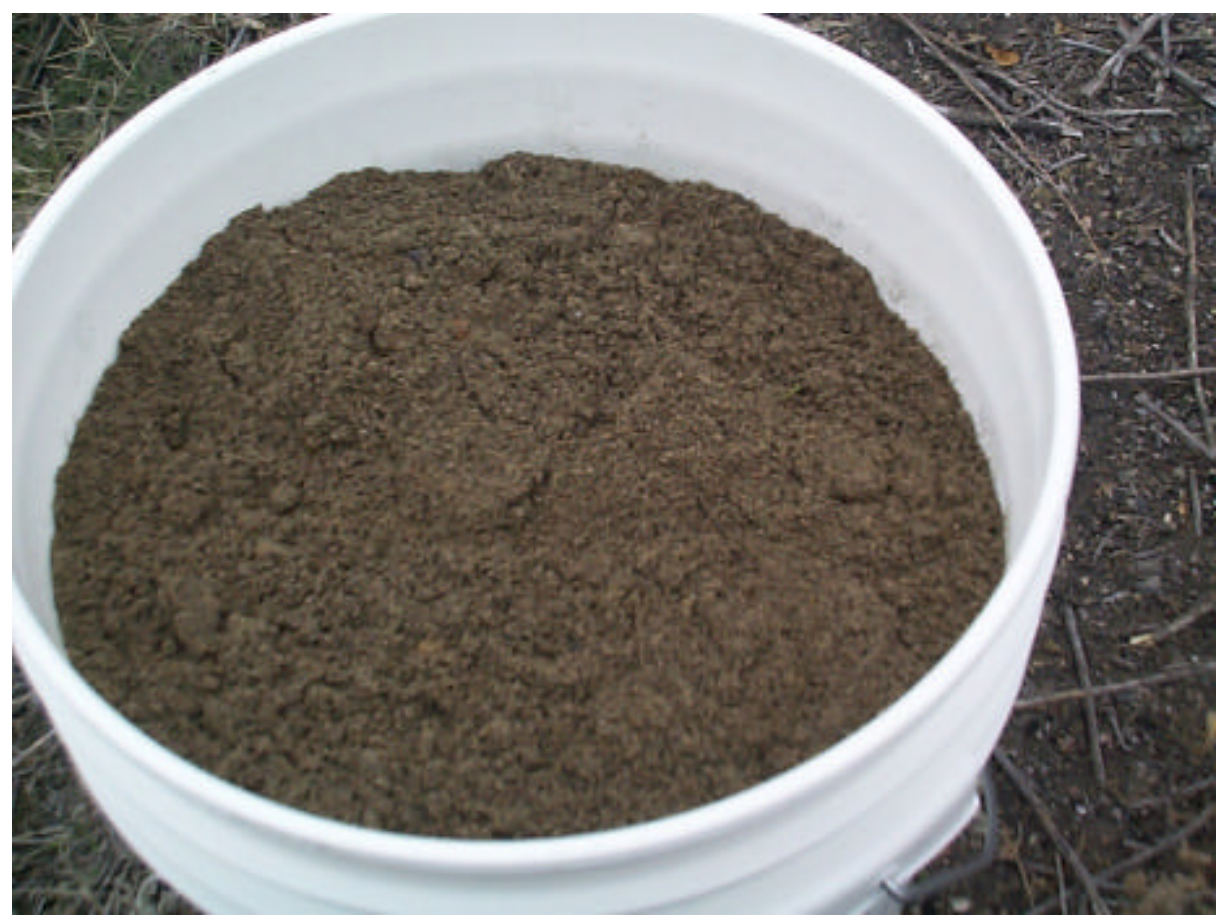


PNNL-14022 300 Area U Leach/Adsorption Study for ERC Final Report Chapter 2. Sample Collection

Figure 2.4 Location Where Sample B11494 was Collected

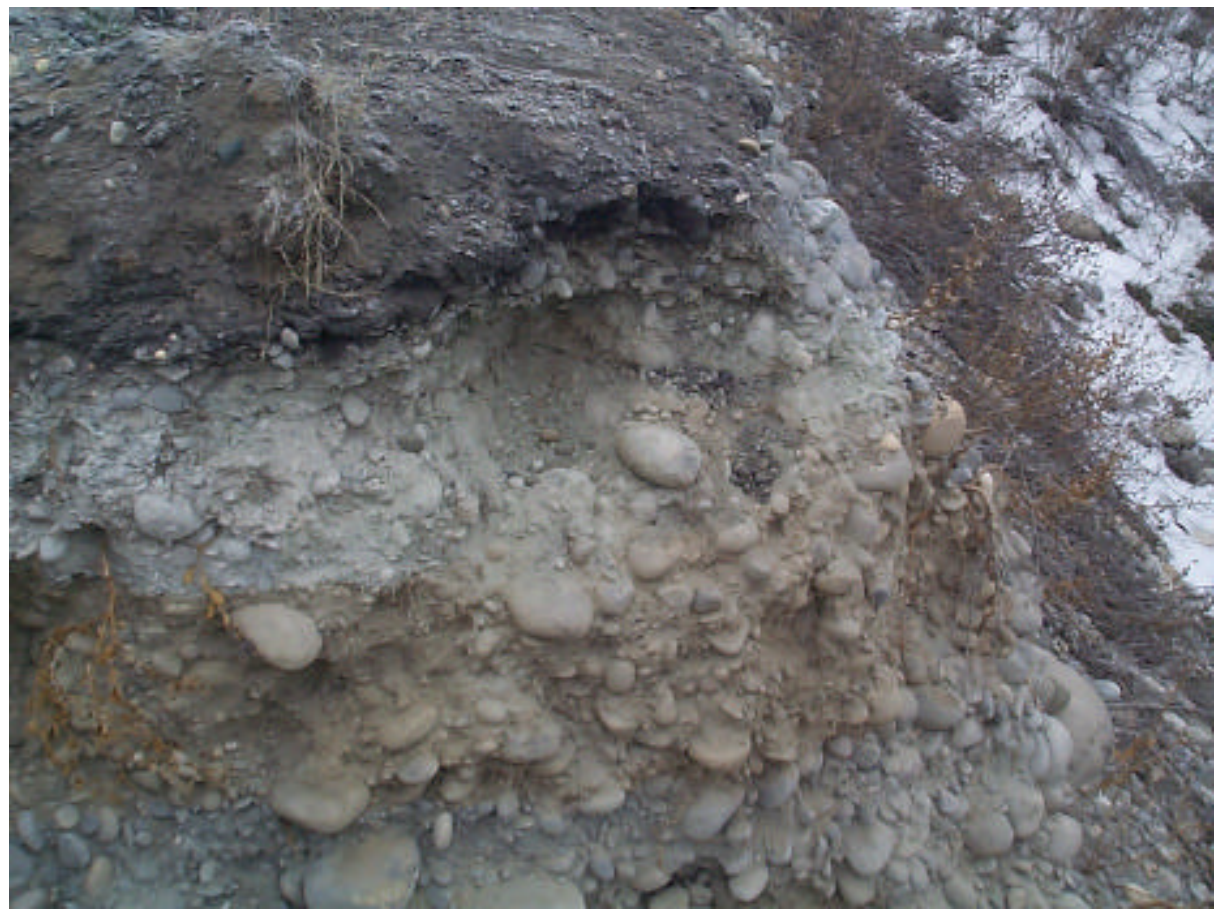

Figure 2.5 Close-up of Sample B11494

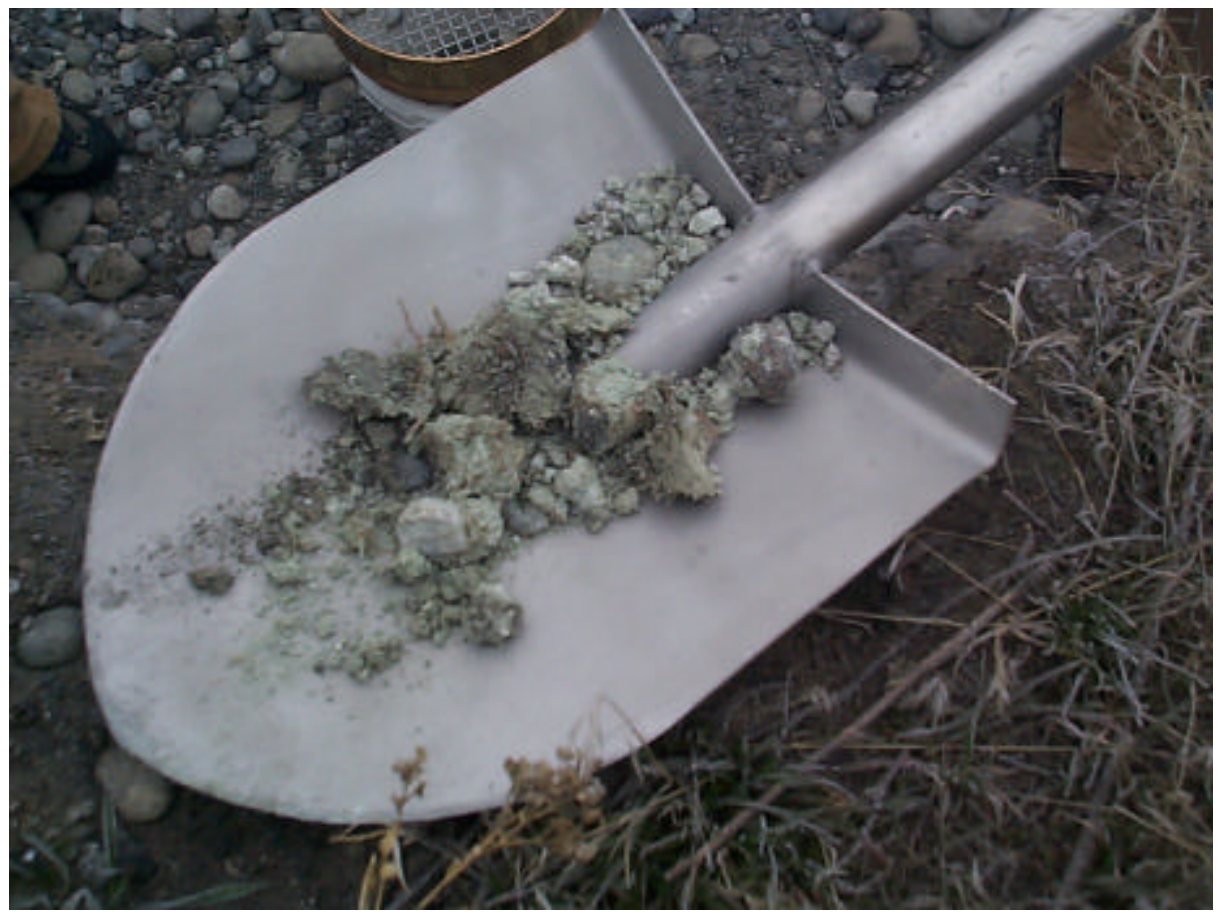


PNNL-14022 300 Area U Leach/Adsorption Study for ERC Final Report Chapter 2. Sample Collection

\section{Figure 2.6 Location Where Sample B11495 was Collected}

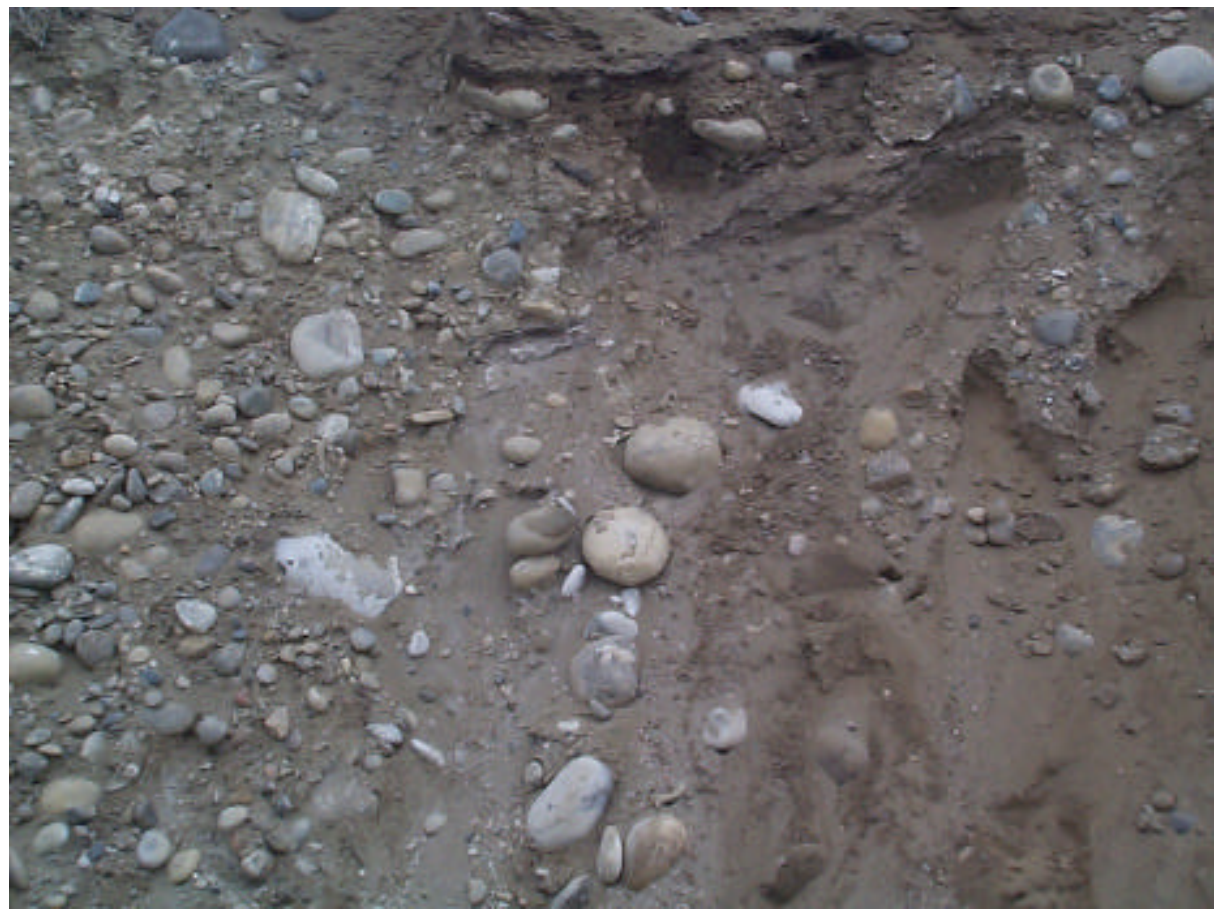

Figure 2.7 Close-up of Sample B11495

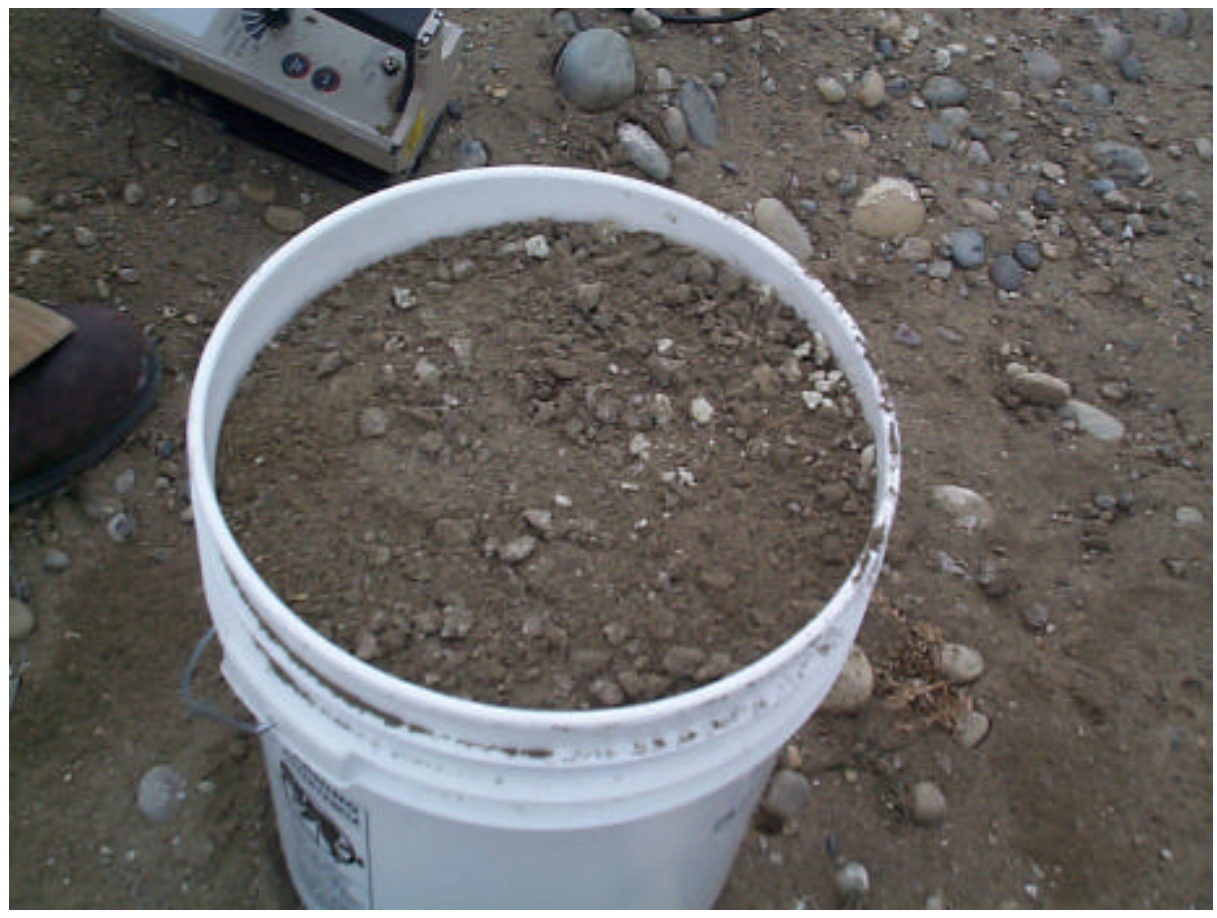


PNNL-14022 300 Area U Leach/Adsorption Study for ERC Final Report Chapter 2. Sample Collection

Table 2.1 Sample Identification

\begin{tabular}{|c|c|}
\hline Sample ID & Description \\
\hline B11491 & Background-West of 300 Area \\
\hline B11492 & Background-West of 300 Area \\
\hline B11493 & Background-West of 300 Area \\
\hline B11494 & Near Southern Inlet of North Process Pond \\
\hline B11495 & Northeast Corner of the North Process Pond \\
\hline B11BY4 & 303K-Adjacent to North-Side Concrete Pad \\
\hline B11BY5 & 303K- East Side of Building \\
\hline B11BY6 & 303K-Adjacent to North-Side Concrete Pad \\
\hline
\end{tabular}


PNNL-14022 300 Area U Leach/Adsorption Study for ERC Final Report

Chapter 3. Experimental Tests

\subsection{EXPERIMENTAL TESTS}

\subsection{Sediment Characterization}

Characterization measurements were performed on the eight near-surface sediment samples. Measurements were conducted to determine basic physical and chemical characteristics of the sediments, as well as determine the forms or "species" of uranium present in a similar fashion to recent studies of sediments from inside and around single-shell tank Waste Management Areas (WMA) (Serne et al., 2002 a-d). Major elements in the sediments (including total uranium) were measured by x-ray fluorescence (XRF) (Sanders and Legore, 2000), and grain size was determined by a combination of dry sieve and hydrometer methods (ASTM D 421-85, 1985; ASTM D 422-63, 1972; and ASTM D 1140-54, 1971). Sediment organic carbon and inorganic carbon content, and calcium carbonate equivalent, were measured using a Coulometrics Inc. $\mathrm{CO}_{2}$ Coulometer, and sediment moisture content was determined by gravimetric method (PNL-MA567-SA-7, 1990). Simple 1:1 sediment to water extracts were performed to gain an understanding of the chemistry of the porewaters in the sediment. The tests consisted of leaching each sediment with deionized (1 part soil to 1 part water-on a weight basis) water for 24 hours. The semi-selective chemical extraction technique (Tessier et al., 1979 with modifications) (Table 3.1) was used to determine the percentage of uranium present in the extractable phases of water soluble, adsorbed species (cation-exchangeable), carbonate solid bearing compounds, amorphous oxides, organic matter, crystalline Fe(III) oxides, and strong acid leachable compounds. The residual uranium content in the remaining bulk sediment was measured by XRF.

Direct spectroscopic measurements (Appendix U) were made on the contaminated sediments using basic research funds from another source. X-ray absorption spectroscopy (XAS) and fluorescence spectroscopy were two tools used. XAS techniques include two fine structure methods called XANES (X-ray absorption near edge spectroscopy) and EXAFS (extended X-ray absorption fine structure) that investigate the valence state and coordination number of the uranium atoms and the local atomic structure of the uranium present in the 300-Area sediments. The EXAFS technique can be considered a fingerprinting tool that allows one to speculate on the exact molecular structure of the solid. If the uranium is present as discrete compounds the EXAFS spectra of unknowns can be matched to known pure uranium bearing minerals.

Fluorescence spectroscopy is used to quantify structural features of both solids and dissolved molecules in aqueous solutions. In these studies, the fluorescence spectra of the contaminated sediments were compared to the fluorescence spectra of known uranium bearing compounds, both pure minerals and clays with uranium loaded onto surface adsorption sites. Using various spectra matching algorithms, the accuracy of fit (match) between unknowns and known compounds can be assessed. The presence of mixtures in unknown samples can be inferred by "adding" spectra together for model pure compounds.

Some preliminary data on directly probing the contaminated sediments is presented in Appendix $\mathrm{U}$ and more detailed information will be published in the future in Jeff Catalano's Ph. D. thesis and various open literature manuscripts authored by Jeff Catalano and Zheming Wang. 
PNNL-14022 300 Area U Leach/Adsorption Study for ERC Final Report Chapter 3. Experimental Tests

Table 3.1 Semi-Selective Extraction Reagents And Details

\begin{tabular}{|c|c|c|c|}
\hline Solid to Solution & Reagent & Phases Dissolved & Details \\
\hline $\begin{array}{l}5 \mathrm{~g} \text { of sediment to } 40 \\
\mathrm{mLs} \text { of solution }\end{array}$ & DI water & Soluble & Shake 1 hour at room temperature \\
\hline \multicolumn{4}{|c|}{ No need to wash between steps } \\
\hline $5 \mathrm{~g}$ to $40 \mathrm{mLs}$ & $\begin{array}{c}0.1 \mathrm{M} \mathrm{Mg}\left(\mathrm{NO}_{3}\right)_{2} \text { at } \mathrm{pH} \\
\text { between } 7.5 \text { and } 8.5\end{array}$ & Adsorbed & Shake 1 hour at room temperature \\
\hline \multicolumn{4}{|c|}{ Wash 15 minutes with $20 \mathrm{mLs}$ DI water, centrifuge and add to $\mathrm{Mg}$ nitrate extract } \\
\hline $5 \mathrm{~g}$ to $40 \mathrm{mLs}$ & $\begin{array}{c}1 \mathrm{MNaOAC@} \mathrm{pH}=5 \\
\text { with acetic acid }\end{array}$ & Carbonate Minerals & Shake 1 hour at room temperature \\
\hline \multicolumn{4}{|c|}{ Wash 15 minutes with $20 \mathrm{mLs}$ DI water, centrifuge and add to sodium acetate extract } \\
\hline $5 \mathrm{~g}$ to $200 \mathrm{mLs}$ & $\begin{array}{l}10.9 \mathrm{~g} / \mathrm{L} \text { oxalic acid } \\
(0.12 \mathrm{M})+16.1 \mathrm{~g} / \mathrm{L} \\
\text { Ammonium Oxalate } \\
\quad(0.11 \mathrm{M}) ; \mathrm{pH} 3 \\
\text { "TAMMS reagent" }\end{array}$ & $\begin{array}{l}\text { Amp. } \mathrm{Fe}, \mathrm{Al}, \mathrm{Mn}, \mathrm{Si} \\
\text { oxides }\end{array}$ & Shake in dark for $4 \mathrm{hrs}$ at room temp. \\
\hline \multicolumn{4}{|c|}{ Wash 15 minutes with $30 \mathrm{~mL}$ DI water, centrifuge and add to oxalate extract. } \\
\hline $5 \mathrm{~g}$ to $40 \mathrm{mLs}$ & \begin{tabular}{|} 
Mix $15 \mathrm{~mL}$ of $0.02 \mathrm{M}$ \\
nitric acid and $25 \mathrm{~mL}$ \\
of $30 \% \mathrm{H}_{2} \mathrm{O}_{2}$. Later \\
add ammonium \\
acetate/nitric acid \\
\end{tabular} & Organics & $\begin{array}{l}\text { Heat to } 85 \mathrm{C} \text { for two hours; add additional } 25 \mathrm{~mL} \\
\text { of } 30 \% \mathrm{H}_{2} \mathrm{O}_{2} \text { and heat to } 85 \mathrm{C} \text { for three hours, add } \\
40 \mathrm{mLs} \text { of } 1 \mathrm{M} \text { ammonium acetate/nitric acid to } \\
\mathrm{pH}=2 \text {, shake } 30 \text { minutes and extract }\end{array}$ \\
\hline \multicolumn{4}{|c|}{ Wash 15 minutes with $30 \mathrm{~mL} \mathrm{DI}$, centrifuge and add to Am acetate extract } \\
\hline $5 \mathrm{~g}$ to $200 \mathrm{mLs}$ & $\begin{array}{c}0.3 \mathrm{M} \text { trisodium } \\
\text { citrate, } 0.2 \mathrm{M} \\
\mathrm{NaHCO}_{3}, 1 \mathrm{~g} / \mathrm{g} \text { sample } \\
\text { sodium dithionite; } \mathrm{pH} \\
\sim 8.3 \\
\end{array}$ & $\begin{array}{c}\text { Crystalline Fe } \\
\text { oxides, hydroxides, } \\
\text { oxyhydroxides }\end{array}$ & $\begin{array}{l}\text { Stir for } 30 \text { minutes at } 85 \text { degrees } C \text {; repeat } \\
\text { extraction (total } 2 \text { times, combine leachate) }\end{array}$ \\
\hline \multicolumn{4}{|c|}{ Wash 15 minutes with $60 \mathrm{~mL}$ DI water, centrifuge and add to citrate extract } \\
\hline $\begin{array}{l}5 \mathrm{~g} \text { to } \sim 50 \mathrm{mLs} \text { at start; } \\
\text { then cook until there is } \\
\text { just enough extract to } \\
\text { pull off for ICP/ICP-MS }\end{array}$ & $8 \mathrm{M} \mathrm{HNO}_{3}$ & Clays, U oxides & $\begin{array}{l}\text { Add } 50 \mathrm{~mL} \text { of } 8 \mathrm{M} \mathrm{HNO}_{3} \text {, mix the slurry and } \\
\text { cover with a watch glass. Heat the sample to } 95 \\
\text { degrees } \mathrm{C} \text { and reflux for } 10 \text { to } 15 \text { minutes without } \\
\text { boiling. Allow the sample to cool, add } 5 \mathrm{~mL} \text { of } \\
\text { concentrated } \mathrm{HNO}_{3} \text {, replace the cover and reflux } \\
\text { for } 30 \text { minutes. If brown fumes are generated, } \\
\text { indicating oxidation of the sample by } \mathrm{HNO}_{3} \text {, } \\
\text { repeat this step (addition of } 5 \mathrm{~mL} \text { of conc. } \mathrm{HNO}_{3} \text { ) } \\
\text { until no brown fumes are given off by the sample, } \\
\text { indicating the complete reaction. Allow the } \\
\text { solution to evaporate to approximately } 25 \mathrm{~mL} \\
\text { without boiling or heat at } 95 \text { degrees C } \pm 5 \text { degrees } \\
\mathrm{C} \text { without boiling for two hours. Remove the acid } \\
\text { extract after solids settle. }\end{array}$ \\
\hline \multicolumn{4}{|c|}{ Wash 15 minutes with $15 \mathrm{~mL}$ DI and add to nitric acid } \\
\hline Bulk Powder & XRF & $\begin{array}{l}\text { Residuals (quartz, } \\
\text { etc.) }\end{array}$ & Oven dry to get weight left; crush for XRF \\
\hline
\end{tabular}




\subsection{Leach Tests}

Saturated flow-through column leach tests were performed on six near-surface sediment samples obtained by ERC field staff from three locations in the 300 Area. The tests were performed in order to determine the amount of uranium that could be removed from the sediment. Sediment from each location was packed into large columns, $10 \mathrm{~cm}$ in diameter by $45 \mathrm{~cm}$ long (Figure 3.1). The columns were tamped as they were filled in an attempt to minimize void space and channelized flow within the columns. The columns were filled in increments; the subsequent interfaces were scored to increase packing homogeneity and link the two fractions. The weight of the water-saturated sediment filled apparatus and the weight of the dry sediment placed in the column, along with the known volume of the columns, were used to calculate the column pore volume and sediment bulk density of each column, respectively (Table 3.2). Leach tests were performed by slowly percolating air saturated distilled water in an up-flow direction in an attempt to remove as much trapped air as possible and thus, creating near water saturation conditions. The residence time for each pore volume of solution contacting the packed sediment was approximately 1 week. The leach tests were performed on bulk sediment, coarse grained sizes were not purposely excluded, although rocks greater than 1/4-zinch in diameter were removed during field collection. All effluent solution was collected in discrete aliquots and volumes were recorded versus time. Aliquots of leachate from each column were collected daily for several weeks. In subsequent weeks, effluent samples were collected every few days to once a week. All leachate samples were analyzed for $\mathrm{pH}$, electrical conductivity (EC), and uranium content (uranium analysis was performed via Inductively Coupled Plasma-Mass Spectrometry [ICP-MS] unless otherwise noted). Selected aliquots were analyzed for major cations, trace metals, anions, and alkalinity.

\section{Figure 3.1 Flow-Through Column Leach Test}

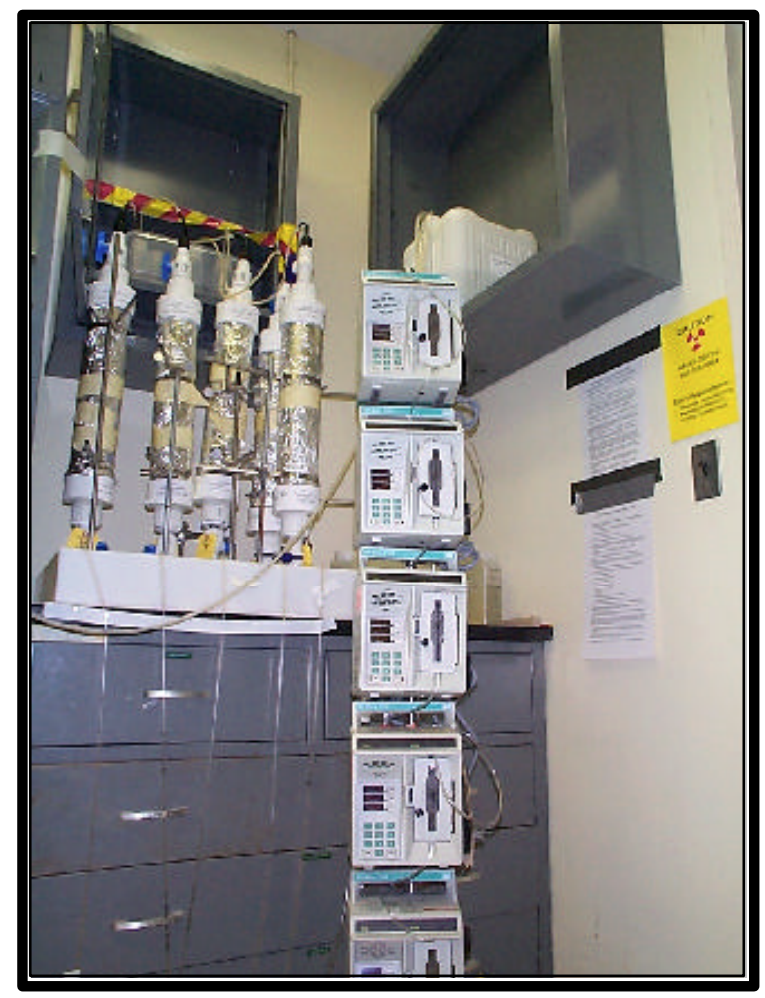


PNNL-14022 300 Area U Leach/Adsorption Study for ERC Final Report Chapter 3. Experimental Tests

Table 3.2 Leach Column Parameters

\begin{tabular}{|c|c|c|c|c|c|c|c|c|}
\hline $\begin{array}{l}\text { Column } \\
\text { Number }\end{array}$ & $\begin{array}{c}\text { Sample } \\
\text { ID }\end{array}$ & $\begin{array}{c}\text { Col. Vol. } \\
\left(\mathrm{cm}^{3}\right)\end{array}$ & $\begin{array}{c}\text { Soil Wt. } \\
\text { (g) }\end{array}$ & $\begin{array}{c}\text { Bulk Density } \\
\left(\mathrm{g} / \mathrm{cm}^{3}\right)\end{array}$ & $\begin{array}{c}\text { Porosity } \\
\left(\mathrm{cm}^{3} / \mathrm{cm}^{3}\right)\end{array}$ & $\begin{array}{c}\text { Pore Volume } \\
\left(\mathrm{cm}^{3}\right)\end{array}$ & $\begin{array}{c}\text { Flow Rate } \\
(\mathrm{mL} / \mathrm{hr})\end{array}$ & $\begin{array}{c}\text { Residence Time } \\
\text { (hr) }\end{array}$ \\
\hline \multicolumn{9}{|c|}{ Background } \\
\hline 1 & B11493 & 3506 & 6671 & 1.90 & 0.320 & 1107 & 6.23 & 178 \\
\hline \multicolumn{9}{|c|}{300 N Process Pond } \\
\hline 2 & B11494 & 3558 & 6406 & 1.80 & 0.350 & 1254 & 7.12 & 176 \\
\hline 3 & B11495 & 3544 & 5879 & 1.66 & 0.400 & 1429 & 8.19 & 175 \\
\hline \multicolumn{9}{|c|}{ 303-K Building Environs } \\
\hline 4 & B11BY4 & 3493 & 7010 & 2.01 & 0.280 & 972 & 5.41 & 180 \\
\hline 5 & B11BY5 & 3469 & 6634 & 1.91 & 0.310 & 1083 & 6.09 & 178 \\
\hline 6 & B11BY6 & 3488 & 7249 & 2.08 & 0.250 & 881 & 4.86 & 181 \\
\hline
\end{tabular}

\subsection{Scouting Adsorption Tests}

In FY 2001, eight scouting batch adsorption tests were run using leachates from one of the North Process Pond leach columns (B11494) and one 303K leach column (B11BY6) described in section 3.2. The scouting adsorption tests were run to get preliminary adsorption $K_{d}$ values for uranium onto the representative background sediment (B11493). The background sediment used in these scouting adsorption tests was sieved through a $\# 4,4.76 \mathrm{~mm}$, screen to remove pebbles. Six high-density polyethylene (HDPE) 50-mL centrifuge tubes had various amounts of the background sediment, B11493, added to them (Table 3.3). The mass of sediment added to each tube was varied to investigate the linearity of uranium adsorption by Hanford sediment. Two additional centrifuge tubes were used as experimental blanks and did not contain sediment. Four of the tubes received composite leachate $(40 \mathrm{~mL})$ from the B11494 leach tests (the first 10 aliquots of leachate were composted to make one leachate solution) and four tubes received composite leachate $(40 \mathrm{~mL})$ from the B11BY6 leach test (the first 10 aliquots of leachate were composited to make one leachate solution). The soil/leachate slurries were gently shaken on a linear shaking table. After $95 \mathrm{hr}$ ( 4 days), the slurries were centrifuged at approximately $2000 \mathrm{~g}$ for 30 minutes and a $2 \mathrm{~mL}$ aliquot of the clear supernatant solution was extracted. The $\mathrm{pH}$ and uranium content of the supernatant were measured. The remaining slurry was then shaken on the shaker table until a second measurement was made after a cumulative time of $187 \mathrm{hr}$ (approximately 7.8 days). The details on how much sediment and what leachates were used are shown in Table 3.3. The volume of solution changed slightly with each sampling.

The $\mathrm{K}_{\mathrm{d}}$ for $\mathrm{U}$ was determined from the traditional equation (Relyea et al. 1980) used for batch $\mathrm{K}_{\mathrm{d}} \mathrm{S}$ as follows:

$$
K_{d}=\frac{(I n f-E f f)}{E f f} * \frac{V o l}{W t}
$$

where Inf is the concentration of $U$ in the Initial Solution Eff is the concentration of $U$ in the Effluent Solution

Vol is the volume of solution in the test

$\mathrm{Wt}$ is the mass of sediment in the test. 
PNNL-14022 300 Area U Leach/Adsorption Study for ERC Final Report Chapter 3. Experimental Tests

Table 3.3 Details for Batch Adsorption Test

\begin{tabular}{|c|c|c|c|c|}
\hline Tube \# & $\begin{array}{c}\text { Wt. of } \\
\text { Sed (g) }\end{array}$ & $\begin{array}{c}\text { Composite } \\
\text { Solution }\end{array}$ & Leachate Type & $\begin{array}{c}\text { Contact } \\
\text { Time (hr) }\end{array}$ \\
\hline 1 & 0.370 & B11494 & Process Pond & 95,187 \\
\hline 2 & 0.340 & B11BY6 & $303-K$ & 95,187 \\
\hline 3 & 1.52 & B11494 & Process Pond & 95,187 \\
\hline 4 & 1.54 & B11BY6 & $303-K$ & 95,187 \\
\hline 5 & 7.13 & B11494 & Process Pond & 95,187 \\
\hline 6 & 7.22 & B11BY6 & $303-K$ & 95,187 \\
\hline 7 (blank) & 0 & B11494 & Process Pond & 95,187 \\
\hline 8 (blank) & 0 & B11BY6 & $303-K$ & 95,187 \\
\hline
\end{tabular}

\subsection{Batch Leach Test}

At the end of the large flow through column leach tests (described in section 3.2) moist sediment (approximately $300 \mathrm{~g}$ on a dry basis) was removed from the bottom third of each column (closest to the inlet end of the column leach tests) and used in batch leach tests. The tests were performed to investigate the long-term release of the "recalcitrant" uranium from the contaminated sediment under varying solution conditions.

Aliquots (100 g on a dry weight basis) of each of the sediments removed from the large leach columns were placed into one of three 2-L high-density polyethylene (HDPE) bottles. The three containers received one of three leaching solutions: deionized water, groundwater collected from the Hanford Patrol Training Facility (represents uncontaminated groundwater up gradient of the 300 Area), or a simulated vadose zone porewater (see Section 3.5 for a description of the simulated porewater). The static leach test was performed at a 1:10 solid to solution weight-tovolume ratio, i.e. $1 \mathrm{~L}$ of leaching solution was added to each reactor. The reactors were sampled at the following time intervals: 14, 28, 49, 77, 119, and 154 days. Sampling consisted of removing $15 \mathrm{~mL}$ of solution from each reactor and filtering it through a $0.2 \mu \mathrm{m}$ Nalgene syringe filter. $15 \mathrm{~mL}$ of fresh solution was added to the reactors to maintain the 1:10 solid to solution ratio. The filtered samples were analyzed for $\mathrm{pH}, \mathrm{EC}$, and ${ }^{238} \mathrm{U}$. Selected aliquots were analyzed for major cations and trace metals using ICP-OES, anions using IC, and alkalinity via titration.

\subsection{Batch Adsorption Test: Variable Uranium Concentration}

In FY 2002, a series of batch adsorption tests were performed to assess the effect of uranium concentration, ionic strength, solution $\mathrm{pH}$, and solution inorganic carbon concentration on uranium sorption onto the background sediment, B11493. The first of three batch adsorption tests involved varying the uranium solution concentration in both a low (2 meq/L) and high (20 $\mathrm{meq} / \mathrm{L}$ ) ionic strength solution (information on solution composition can be found in Table 3.4). The low ionic strength solution was used to simulate Columbia River water; the high ionic strength solution was used to simulate vadose zone porewater (these solutions represent the two extremes expected in the 300 Area). The solution $\mathrm{pH}$ was maintained between 7.5 and 8 using 
either $0.1 \mathrm{~N} \mathrm{HNO}_{3}$ or $0.1 \mathrm{M} \mathrm{NaOH}$. Duplicate batch reactors were prepared by placing $5 \mathrm{~g}$ of sediment into a $125 \mathrm{~mL}$ HDPE bottle. The sediment was washed three times overnight in the respective solutions (without uranium) at a solid to solution ratio of 1:10. After the third wash, the reactors received the respective low and high ionic strength solutions containing natural uranium in concentrations ranging from $0.05 \mathrm{mg} / \mathrm{L}$ to $5 \mathrm{mg} / \mathrm{L}$. Contact time for this test was three days and the slurries were gently agitated on a linear shaker table. The reactors were sampled again after 175 days to assess the effect of long-term contact time on uranium sorption. Effluent samples were filtered through $0.2 \mu \mathrm{m}$ Nalgene syringe filters and analyzed for $\mathrm{pH}, \mathrm{EC}$, and ${ }^{238} \mathrm{U}$. Uranium $\mathrm{K}_{\mathrm{d}}$ values were determined using equation 1 (above) with corrections for residual wash water (pre-equilibration) described in Relyea et al. (1980).

Table 3.4 Details of the Synthetic Porewater Solution (High Ionic Strength)

\begin{tabular}{|c|c|c|c|}
\hline Constituent & Units & Value & meq/L \\
\hline $\mathrm{Ca}$ & $\mathrm{mM}$ & 2 & 4 \\
\hline $\mathrm{Na}$ & $\mathrm{mM}$ & 16 & 16 \\
\hline $\mathrm{CO}_{3}$ & $\mathrm{mM}$ & 10 & 10 \\
\hline $\mathrm{NO}_{3}$ & $\mathrm{mM}$ & 4 & 4 \\
\hline $\mathrm{SO}_{4}$ & $\mathrm{mM}$ & 3 & 6 \\
\hline Cations & $\mathrm{N} / \mathrm{A}$ & $\mathrm{N} / \mathrm{A}$ & 20 \\
\hline Anions & $\mathrm{N} / \mathrm{A}$ & $\mathrm{N} / \mathrm{A}$ & 20 \\
\hline
\end{tabular}

Note: the artificial river water (low ionic strength) is a ten-fold dilution of this solution.

After analysis of the $\mathrm{K}_{\mathrm{d}}$ data, it was determined that a higher solid to solution ratio was required for the high ionic strength matrix in order to promote enough sorption to generate reproducible results. The batch $\mathrm{K}_{\mathrm{d}}$ test was performed a second time for the high ionic strength solution (following the same protocol described above) with a new solid to solution ratio of 1:1.5. Duplicate batch reactors were prepared by placing 50 grams of sediment into 250- $\mathrm{mL}$ HDPE bottles. The sediment was washed and the reactors were prepared and sampled in the same manner described above. Samples were filtered through $0.2 \mu \mathrm{m}$ Nalgene syringe filters and analyzed for $\mathrm{pH}, \mathrm{EC}$, and ${ }^{238} \mathrm{U}$. Uranium $\mathrm{K}_{\mathrm{d}}$ values were determined as described above and detailed in Relyea et al. (1980) and are shown in Appendix N.

\subsection{Batch Adsorption Test: Variable Solution pH}

The second batch adsorption test involved varying the solution $\mathrm{pH}$. This test was performed at two uranium concentrations: $0.5 \mathrm{mg} / \mathrm{L}$ and $3 \mathrm{mg} / \mathrm{L}$. The $\mathrm{pH}$ range tested in the low ionic strength solution (same as section 3.5) was from 6.5 to 8.5; the $\mathrm{pH}$ range tested in the high ionic strength solution (same as section 3.5) was from 6.5 to 8.0. The reason why a narrower $\mathrm{pH}$ range was examined in the high ionic strength solution was due to the propensity to precipitate calcium carbonate in the high ionic strength solution when the $\mathrm{pH}$ was above 8.1. Solution $\mathrm{pH}$ was adjusted using $0.1 \mathrm{~N} \mathrm{HNO}_{3}$ or $0.1 \mathrm{M} \mathrm{NaOH}$. Duplicate batch reactors were prepared by placing 5 grams of sediment into a 125-mL HDPE bottle for the low ionic strength solution, and 50 grams of sediment into a 250-mL HDPE bottle for the high ionic strength solution. The 
sediment was washed three times overnight in the respective solutions (without uranium) at a solid to solution ratio of 1:10 for the low ionic strength solution and 1:1.5 for the high ionic strength solution. After the third wash, the reactors received the respective low ionic strength ( $\mathrm{pH}$ 6.5-8.5) and high ionic strength ( $\mathrm{pH} 6.5-8.0$ ) solutions containing $0.5 \mathrm{mg} / \mathrm{L}$ or $3 \mathrm{mg} / \mathrm{L}{ }^{238} \mathrm{U}$. Contact time for this test was three days with gentle shaking on a linear shaker table. Samples were filtered through $0.2 \mu \mathrm{m}$ Nalgene syringe filters and analyzed for $\mathrm{pH}, \mathrm{EC}$, and ${ }^{238} \mathrm{U}$. Uranium $\mathrm{K}_{\mathrm{d}}$ values were determined as described in Section 3.5. See details in Relyea et al. (1980) and Appendix O.

\subsection{Batch Adsorption Test: Variable Bicarbonate Solution Concentration}

The final batch adsorption test involved varying the carbonate concentration in solution. The test was performed at the same two uranium solution concentrations used in the variable $\mathrm{pH}$ batch tests, $0.5 \mathrm{mg} / \mathrm{L}$ and $3 \mathrm{mg} / \mathrm{L}$. Once again, the test was performed using a low ionic strength and high ionic strength solution with $\mathrm{pH}$ of the solutions maintained between 7.5 and 8 . However, the solutions were composed of two constituents: sodium bicarbonate and sodium sulfate. The low ionic strength solution ( $2 \mathrm{meq} / \mathrm{L}$ ) had bicarbonate concentrations of $0.5,1$ and $2 \mathrm{mM}$, respectively. The high ionic strength solution $(20 \mathrm{meq} / \mathrm{L})$ had bicarbonate concentrations of 2,8 , and $16 \mathrm{mM}$, respectively. The balance of the ionic strength in the respective solutions was achieved by adding appropriate quantities of sodium sulfate. Duplicate batch reactors were prepared in the same manner described in section 3.6. Contact time for this test was also three days, and filtered samples were analyzed for $\mathrm{pH}, \mathrm{EC}$, and ${ }^{238} \mathrm{U}$. Uranium $\mathrm{K}_{\mathrm{d}}$ values were determined as described in Section 3.5 (see details in Relyea et al. (1980) and Appendix P).

\subsection{Column Flow-Through Test: Adsorption/Desorption Study}

The final laboratory studies performed in FY 2002 were two column flow-through experiments to test the adsorption of uranium onto the background sediment (B11493) using a dilute (low ionic strength) and saline (high ionic strength) solution (See Table 3.4 for solution composition). This test was performed to determine how much uranium could be sorbed or "loaded" onto the sediment when in contact with uranium contaminated solutions. Subsequently, the same solutions, containing no uranium, were injected into the column to determine how much of the sorbed uranium would again become soluble and could ultimately be removed from the sediment. These experiments most closely simulate in-situ aquifer conditions, where uranium contaminated groundwater plumes migrate through the aquifer sediments.

The background sediment was packed into small $(3.8 \mathrm{~cm}$ diameter by $30.5 \mathrm{~cm}$ long) Teflon columns. The known column apparatus volume, the weight of the sediment and water filled column, and the weight of the sediment used to fill the columns were used to calculate the column pore volume (void space) and bulk density, respectively. Details of the measurements and calculations are shown in Table 3.5. The tests were performed by slowly percolating the respective solutions in an up-flow configuration to remove as much trapped air as possible and to create water saturated flow conditions. The nominal residence time for each pore volume of solution was approximately 2 weeks (336 hours). After approximately three pore volumes of rinsing with solutions without uranium (to equilibrate the sediments to the influent solution 
chemistry), the same low and high ionic strength solutions spiked with $1 \mathrm{mg} / \mathrm{L}$ natural uranium were run through the columns. Aliquots of leachate from both columns were collected every few days and analyzed for $\mathrm{pH}, \mathrm{EC}$, and ${ }^{238} \mathrm{U}$ content. Selected aliquots were analyzed for major cations and trace metals using ICP-OES, anions using IC, and alkalinity via titration. After approximately fifty percent break-through was achieved $\left(C / C_{0}=0.5\right)$, the uranium-spiked solution was replaced with non-spiked solutions. The subsequent desorption of uranium from the sediment was monitored through the collection of effluent samples every few days. The effluent samples were first filtered through $0.2 \mu \mathrm{m}$ Nalgene syringe filters and then analyzed for $\mathrm{pH}, \mathrm{EC}$, and ${ }^{238} \mathrm{U}$. Selected aliquots were analyzed for major cations and trace metals using ICPOES, anions using IC, and alkalinity via titration.

Table 3.5 Adsorption/Desorption Column Details

\begin{tabular}{|c|c|c|c|c|c|}
\hline $\begin{array}{c}\text { Sample } \\
\text { ID }\end{array}$ & $\begin{array}{c}\text { Column } \\
\text { Number }\end{array}$ & $\begin{array}{c}\text { Tare } \\
(\mathbf{g})\end{array}$ & $\begin{array}{c}\text { Soil Filled Weight } \\
(\mathbf{g})\end{array}$ & $\begin{array}{c}\text { Soil Weight } \\
(\mathbf{g})\end{array}$ & $\begin{array}{c}\text { Col. Vol. } \\
(\mathbf{c m 3})\end{array}$ \\
\hline B11493-1 & 1 & 407.99 & 962.38 & 554.39 & 323.89 \\
\hline B11493-4 & 4 & 409.41 & 980.40 & 570.99 & 323.89 \\
\hline & & & & & \\
\hline $\begin{array}{c}\text { Sample } \\
\text { ID }\end{array}$ & $\begin{array}{c}\text { Column } \\
\text { Number }\end{array}$ & $\begin{array}{c}\text { Bulk Density } \\
(\mathbf{g} / \mathbf{c m} 3)\end{array}$ & Porosity & $\begin{array}{c}\text { Pore Volume } \\
(\mathbf{c m 3})\end{array}$ & $\begin{array}{c}\text { Flow Rate } \\
(\mathbf{m l} / \mathbf{h r})\end{array}$ \\
\hline B11493-1 & 1 & 1.71 & 0.37 & 120.69 & 0.36 \\
\hline B11493-4 & 4 & 1.76 & 0.35 & 114.59 & 0.34 \\
\hline
\end{tabular}




\subsection{RESULTS AND DISCUSSION}

This section presents the geochemical and physical characterization data collected on the nearsurface sediment samples obtained in the 300 Area, as well as the results of the leaching and adsorption experiments performed. Information on the sediments presented in this section includes moisture content, $\mathrm{pH}$ and $\mathrm{EC}$, and measurements of major cations, anions, and radionuclides of 1:1 sediment to water extracts. Particle size and total and inorganic carbon measurements were also performed on the sediments. Semi-selective extractions of the sediments were performed to aid in uranium speciation estimates. Results from the flow-through leach tests that were the emphasis of work in FY 2001 are presented. Data from the preliminary adsorption tests using leachate produced during the column leach tests are presented. Finally, results of the FY 2002 batch adsorption, long-term batch leach, as well as the adsorption/desorption flow-through column experiments are presented.

\subsection{Sediment Characterization Results}

\subsubsection{Moisture Content}

The moisture content of the air-dried sediment (dried for approximately 72 hours on a tarp in a fume hood) collected from each sampling location is listed in Table 4.1. Air drying was performed to allow us to thoroughly mix the 5-gal samples to assure that each sample was well homogenized prior to characterization and experimentation.

Table 4.1 Air-Dried Moisture Content of Sediments from 300 Area

\begin{tabular}{|cc|}
\hline $\begin{array}{c}\text { Sample } \\
\text { ID }\end{array}$ & $\begin{array}{c}\text { Moisture } \\
\text { (\% wt.) }\end{array}$ \\
\hline \multicolumn{2}{|c|}{ Background } \\
\hline B11491 & $0.60 \%$ \\
B11492 & $0.50 \%$ \\
B11493 & $0.50 \%$ \\
\hline \multicolumn{2}{|c|}{ 300 N Process Pond } \\
\hline B11494 & $8.92 \%$ \\
B11495 & $1.00 \%$ \\
\hline 303-K Building Environs \\
\hline B11BY4 & $0.92 \%$ \\
B11BY5 & $1.72 \%$ \\
B11BY6 & $0.66 \%$ \\
\hline
\end{tabular}

As expected, the air-dried moisture content of the coarse grained sediments is quite low. The one exception is sample B11494, which consists of scrapings of fine-grained sediment from the 300 Area North Process Pond. The combination of being finer grained, and perhaps containing 
very fine-grained hydrous oxide precipitates from sediment neutralization reactions with the past slightly acidic liquid disposal, causes this sample to retain more water after air-drying. That is, fine-grained sediments retain more moisture via capillary forces than coarse-grained sediment. Hydrous oxide precipitates also retain more loosely bound water than "normal" aluminosilicate minerals.

\subsubsection{1:1 Sediment to Water Extracts}

The most economical method of determining the distribution of mobile contaminants in the vadose zone sediments is to generate and measure constituents in sediment-water extracts (1:1 ratio based on weight) because direct extraction of porewater is costly, difficult at best, and impossible for some very dry sediments. It should be noted that calculations involving "pore concentrations" in the following sections refer to the residual moisture after the samples were air-dried in the laboratory. The actual concentrations of solutes in the vadose zone porewaters are difficult to determine on sediments unless they are carefully sampled and preserved prior to measurement. Determining the porewater composition of near-surface sediments is especially problematic because of seasonal evapotranspiration events.

\subsubsection{1. $\quad \mathrm{pH}$ and Electrical Conductivity}

The $\mathrm{pH}$ and electrical conductivity (EC) for the 1:1 sediment to water extracts are shown in Table 4.2. The $\mathrm{EC}$ has been corrected for the dilution with deionized water (dilution factor $\mathrm{X}$ measured value), but the $\mathrm{pH}$ is reported as measured. That is, the EC can be reported on both the measured extract and the undiluted air-dried porewater basis, where it is assumed that adding deionized water does not release material out of or off the sediment, but only dilutes the existing porewater to allow its extraction.

Table 4.2 Water Extract pH and EC Values

\begin{tabular}{|c|c|c|c|c|}
\hline $\begin{array}{c}\text { Sample } \\
\text { ID }\end{array}$ & $\begin{array}{c}\text { Dilution } \\
\text { Factor }\end{array}$ & $\begin{array}{c}1: 1 " \\
\mathrm{pH}\end{array}$ & $\begin{array}{c}\text { "1:1" } \\
\mathrm{EC} \\
\mathrm{uS} / \mathrm{cm}\end{array}$ & $\begin{array}{c}\text { Pore } \\
\mathrm{EC} \\
\mathrm{uS} / \mathrm{cm}\end{array}$ \\
\hline \multicolumn{5}{|c|}{ Background } \\
\hline B11491 & 169 & 7.65 & 0.230 & 38.8 \\
\hline B11492 & 202 & 7.75 & 0.268 & 54.1 \\
\hline B11493 & 200 & 7.68 & $\mathrm{ND}$ & $\mathrm{ND}$ \\
\hline \multicolumn{5}{|c|}{ 300 N Process Pond } \\
\hline B11494 & 11.3 & 7.67 & 0.660 & 7.44 \\
\hline B11495 & 100 & 7.8 & 0.275 & 27.6 \\
\hline B11BY4 & 108 & 7.76 & 0.169 & 18.3 \\
\hline B11BY5 & 58.1 & 7.13 & 0.059 & 3.43 \\
\hline B11BY6 & 153 & 7.74 & 0.133 & 20.3 \\
\hline
\end{tabular}

Note: ND = Not Determined, limited sample volume did not allow for analysis. 
PNNL-14022 300 Area U Leach/Adsorption Study for ERC Final Report

Chapter 4. Results and Discussion

\subsubsection{Water Extract Anions and Cations}

The1:1 sediment to water extract's anion/cation composition are shown in Tables 4.3 through 4.5. Using the moisture content, one can also calculate what the maximum concentration of constituents in the air-dried vadose zone porewater is from the dilution factor. This assumes that all the constituents found in the 1:1 extract were originally present in the porewater and that no material leached from the sediment. In reality, some material leached from the sediment such that the porewaters are not as "salty" as the calculation. This is especially true for these nearsurface 300 Area sediments that undoubtedly contain evaporated salts. For deeper sediments, it has been shown by actual "squeezing" of porewater from vadose zone sediments that this calculated porewater composition is a fairly good estimate of the actual vadose zone porewater (see Serne et al. 2002 a,b,c,d).

Table 4.3 Anion Composition of the 1:1 Sediment to Water Extract

\begin{tabular}{||c|c|c|c|c|c|c||}
\hline $\begin{array}{c}\text { Sample } \\
\text { ID }\end{array}$ & $\begin{array}{c}\text { Nitrate }\left(\mathrm{NO}_{3}\right) \\
\mathrm{mg} / \mathrm{L}\end{array}$ & $\begin{array}{c}\text { Fluoride } \\
\mathrm{mg} / \mathrm{L}\end{array}$ & $\begin{array}{c}\text { Nitrite }\left(\mathrm{NO}_{2}\right) \\
\mathrm{mg} / \mathrm{L}\end{array}$ & $\begin{array}{c}\text { Chloride } \\
\mathrm{mg} / \mathrm{L}\end{array}$ & $\begin{array}{c}\text { Sulfate } \\
\mathrm{mg} / \mathrm{L}\end{array}$ & $\begin{array}{c}\text { Phosphate }\left(\mathrm{PO}_{4}\right) \\
\mathrm{mg} / \mathrm{L}\end{array}$ \\
\hline \multicolumn{7}{|c|}{ Background } \\
\hline B11491 & 2.873 & $\mathrm{ND}$ & $\mathrm{ND}$ & 0.753 & 1.745 & 1.346 \\
\hline B11492 & 4.05 & 0.882 & 0.097 & 0.737 & 9.92 & 0.988 \\
\hline B11493 & 4.809 & 0.788 & 0.087 & 0.477 & 4.153 & 1.45 \\
\hline \multicolumn{7}{|c|}{ 300 N Process Pond } \\
\hline B11494 & 106.01 & 1.99 & $<0.498$ & 2.01 & 120.05 & $<0.746$ \\
\hline B11495 & 35.96 & 1.74 & $<0.498$ & 4.29 & 14.23 & $<0.746$ \\
\hline \multicolumn{7}{|c|}{$303-K$ Building Environs } \\
\hline B11BY4 & 9.41 & 0.22 & $<0.498$ & $<0.249$ & 4.77 & 2.12 \\
\hline B11BY5 & 8.52 & $<0.100$ & $<0.498$ & $<0.249$ & 3.22 & 1.06 \\
\hline B11BY6 & 5.64 & 0.22 & $<0.498$ & $<0.249$ & 4.42 & 2.09 \\
\hline
\end{tabular}

Note: ND = Not Determined due to instrument difficulties.

Based on Tables 4.2 and 4.3 it is apparent that the sediment from the southern end of the $\mathrm{N}$ Process Pond that contains the hydrous sludge (B11494) water extracts significantly more EC, nitrate, and sulfate than the other samples. The other sediment from the N Process Pond side wall (B11495) also water extracts slightly more nitrate, chloride, and sulfate than the background sediment. There are no significant differences in the water extracts from the three near-surface sediment samples taken from around $303-\mathrm{K}$ building versus the background sediment. This suggests that there is no sign of elevated water extractable material in the $303-\mathrm{K}$ sediments.

Table 4.4 shows the concentrations of cations in the 1:1 sediment to water extracts. The North Process Pond samples contain a bit more soluble $\mathrm{Al}, \mathrm{Ba}, \mathrm{Ca}, \mathrm{Mg}, \mathrm{Na}$, and $\mathrm{Sr}$ than the background sediment and the sediments from around the 303-K building. Conversely, the sediments from the North Process Pond contained less soluble (aqueous) silica than the background sediment and 
PNNL-14022 300 Area U Leach/Adsorption Study for ERC Final Report Chapter 4. Results and Discussion

303-K sediments. The 1:1 sediment-to-water extract iron value for the background sediment may be atypically high for sediments. The high water extractable Al, and alkaline earth cations ( $\mathrm{Ca}, \mathrm{Mg}, \mathrm{Ba}$, and $\mathrm{Sr}$ ) in the North Process Pond sediments likely reflect evaporates from past liquid waste disposals that contained dissolved salts. The high sodium may have come from prior neutralization of acid waste streams with $\mathrm{NaOH}$. The major cation composition of the 1:1 water extracts from the sediments around the 303-K building do not yield any clues (the values are very similar to natural background sediments) as to the nature of the uranium contamination.

Table 4.4 Cation Composition of the 1:1 Sediment to Water Extracts

\begin{tabular}{|c|c|c|c|c|c|c|c|c|c|c|}
\hline $\begin{array}{c}\text { Sample } \\
\text { ID }\end{array}$ & $\begin{array}{c}\mathrm{Al} \\
\mathrm{ug} / \mathrm{L}\end{array}$ & $\begin{array}{c}\mathrm{Ba} \\
\mathrm{ug} / \mathrm{L}\end{array}$ & $\begin{array}{c}\mathrm{Ca} \\
\mathrm{mg} / \mathrm{L}\end{array}$ & $\begin{array}{c}\mathrm{Fe} \\
\mathrm{ug} / \mathrm{L}\end{array}$ & $\begin{array}{c}\mathrm{K} \\
\mathrm{mg} / \mathrm{L}\end{array}$ & $\begin{array}{c}\mathrm{Mg} \\
\mathrm{mg} / \mathrm{L}\end{array}$ & $\begin{array}{c}\mathrm{Na} \\
\mathrm{mg} / \mathrm{L}\end{array}$ & $\begin{array}{c}\mathrm{Si} \\
\mathrm{mg} / \mathrm{L}\end{array}$ & $\begin{array}{c}\mathrm{Sr} \\
\mathrm{ug} / \mathrm{L}\end{array}$ & $\begin{array}{c}\mathrm{Mn} \\
\mathrm{ug} / \mathrm{L}\end{array}$ \\
\hline \multicolumn{8}{|c||}{ Background } \\
\hline B11493 & $<50$ & 27 & 7.3 & 40 & 3.9 & 2.5 & 12.5 & 13.5 & 43 & 5 \\
\hline \multicolumn{8}{|c|}{ 300 Area North Process Pond } \\
\hline B11494 & 67 & 68 & 48.9 & $<10$ & 3.6 & 14.5 & 56.9 & 5 & 285 & 3 \\
\hline B11495 & 206 & 34 & 27.7 & 13 & 5.9 & 5.6 & 8.8 & 5.5 & 128 & 2 \\
\hline \multicolumn{8}{|c|}{ 303-K Building Environs } \\
\hline B11BY4 & $<50$ & 18 & 18.5 & $<10$ & 3.4 & 2.4 & 5.1 & 12.9 & 72 & 2 \\
\hline B11BY5 & $<50$ & 12 & 4.5 & 18 & 2.2 & 0.8 & 1.3 & 10.9 & 20 & 38 \\
\hline B11BY6 & $<50$ & 17 & 18.9 & $<10$ & 3.3 & 2.5 & 3.9 & 13.9 & 72 & 1 \\
\hline
\end{tabular}

Note: some analytes are reported as ug/L and others $\mathrm{mg} / \mathrm{L}$. Reported sodium values are considered qualitative.

Table 4.5 shows the 1:1 sediment-to-water extract concentration of trace metals. Table 4.5 shows that there are elevated concentrations of uranium in 1:1 water extracts for all of the samples from the North Process Pond and 303-K environs, excluding sample B11BY5. There also appears to be elevated water extractable chromium and copper in the samples from the North Process Pond and 303-K environs. The Pond Scrapings sample (B11494) has high concentrations of soluble copper, and the extraction from sample B11BY5 contains high concentrations of zinc. The following information has been collected, but is not presented in the tables: sample B11494 contained $4784 \mathrm{ug} / \mathrm{L}$ boron and none of the samples contained

Table 4.5 Trace Metal Composition of the 1:1 Sediment to Water Extracts

\begin{tabular}{|c|c|c|c|c|c|c|}
\hline $\begin{array}{c}\text { Sample } \\
\text { ID } \\
\end{array}$ & $\begin{array}{c}\mathrm{U} \\
\left(\mu_{\mathrm{g} / \mathrm{L})}\right.\end{array}$ & $\begin{array}{c}\mathrm{Cr} \\
\left(\mu_{\mathrm{g} / \mathrm{L})}\right.\end{array}$ & $\begin{array}{c}\text { As } \\
\left(\mu_{\mathrm{g} / \mathrm{L})}\right.\end{array}$ & $\begin{array}{c}\mathrm{Cu} \\
\left(\mu_{\mathrm{g} / \mathrm{L})}\right. \\
\end{array}$ & $\begin{array}{c}\mathrm{Cd} \\
\left(\mu_{\mathrm{g} / \mathrm{L})}\right. \\
\end{array}$ & $\begin{array}{c}\mathrm{Zn} \\
\left(\mu_{\mathrm{g} / \mathrm{L})}\right) \\
\end{array}$ \\
\hline \multicolumn{7}{|c|}{ Background } \\
\hline B11493 & 0.698 & (2) & 19 & 34 & $<250$ & 32 \\
\hline \multicolumn{7}{|c|}{300 N Process Pond } \\
\hline B11494 & 2096 & 39 & 12 & 254 & 58 & 31 \\
\hline B11495 & 242 & 10 & 11 & 72 & (21) & (21) \\
\hline \multicolumn{7}{|c|}{ 303-K Building Environs } \\
\hline B11BY4 & 1369 & 9 & 12 & 22 & (18) & (13) \\
\hline B11BY5 & 24.2 & 8 & 7 & 67 & (2) & 178 \\
\hline B11BY6 & 2448 & 12 & 14 & 14 & $(41)$ & (13) \\
\hline
\end{tabular}

Note: (--) reported value is below limit of quantification. < Indicates reported value from instrument was 0 . measurable cobalt (detection limit $5 \mu \mathrm{g} / \mathrm{L}$ ) or lead (detection limit $100 \mu \mathrm{g} / \mathrm{L}$ ). The source of 
copper in the North Process Pond sediments is cladding wastes. The source of the high zinc value for the water extract and in the sediment (see section 4.1.4) from B11BY5 may be from the galvanized down spout. Therefore, it is believed that the high water extractable zinc is accurate. Finally, Se, Mo, and Ni were all monitored and found to be at concentrations less than 100,25 , and $25 \mu \mathrm{g} / \mathrm{L}$, respectively in the $1: 1$ sediment-to-water extracts.

\subsubsection{Total Carbon, $\mathrm{CaCO}_{3}$ and Organic Carbon Content of Sediment Samples}

Table 4.6 shows the total carbon, inorganic carbon, and organic carbon content of the nearsurface 300 Area sediments. The inorganic carbon was also converted to the equivalent calcium carbonate content. The background sediment is typical of most Hanford sediments that have very low organic carbon ( 0.05 to $0.2 \%$ ) and a small amount of calcium carbonate. The sediment from the 300 Area North Process Pond (B11494 \& B11495) shows slightly higher concentrations of calcium carbonate than the background sediment; the Pond Scrapings sample (B1194) shows about $1 \%$ by weight organic carbon. One of the samples from the $303-\mathrm{K}$ environs (B11BY5) has

Table 4.6 Carbon Content in Near-Surface Vadose Sediments from 300 Area

\begin{tabular}{|c|c|c|c|c|}
\hline $\begin{array}{c}\text { Sample } \\
\text { ID }\end{array}$ & $\begin{array}{c}\text { Total } \\
\text { Carbon } \\
\text { (\% wt.) }\end{array}$ & $\begin{array}{c}\text { Inorganic } \\
\text { Carbon } \\
\text { (\% wt.) }\end{array}$ & $\begin{array}{c}\mathrm{IC} \text { as } \\
\mathrm{CaCO}_{3} \\
\text { (\% wt.) }\end{array}$ & $\begin{array}{l}\text { Organic } \\
\text { Carbon } \\
(\% \text { wt. })\end{array}$ \\
\hline \multicolumn{5}{|c|}{ Background } \\
\hline B11491 rep1 & 0.13 & 0.09 & 0.789 & 0.04 \\
\hline B11491 rep2 & 0.12 & 0.08 & 0.635 & 0.04 \\
\hline B11492 rep1 & 0.13 & 0.07 & 0.577 & 0.06 \\
\hline B11492 rep2 & $\mathrm{ND}$ & 0.09 & 0.722 & $\mathrm{ND}$ \\
\hline B11493 rep1 & 0.13 & 0.07 & 0.589 & 0.06 \\
\hline B11493 rep2 & $\mathrm{ND}$ & 0.07 & 0.568 & $\mathrm{ND}$ \\
\hline \multicolumn{5}{|c|}{300 N Process Pond } \\
\hline B11494 rep1 & 1.11 & 0.14 & 1.167 & 0.97 \\
\hline B11494 rep2 & 1.12 & 0.14 & 1.167 & 0.98 \\
\hline B11495 rep1 & 0.27 & 0.11 & 0.917 & 0.16 \\
\hline B11495 rep2 & 0.27 & ND & ND & $\mathrm{ND}$ \\
\hline \multicolumn{5}{|c|}{ 303-K Building Environs } \\
\hline B11BY4 & 0.77 & 0.11 & 0.917 & 0.66 \\
\hline B11BY5 rep1 & 2.93 & 0.01 & 0.083 & 2.92 \\
\hline B11BY5 rep2 & 2.94 & 0.01 & 0.083 & 2.93 \\
\hline B11BY5 rep3 & ND & 0.01 & 0.083 & $\mathrm{ND}$ \\
\hline B11BY6 & 0.37 & 0.07 & 0.583 & 0.3 \\
\hline
\end{tabular}

Note: $\mathrm{ND}=$ Not Determined. Additional replicate data was not required, therefore, the analysis was not performed.

low calcium carbonate content, but atypically high organic carbon content. The higher than average orga nic carbon content could be an artifact of where the sample was collected (i.e. 
adjacent to a downspout on the $303 \mathrm{~K}$ building). Perhaps the sample's organic carbon content was increased due to contamination by roofing material. The third sample from the vicinity of the $303-\mathrm{K}$ building has typical concentrations of calcium carbonate and slightly more organic carbon than the background sediment. It is known from past work that the 300 -Area Process Pond had some enriched carbonate layers that correlated with elevated uranium concentrations (see for example Serne et al 1992, ART 1994).

\subsubsection{Sediment Uranium Concentration}

The eight near-surface sediment samples were analyzed via gamma energy analysis (GEA) by the ERC's Radiological Counting Facility (RCF). The GEA data was used to estimate the total ${ }^{238} \mathrm{U}$ content of the sediment using the ${ }^{234} \mathrm{Th}$ daughter. The total uranium content in the soils was also measured via X-ray fluorescence (XRF). A comparison of the total uranium mass based on the estimated ${ }^{238} \mathrm{U}$ content and the XRF chemical analyses of uranium is shown in Table 4.7. Assuming that the uranium is present as "natural" uranium (i.e. non-enriched) with $99.7 \%$ abundance ${ }^{238} \mathrm{U}$, XRF mass $U$ values were converted to activity of ${ }^{238} \mathrm{U}$. For the XRF data, two separate excitation sources were available that gave independent measurements of uranium. The two sources are designated XRF and XRF-2 in the table headings. The agreement between the two labs and two techniques is satisfactory, although one data point was not used in making the comparisons. The average mass uranium concentrations in the last column are used throughout this report as the best values of the total uranium content in the sediment samples.

\section{Table 4.7 Comparison of the U Content of the Bulk Sediments Using Two Analytical} Techniques

\begin{tabular}{|c|c|c|c|c|c|}
\hline $\begin{array}{c}\text { Sample } \\
\text { ID }\end{array}$ & $\begin{array}{c}\text { XRF } \\
(\mathrm{pCi} / \mathrm{g})\end{array}$ & $\begin{array}{c}\text { XRF-2 } \\
(\mathrm{pCi} / \mathrm{g})\end{array}$ & $\begin{array}{c}\text { GEA- RCF } \\
(\mathrm{pCi} / \mathrm{g})\end{array}$ & $\begin{array}{c}\text { Ave } \\
(\mathrm{pCi} / \mathrm{g})\end{array}$ & $\begin{array}{c}\text { Mass Ave } \\
(\mathrm{mg} / \mathrm{Kg})\end{array}$ \\
\hline B11491 & 1.8 & 2.2 & 1.4 & & \\
\hline B11492 & 1.7 & 2.1 & 0.91 & & \\
\hline B11493 & 1.8 & 2.1 & 1.2 & 1.7 & 5.1 \\
\hline B11494 & 173 & 188 & 180 & 180 & 539.9 \\
\hline B11495 & 11.2 & 4.2 & 15 & 13 & 39.2 \\
\hline B11BY4 & 175 & 186 & 220 & 188 & 562.9 \\
\hline B11BY5 & 101 & 104 & 83 & 96 & 287.4 \\
\hline B11BY6 & 311 & 330 & 350 & 330 & 988.8 \\
\hline
\end{tabular}

Note: Shaded values were discarded before calculating the averages due to instrument anomaly.

\subsubsection{Sediment Total Oxide Composition}

A representative aliquot of each sediment was crushed and analyzed using XRF to obtain the complete elemental composition of the sample. Additional aliquots of these same sediments were subjected to particle size analysis, and the sand, silt, and clay separates were retained for mineralogic analysis (Appendix S). The clay separates were analyzed by XRF to allow total oxide composition to be calculated for the clay fractions. The total oxide composition of both the 
PNNL-14022 300 Area U Leach/Adsorption Study for ERC Final Report

Chapter 4. Results and Discussion

bulk and clay size separates were used to aid in the quantification of mineralogy found in Appendix S.

The total elemental oxide composition for the bulk sediments is shown in Table 4.8. The minor trace constituent concentrations in the sediments are shown in Table 4.9. Using two types of XRF instruments, we were able to quantify all natural elements in the periodic table between $\mathrm{Na}$ and $\mathrm{U}$, with the exception of the noble gases. The XRF technique lacks the capability to measure

Table 4.8 Total Composition of the Vadose Zone Sediments from the 300 Area As \% Wt.

\begin{tabular}{|c|c|c|c|c|c|c|}
\hline Oxide & $\begin{array}{c}\text { B11493 } \\
\text { Bkg. }\end{array}$ & $\begin{array}{c}\text { B11494 } \\
\text { Pond } \\
\end{array}$ & $\begin{array}{c}\text { B11495 } \\
\text { Pond } \\
\end{array}$ & $\begin{array}{c}\text { B11BY4 } \\
303-\mathrm{K} \\
\end{array}$ & $\begin{array}{c}\text { B11BY5 } \\
303-\mathrm{K} \\
\end{array}$ & $\begin{array}{c}\text { B11BY6 } \\
303-\mathrm{K} \\
\end{array}$ \\
\hline $\mathrm{CO}_{2}$ & 2.37 & 4.28 & 3.36 & 3.36 & 0.304 & 2.14 \\
\hline $\mathrm{Na}_{2} \mathrm{O}$ & 2.53 & 1.40 & 2.13 & 2.06 & 1.98 & 2.49 \\
\hline $\mathrm{MgO}$ & 1.48 & 2.19 & 1.59 & 2.02 & 1.56 & 1.81 \\
\hline $\mathrm{Al}_{2} \mathrm{O}_{3}$ & 9.57 & 15.4 & 10.3 & 9.83 & 10.7 & 10.4 \\
\hline $\mathrm{SiO}_{2}$ & 67.7 & 50.8 & 66.0 & 61.9 & 63.6 & 67.7 \\
\hline $\mathrm{P}_{2} \mathrm{O}_{5}$ & 0.205 & 0.774 & 0.202 & 0.229 & 0.273 & 0.215 \\
\hline $\mathrm{SO}_{3}$ & 0.179 & 0.270 & 0.067 & 0.097 & 0.345 & 0.082 \\
\hline $\mathrm{Cl}$ & $<0.010$ & $<0.010$ & $<0.010$ & $<0.010$ & $<0.010$ & $<0.010$ \\
\hline $\mathrm{K}_{2} \mathrm{O}$ & 1.93 & 1.12 & 1.78 & 1.43 & 1.62 & 1.79 \\
\hline $\mathrm{CaO}$ & 3.72 & 5.15 & 3.47 & 5.74 & 3.32 & 4.32 \\
\hline $\mathrm{TiO}_{2}$ & 1.04 & 1.23 & 0.777 & 1.12 & 1.03 & 1.04 \\
\hline $\mathrm{V}_{2} \mathrm{O}_{5}$ & 0.020 & 0.022 & 0.010 & 0.025 & 0.024 & 0.019 \\
\hline $\mathrm{Cr}_{2} \mathrm{O}_{3}$ & 0.005 & 0.125 & 0.007 & 0.006 & 0.022 & 0.006 \\
\hline $\mathrm{MnO}$ & 0.096 & 0.122 & 0.076 & 0.147 & 0.107 & 0.127 \\
\hline $\mathrm{Fe}_{2} \mathrm{O}_{3}$ & 5.49 & 7.44 & 4.32 & 7.37 & 7.59 & 6.62 \\
\hline $\mathrm{SrO}$ & 0.049 & 0.037 & 0.047 & 0.041 & 0.040 & 0.044 \\
\hline $\mathrm{BaO}$ & 0.040 & 0.096 & 0.092 & 0.091 & 0.083 & 0.093 \\
\hline $\mathrm{NiO}$ & 0.002 & 0.032 & 0.002 & 0.004 & 0.025 & 0.002 \\
\hline $\mathrm{CuO}$ & 0.004 & 0.632 & 0.004 & 0.009 & 0.027 & 0.008 \\
\hline $\mathrm{ZnO}$ & 0.008 & 0.020 & 0.007 & 0.019 & 0.078 & 0.017 \\
\hline $\mathrm{ZrO}_{2}$ & 0.020 & 0.138 & 0.020 & 0.024 & 0.041 & 0.025 \\
\hline $\mathrm{UO}_{3}$ & 0.001 & 0.058 & 0.002 & 0.058 & 0.033 & 0.103 \\
\hline Total & 96.5 & 91.3 & 94.3 & 95.6 & 92.8 & 99.1 \\
\hline
\end{tabular}

Note: < Indicates reported value from instrument was 0. 
the following light elements: $\mathrm{Li}, \mathrm{Be}, \mathrm{B}, \mathrm{C}, \mathrm{N}$, and F. However, as discussed in Section 3.0, we analyzed the carbon content of the bulk sediments and have included $\mathrm{C}$ in the mass balance calculation. The $\mathrm{Li}, \mathrm{Be}, \mathrm{B}, \mathrm{N}$, and $\mathrm{F}$ content of the sediments is likely small enough that their mass can be excluded from the calculation with little to no effect on the mass balance calculation. We have assumed that the $\mathrm{Fe}$ present in the sediments is all $\mathrm{Fe}_{2} \mathrm{O}_{3}$, although there may be some reduced (ferrous oxides) iron also present.

As shown in red type in Table 4.9, the pond scrapings sediment (B11494) shows high Table 4.9 Other Trace Constituents Found in the Bulk Sediments From Near-Surface
Sediments (ug/g)

\begin{tabular}{|c|c|c|c|c|c|c||}
\hline Element & $\begin{array}{c}\text { B11493 } \\
\text { Bkg. }\end{array}$ & $\begin{array}{c}\text { B11494 } \\
\text { Pond }\end{array}$ & $\begin{array}{c}\text { B11495 } \\
\text { Pond }\end{array}$ & $\begin{array}{c}\text { B11BY4 } \\
303-\mathrm{K}\end{array}$ & $\begin{array}{c}\text { B11BY5 } \\
303-\mathrm{K}\end{array}$ & $\begin{array}{c}\text { B11BY6 } \\
303-\mathrm{K}\end{array}$ \\
\hline $\mathrm{Ga}$ & 13.6 & 47.6 & 11.5 & 14.2 & 12.0 & 14.3 \\
$\mathrm{Se}$ & $<2.3$ & $<2.8$ & $<2.2$ & $<2.5$ & $<2.5$ & $<2.6$ \\
$\mathrm{~Pb}$ & 13.2 & 30.7 & 14.4 & 42.0 & 180 & 40.6 \\
$\mathrm{As}$ & $<3.6$ & 9.10 & 3.4 & 4.50 & 13.3 & $<4$ \\
$\mathrm{Br}$ & $<2.1$ & 3.20 & $<2$ & $<2.4$ & $<2.5$ & $<2.5$ \\
$\mathrm{Rb}$ & 63.0 & 45.2 & 62.8 & 42.3 & 50.9 & 56.8 \\
$\mathrm{Y}$ & 23.6 & 34.0 & 19.5 & 32.5 & 30.8 & 33.5 \\
$\mathrm{Nb}$ & 11.5 & 11.7 & 7.07 & 11.1 & 10.3 & 13.2 \\
$\mathrm{Mo}$ & 1.97 & 7.55 & 2.00 & 4.90 & 5.70 & 7.80 \\
$\mathrm{Th}$ & 6.85 & 16.1 & 6.35 & 8.15 & 10.8 & 8.85 \\
$\mathrm{Co}$ & $<61$ & $<69$ & $<48$ & $<68$ & $<65$ & 90.0 \\
$\mathrm{Hg}$ & $<5.2$ & $<8$ & $<5.1$ & $<6.2$ & 9.70 & $<6.1$ \\
$\mathrm{Rb}$ & 56.5 & 49.7 & 52.9 & 46.9 & 48.3 & 69.5 \\
$\mathrm{Ru}$ & $<9.3$ & $<14$ & $<13$ & $<17$ & $<14$ & $<13$ \\
$\mathrm{Pd}$ & $<10$ & $<14$ & $<13$ & $<16$ & $<14$ & $<14$ \\
$\mathrm{Ag}$ & $<10$ & 87.1 & $<14$ & $<17$ & $<15$ & $<14$ \\
$\mathrm{Cd}$ & $<12$ & $<16$ & $<15$ & $<19$ & $<17$ & $<16$ \\
$\mathrm{In}$ & $<13$ & $<18$ & $<18$ & $<21$ & $<19$ & $<18$ \\
$\mathrm{Sn}$ & $<13.8$ & $<19$ & $<18$ & 41.0 & $<20$ & 32.5 \\
$\mathrm{Sb}$ & $<16$ & $<20$ & $<21$ & $<25$ & $<23$ & $<21$ \\
$\mathrm{Te}$ & $<18$ & $<24$ & $<22$ & $<28$ & $<24$ & $<24$ \\
$\mathrm{I}$ & $<23$ & $<30$ & $<31$ & $<35$ & $<33$ & $<31$ \\
$\mathrm{Cs}$ & $<28$ & $<33$ & $<37$ & $<38$ & $<36$ & $<33$ \\
$\mathrm{La}$ & $<38$ & $<51$ & $<48$ & $<56$ & $<51$ & $<47$ \\
$\mathrm{Ce}$ & $<41$ & $<55$ & $<56$ & $<61$ & $<60$ & 61 \\
\hline
\end{tabular}

Note: < Indicates reported value from instrument was 0. 
concentrations of several trace metals, especially copper, with chromium, nickel, zirconium, silver, arsenic, lead, gallium, molybdenum, and uranium all significantly higher than background. The high zirconium and aluminum oxide contents likely reflect precipitation of hydrous $\mathrm{Zr}$ and $\mathrm{Al}$ oxides from cladding wastes. As expected, there is elevated phosphorus in the B11494 pond scrapings (likely due to testing of the bismuth-phosphate precipitation process). B11BY5 is the only other sediment sample that appears to have higher than natural background concentrations of metals other than uranium, with elevated levels of zinc, nickel, and lead. Sample B11BY6 may have slightly elevated levels of molybdenum and lead compared to the background sediment. Other trace metals found in the bulk sediment via XRF at low concentrations are shown in Table 4.9.

The mass balances for the bulk sediments vary from 91.3 to $99.1 \%$. The sediment with the largest shortfall is the pond scrapings, which undoubtedly contained bound waters of hydration and a small amount of organic matter that are not accounted for in the mass balance calculation.

Similar to the uncontaminated sediment, the Pond samples and 303-K near-surface contaminated sediments are dominated by silica and alumina. Iron, magnesium, calcium, sodium, potassium, carbonate, and titanium comprise most of the remaining oxides. The pond scrapings (B11494) contain less silica and sodium than the background sediment and other contaminated sediments. We also found less soluble Si in the water extract from the Pond sediments. It would appear that the normal quartz and feldspar background sediment is "diluted" with the Al and carbonate rich fine-grained precipitates, and that readily leachable Si has already been removed from these sediments from the large volumes of dilute solutions disposed near the end of the ponds lifetime (see Hartman et. al, 2002 for more discussion).

\subsubsection{Particle Size Measurements on 300 Area Vadose Zo ne Sediments}

The dry sieving/hydrometer methods were used to determine the particle size distributions of the near-surface sediments taken from the 300 Area. The particle size results are shown in Table 4.10 and Figure 4.1. Table 4.10 suggests that the uranium-contaminated sediments contain more gravel than the background sediment and that sample B11494, which consists of pond scrapings, contains more clay-sized material than any of the other samples. Sample B11BY5 also contains significantly more silt plus clay than the background sample.

Figure 4.1 shows the particle size distribution of the samples as determined by the hydrometer method AFTER the gravel ( $>2 \mathrm{~mm}$ material) had been removed. Thus the Y-axis of the figure represents "cumulative \% finer than" EXCLUDING the gravel fraction. The data used to construct Figure 4.1 is shown in Table 4.11 for convenience. All the data for the four measurements on background sediment (B11491, B11492, B11493, and B11493 duplicate) have been averaged because the size separates were quite similar. 
PNNL-14022 300 Area U Leach/Adsorption Study for ERC Final Report

Chapter 4. Results and Discussion

Table 4.10 Particle Size Distribution (\% Wt.) Measured by Wet Sieve/Hydrometer Method

\begin{tabular}{|c|c|c|c|c|}
\hline Sample ID & $\begin{array}{c}\text { Wt. \% Gravel } \\
(>\mathbf{~ 2 ~ m m )}\end{array}$ & $\begin{array}{c}\text { Wt. \% Sand } \\
\mathbf{( 0 . 0 6} \mathbf{~ m m}<\mathbf{x}<\mathbf{2 ~ m m})\end{array}$ & $\begin{array}{c}\text { Wt. \% Silt } \\
\mathbf{( 0 . 0 0 2} \mathbf{~ m m}<\mathbf{x}<\mathbf{0 . 0 6} \mathbf{~ m m})\end{array}$ & $\begin{array}{c}\text { Wt. \% Clay } \\
(\mathbf{x}<\mathbf{0 . 0 0 2} \mathbf{~ m m})\end{array}$ \\
\hline \multicolumn{5}{|c|}{ Background } \\
\hline B11491 & $1.80 \%$ & $94.0 \%$ & $3.20 \%$ & $1.10 \%$ \\
B11492 & $1.80 \%$ & $94.7 \%$ & $2.80 \%$ & $0.80 \%$ \\
B11493-A & $1.80 \%$ & $94.2 \%$ & $3.20 \%$ & $0.90 \%$ \\
B11493-B & $1.80 \%$ & $93.7 \%$ & $3.40 \%$ & $1.10 \%$ \\
\hline \multicolumn{5}{|c|}{ 300 NProcess Pond } \\
\hline B11494 & $47.7 \%$ & $40.4 \%$ & $4.10 \%$ & $7.90 \%$ \\
\hline B11495 & $5.80 \%$ & $88.4 \%$ & $3.10 \%$ & $2.80 \%$ \\
\hline \multicolumn{5}{|c|}{ 303-K Building Environs } \\
\hline B11BY4 & $28.8 \%$ & $63.2 \%$ & $4.90 \%$ & $3.00 \%$ \\
\hline B11BY5 & $19.2 \%$ & $66.7 \%$ & $10.0 \%$ & $4.10 \%$ \\
\hline B11BY6 & $45.8 \%$ & $46.6 \%$ & $4.70 \%$ & $2.80 \%$ \\
\hline
\end{tabular}

Note: Duplicate measurements were made on B11493 aliquots of sediment.

Figure 4.1: Particle Size Distribution of 300 Area Sediments After Removal of Gravel

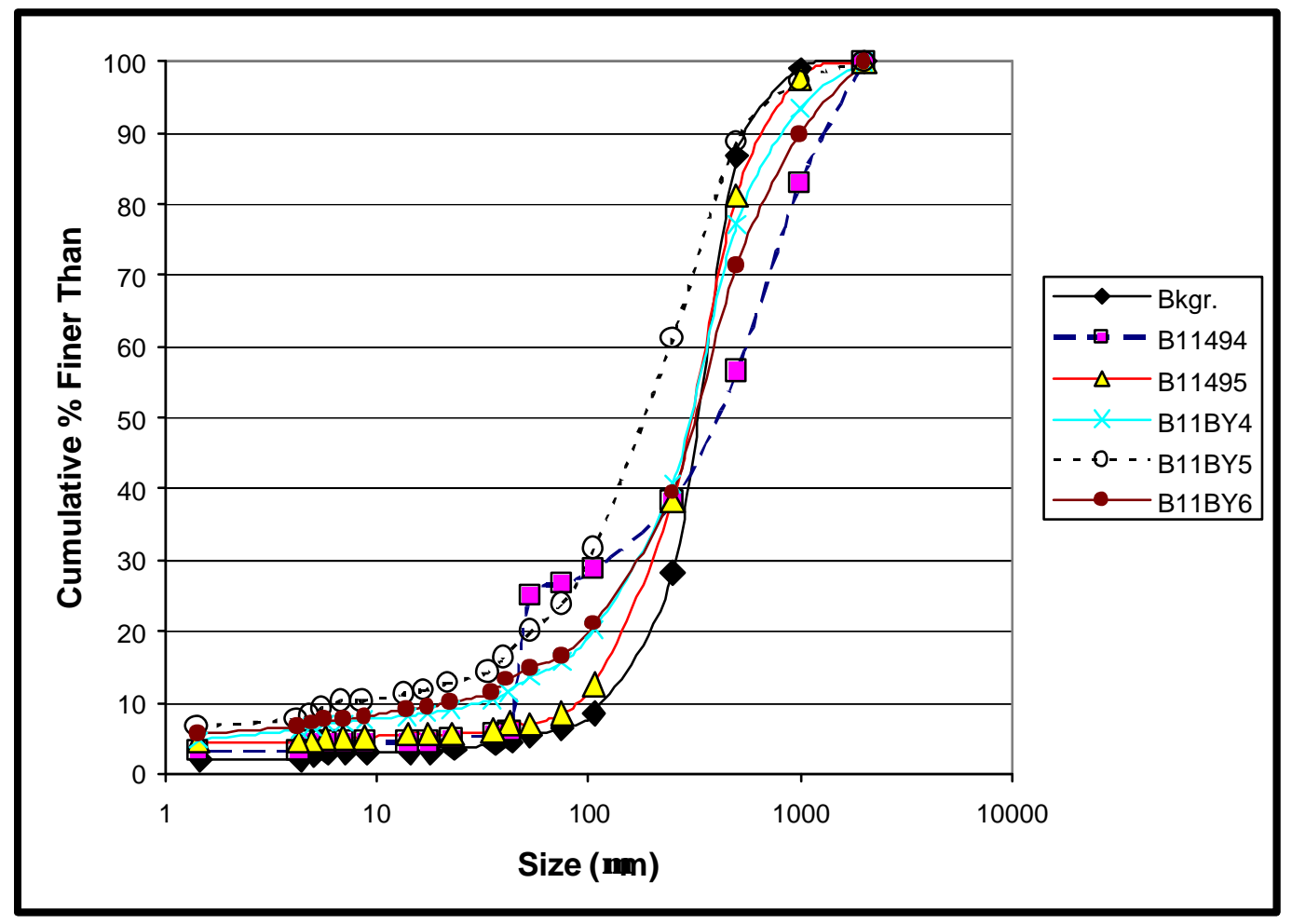


Table 4.11. Cumulative Percent Finer Than Particle Size Distribution (\% Wt.) After Gravel Removal

\begin{tabular}{|c|c|c|c|c|c|c|}
\hline $\mathbf{X}(\mu \mathbf{m})$ & Bkgr. & B11494 & B11495 & B11BY4 & B11BY5 & B11BY6 \\
\hline 2000 & 100 & 100 & 100 & 100 & 100 & 100 \\
\hline 1000 & 99 & 83 & 97.7 & 93.5 & 97.3 & 89.8 \\
\hline 500 & 86.7 & 56.5 & 81.2 & 77.2 & 88.8 & 71.4 \\
\hline 250 & 28.2 & 38.3 & 38.4 & 40.8 & 61.1 & 39.5 \\
\hline 106 & 8.5 & 28.7 & 12.5 & 20.3 & 31.6 & 21.1 \\
\hline 75 & 6.3 & 26.6 & 8.4 & 15.7 & 23.8 & 16.5 \\
\hline 53 & 5.4 & 25.1 & 7 & 13.6 & 20 & 14.8 \\
\hline 43.4 & 4.5 & 6 & 7.1 & 11.4 & 16.3 & 13.2 \\
\hline 36.3 & 4.1 & 5.4 & 6.1 & 10.4 & 14.2 & 11.3 \\
\hline 23.1 & 3.5 & 4.9 & 5.6 & 9 & 12.7 & 9.9 \\
\hline 18 & 3 & 4.4 & 5.6 & 8.5 & 11.7 & 9.5 \\
\hline 14.3 & 3 & 4.4 & 5.6 & 8.1 & 11.2 & 9 \\
\hline 9 & 3 & 4.4 & 5.1 & 7.6 & 10.2 & 8 \\
\hline 7.2 & 3 & 4.4 & 5.1 & 7.1 & 10.2 & 7.6 \\
\hline 5.8 & 2.8 & 4.4 & 5.1 & 7.1 & 9.2 & 7.6 \\
\hline 5.1 & 2.5 & 4.4 & 4.5 & 6.6 & 8.1 & 7.1 \\
\hline 4.4 & 2 & 3.3 & 4.5 & 6.2 & 7.6 & 6.6 \\
\hline 1.5 & 2 & 3.3 & 4.5 & 4.7 & 6.6 & 5.7 \\
\hline
\end{tabular}

\subsubsection{Selective Extraction Results}

As described in Section 3.1, an attempt was made to determine what sediment phases the uranium was associated with by using classic soil chemistry extractions with reagents that are selective for specific phases. The results for uranium are shown in Table 4.12. Other data for major metals and trace metals found in the sediment are shown in Figures 4.3-4.6 and Appendix K. Duplicate 5-gram aliquots of the background, both North Process Pond samples, and all three 303-K environs sediment samples were extracted with reagents in a sequential fashion. The residual material after extraction was oven-dried, weighed and analyzed by XRF. All the leachates were analyzed by both ICP (common cations and trace metals) and ICP-MS (U). Table 4.12 shows the amount of uranium in each chemical reagent and the percentage of the total uranium present in the sediment that was leached by each reagent (data from the duplicate samples has been averaged). The data has been normalized for the total uranium recovered in the 7 extraction solutions and the residual as measured via XRF. Figure 4.2 is a plot of the data from Table 4.12. 
PNNL-14022 300 Area U Leach/Adsorption Study for ERC Final Report

Chapter 4. Results and Discussion

Table 4.12 Selective Extraction Results for $U$ in the Six Near-surface Sediment Samples \% of Total U Removed by Each Extractant

\begin{tabular}{||c|c|c|c|c|c|c|}
\hline Phase/Compound Targeted & Background & B11494 & B11495 & B11BY4 & B11BY5 & B11BY6 \\
\hline Water soluble (1) & $0.01 \%$ & $0.44 \%$ & $0.95 \%$ & $0.22 \%$ & $0.08 \%$ & $0.15 \%$ \\
\hline Ion Exchangable (2) & $0.31 \%$ & $0.70 \%$ & $1.57 \%$ & $0.21 \%$ & $0.04 \%$ & $0.29 \%$ \\
\hline Carbonate Solids (3) & $0.62 \%$ & $30.2 \%$ & $23.9 \%$ & $36.9 \%$ & $20.3 \%$ & $31.1 \%$ \\
\hline Amorphous Oxides (4) & $1.82 \%$ & $55.0 \%$ & $28.0 \%$ & $37.2 \%$ & $54.2 \%$ & $45.5 \%$ \\
\hline Organics (5) & $0.38 \%$ & $10.1 \%$ & $20.0 \%$ & $12.8 \%$ & $9.19 \%$ & $13.3 \%$ \\
\hline Crystalline Oxides (6) & $0.36 \%$ & $1.54 \%$ & $2.84 \%$ & $2.77 \%$ & $5.11 \%$ & $2.94 \%$ \\
\hline Stron Acid Leachable (7) & $1.05 \%$ & $0.45 \%$ & $0.92 \%$ & $8.38 \%$ & $1.31 \%$ & $6.11 \%$ \\
\hline Residual (8) & $95.4 \%$ & $1.58 \%$ & $21.8 \%$ & $1.53 \%$ & $3.18 \%$ & $0.61 \%$ \\
\hline
\end{tabular}

As shown in Table 4.12 and Figure 4.2, the uranium content in the background sediment is primarily bound tightly in crystalline mineral sites. About 95 percent of the uranium is not extractable in the test. Less than one percent of the uranium was leached by "mild" reagents that likely represent phases that would be active in porewater leaching processes.

For the North Process Pond samples (B11494 \& B11495), the uranium extraction characteristics differ strikingly from the background sediment. Both samples show a small percentage of "readily mobile" uranium, steps $1 \& 2$ of the extraction process. The majority of the uranium in samples B11494 and B11495 is present in forms that represent uranyl carbonates and/or weak acid soluble uranium compounds and uranium associated with iron and aluminum amorphous hydrous oxides. That is, the sodium acetate and Tamm's reagents remove 50-80 percent of total uranium present. The Process Pond samples differ in the percentage of uranium that is recalcitrant to leaching, with approximately 2 percent left in sample B11494 vs. more than 20 percent for sample B11495. This perceived anomaly could be due in part to the limited detection limits of XRF, which is in the low (7-10) $\mathrm{mg} / \mathrm{Kg}$ range. In other words, a less than value was used to calculate the percent of uranium remaining after the sample (B11495) had been contacted with the seven leaching solutions. About 10-20\% of the uranium in sediments B11494 and B11495 is leached in the hydrogen peroxide step that purports to destroy organic matter. It is not clear if this result is accurate or if it reflects an incomplete dissolution of the amorphous oxide containing material from the previous step.

Table 4.12 and Figure 4.2 also show the results for the three sediment samples obtained around the $303-\mathrm{K}$ building. The results for all three samples are qualitatively similar. In all cases, the highest percentage (37 to 54\%) of the uranium was removed by the Tamm's reagent, which dissolves weak acid soluble uranium and amorphous iron and aluminum oxide phases. Ten to fifteen percent of the total uranium is leached in the subsequent step that purports to remove organic bound metals. Again, this result may represent uranium that was incompletely removed in the previous step. Approximately $20-35 \%$ of the uranium was removed in step three, which targets uranyl carbonates; however we suspect that other uranium(VI) compounds are also dissolving in this step. The residual material contained less than five percent of the total uranium present in any of the 303-K samples. 


\section{Figure 4.2: Plot of the \% Uranium Released in the Respective Leaching Solutions}

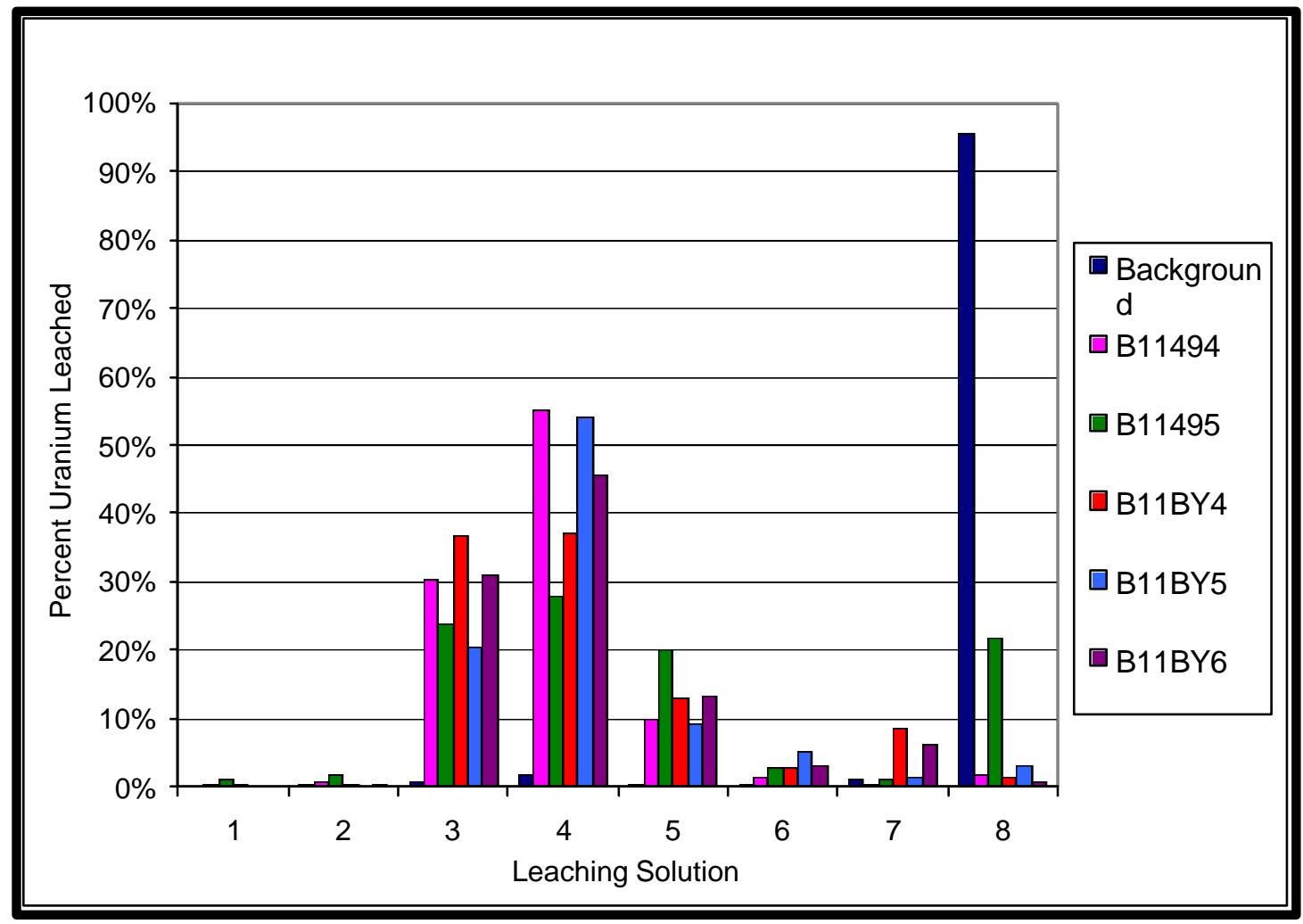

In summary, all five contaminated sediments contained uranium that was mostly extractable by the sodium acetate and Tamm's solutions, which dissolve uranyl carbonates (and we suspect other U(VI) solids) and amorphous iron and aluminum hydrous oxide phases, respectively. Less than a few percent of the total uranium was present in water leachable and cation exchangeable phases.

These results suggest that the uranium is present as co-precipitates or as weak-acid extractable amorphous uranyl compounds and associated with carbonates and hydrous iron and aluminum oxides. As discussed in the mineralogy section (Appendix S), we did not find evidence of crystalline uranyl oxides using XRD and SEM. However, our detection limit for identifying crystalline uranyl oxides is not sensitive enough to see the low concentrations $(=0.1 \%)$ of uranium present in the sediments. Further, both of the state-of-the-art molecular probe studies (Appendix U) suggest that the uranium is in fact present as crystalline or a mix of crystalline and amorphous uranium(VI) phases with silicates, oxides, hydroxides, carbonates and phosphates. The selective extraction results do suggest that the uranium in the contaminated sediments is not readily water leachable or cation exchangeable.

As shown in Figure 4.3, the aluminum content of the 300 Area near-surface sediment samples is primarily bound tightly in crystalline mineral sites. Generally, 85 percent of the aluminum is not extractable in the test. However, in sharp contrast to this general trend, the process pond samples (B11494 and B11495) released significant quantities of aluminum in the Tamm's reagent, which targets amorphous oxide compounds. A review of the semi-selective extraction data for 
aluminum yields the conclusion that the readily leachable aluminum is present as amorphous aluminum hydrous oxides. As reported in Section 4.1.5, the atypically high aluminum content in the North Process Pond soil samples is a result of the fuel processing and cladding activities that were performed in the 300 Area.

\section{Figure 4.3: Plot of the \% Aluminum Released in the Respective Leaching Solutions}

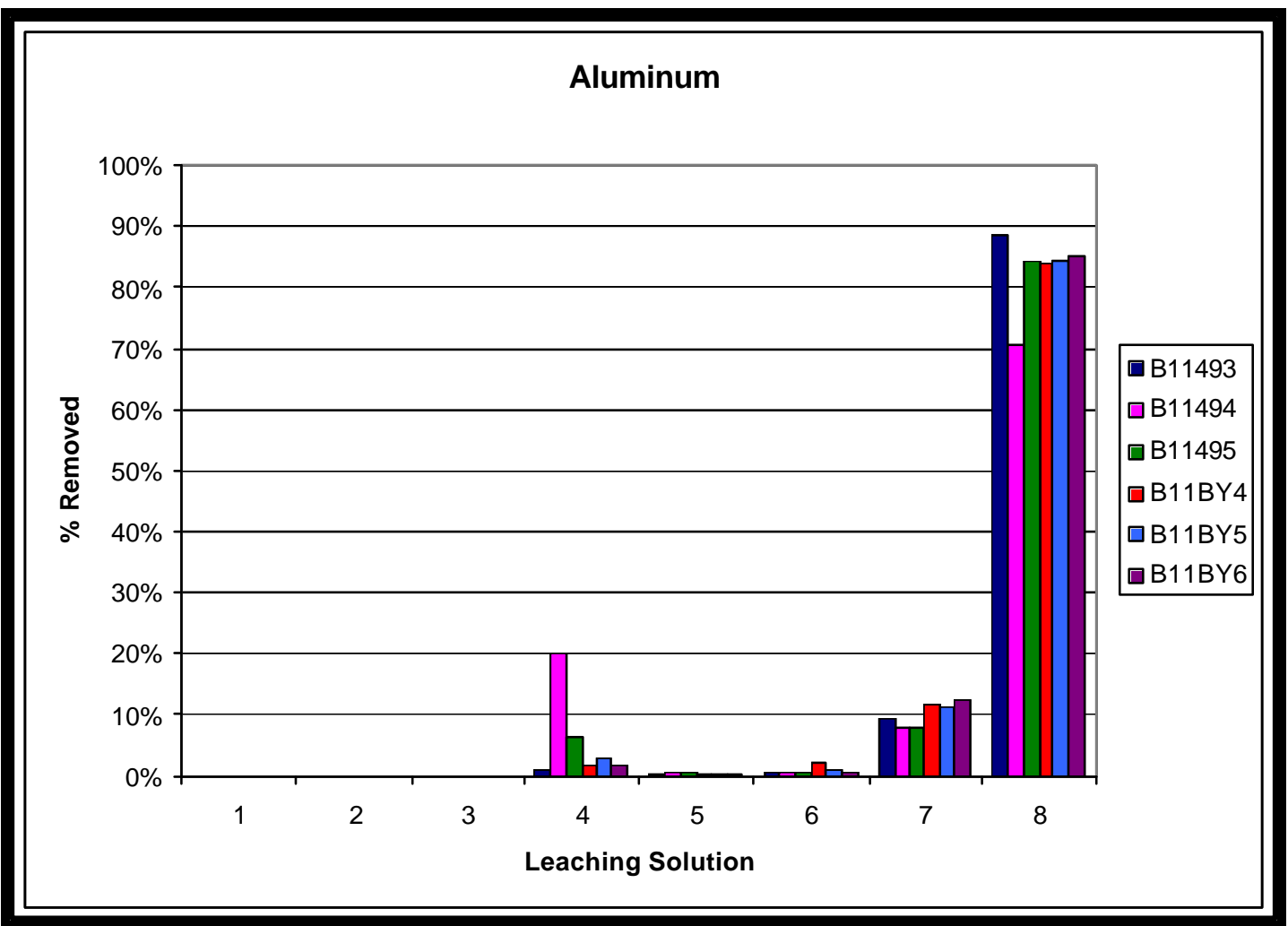

Figure 4.4 is a plot of the semi-selective extraction data for silica. As seen in the plot, more than 90 percent of the silica is not extractable in the test. Once again, the Tamm's extractant was the most effective leaching solution.

Figure 4.5 is a plot of the semi-selective extraction data for iron. As seen in Figure 4.5, considerable quantities of iron are extracted in the Tamm's, Sodium Dithionite, and concentrated Nitric Acid leaching steps; representing amorphous ferric oxides, crystalline ferric oxides, and strong acid leachable compounds, respectively. It is difficult to be certain that the Tamm's and dithionite solutions only target the amorphous and crystalline phases, respectively. Therefore, it is uncertain if the iron in the dithionite extractant is solely crystalline, or if it is partially a remnant of incomplete dissolution from the Tamm's extraction step. 
PNNL-14022 300 Area U Leach/Adsorption Study for ERC Final Report

Chapter 4. Results and Discussion

Figure 4.4: Plot of the \% Silica Released in the Respective Leaching Solutions

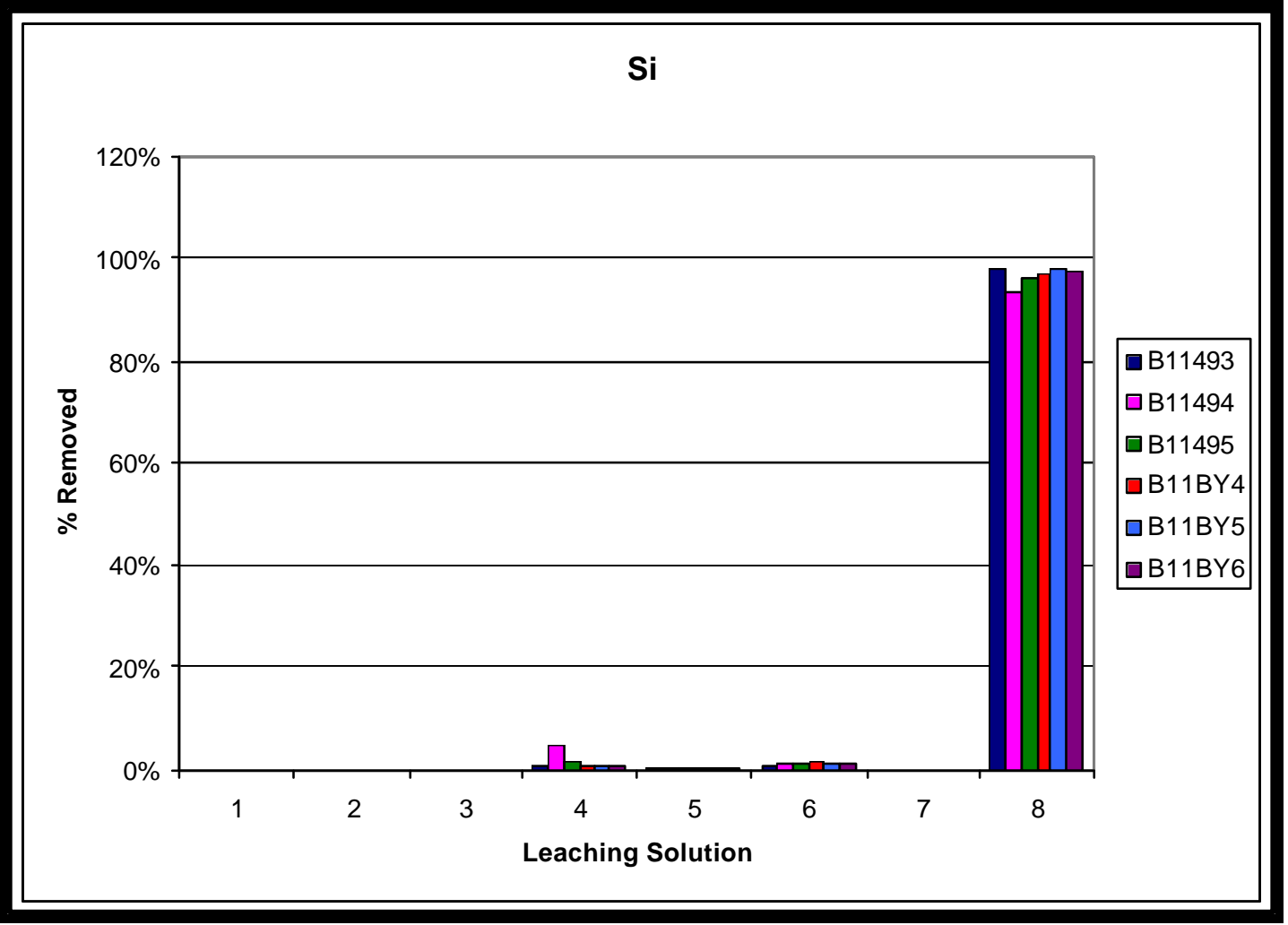

Figure 4.6 is a plot of the semi-selective extraction data for manganese. As seen in the plot, the majority of the extractable manganese is found in the Tamm's and strong nitric acid extraction steps, which target amorphous oxides and strong acid leachable compounds, respectively. With the exception of sample B11BY4, very little of the total manganese is removed by the sodium dithionite solution, which targets crystalline ferric and manganese oxides. 
PNNL-14022 300 Area U Leach/Adsorption Study for ERC Final Report Chapter 4. Results and Discussion

Figure 4.5: Plot of the \% Iron Released in the Respective Leaching Solutions

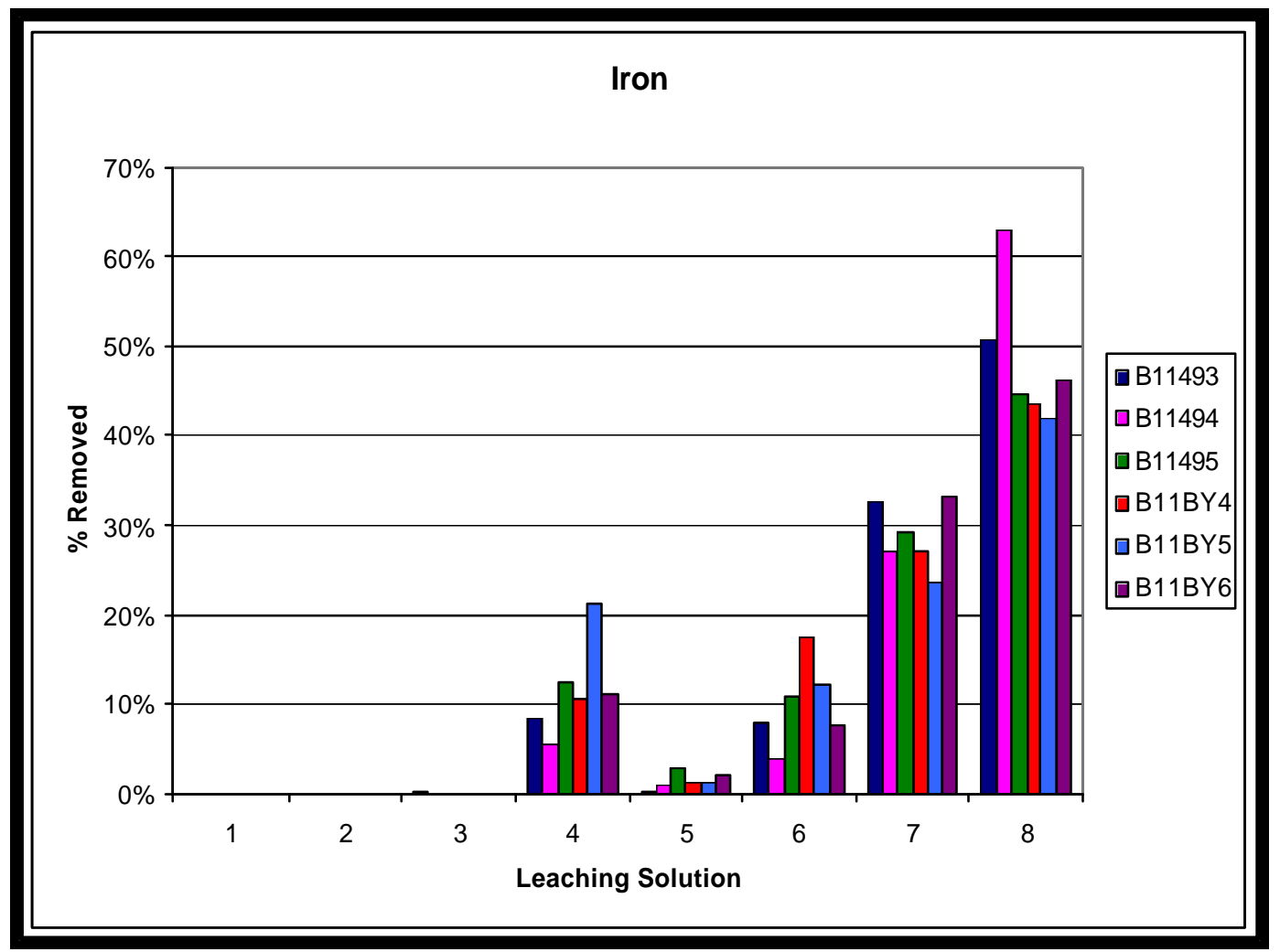

Figure 4.6: Plot of the \% Manganese Released in the Respective Leaching Solutions

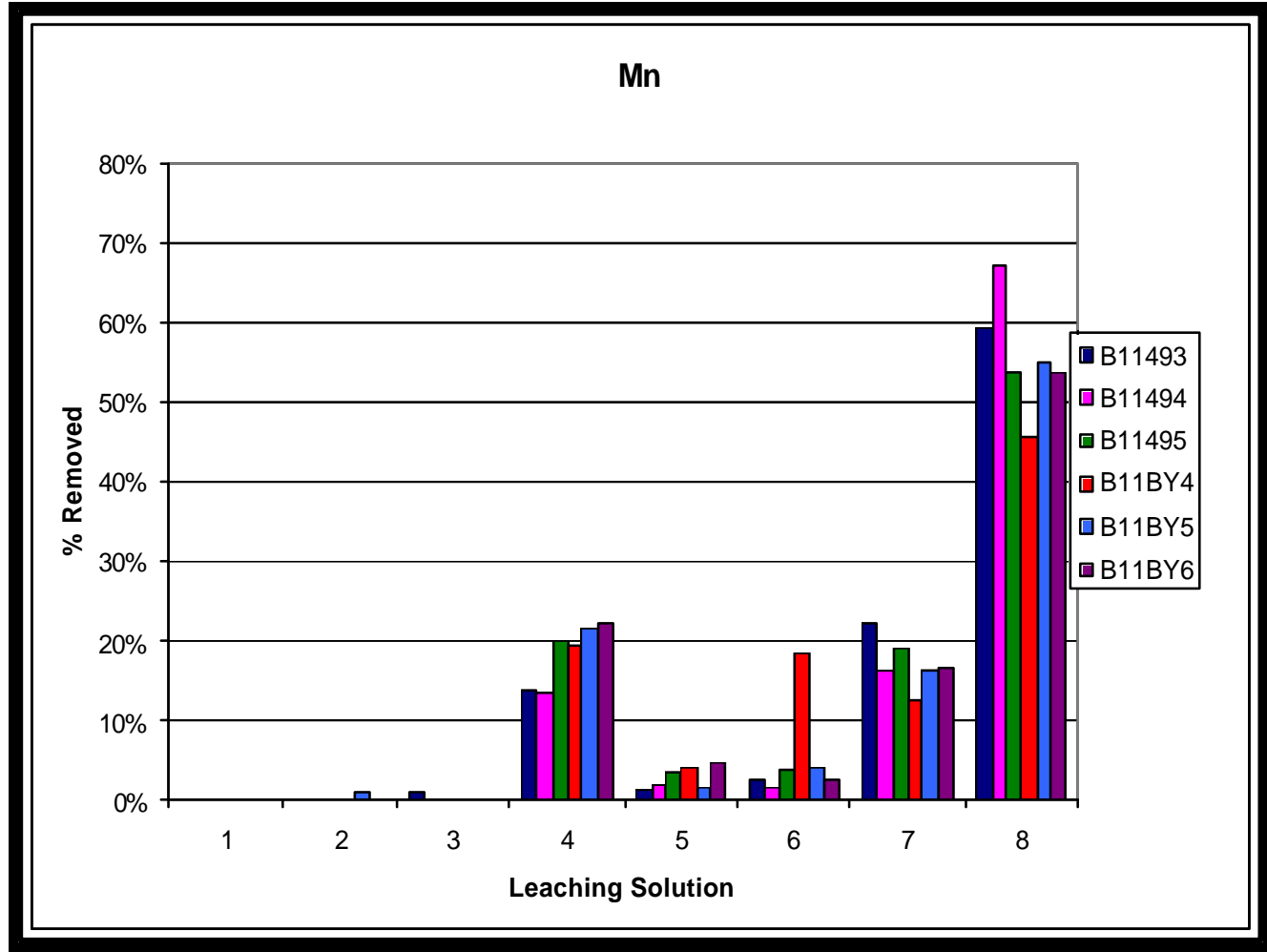


PNNL-14022 300 Area U Leach/Adsorption Study for ERC Final Report

Chapter 4. Results and Discussion

\subsection{Experimental Results}

\subsubsection{Flow-Through Column Leach Tests}

Six column leach tests were performed in FY 2001. As discussed in more detail in section 3.2, the columns were packed with between 6 and 7 kilograms of each of the sediments, and air saturated distilled water was slowly percolated in an up-flow manner through the sediment in an attempt to create water saturated conditions. The residence time for the fluid was approximately 7 days (flow rate equals 1 pore volume per 7 days). A pore volume is the amount of fluid needed to fill the void volume of the packed column and, for saturated water conditions is equal to the porosity. The pore volumes ranged from 900 to $1400 \mathrm{~mL}$ for the large columns used in these tests. The leachate from each column was collected in small aliquots (approximately 100 to 200 $\mathrm{mL}$ ). The aliquots were measured for $\mathrm{pH}, \mathrm{EC}$, and uranium concentrations. The results for uranium solution concentration are shown in Figures 4.7 through 4.9. In addition, selected aliquots were analyzed for major cations and anions including alkalinity, a measure of carbonate concentration. A detailed tabulation of the data for each aliquot collected from each column is shown in Appendix L; only summary figures are presented here.

Figure 4.7 shows the uranium leach characteristics for the pond scrapings sample (B11494). This sediment contains $540 \mathrm{mg} / \mathrm{Kg}$ total uranium and the concentration of uranium in the leachate slowly decreases from $7000 \mu \mathrm{g} / \mathrm{L}$ to $1700 \mu \mathrm{g} / \mathrm{L}$ over the first 8 pore volumes collected. Despite the high concentration of uranium in the leachate, the percentage of the total uranium in the sediment that leaches scarcely exceeds $1 \%$ after more than 11 pore volumes.

Figure 4.7 also shows the leach characteristics of the other sample taken from the 300 Area North Process Pond, B11495 that contains $39 \mathrm{mg} / \mathrm{Kg}$ total uranium. The leachate uranium concentration is high $(5000$ to $3000 \mu \mathrm{g} / \mathrm{L})$ in the first few aliquots. Even after 10 pore volumes of leachate has been collected, the solution concentration contains $43 \mu \mathrm{g} / \mathrm{L}$ of uranium. As shown in Figure 4.7, the leach curve has a much steeper descent than the more contaminated pond scrapings sample (B11494). After 10 pore volumes of leachate, sample B11495 had leached only $3.5 \%$ of the total uranium in the sediment. These saturated column leach tests give results in agreement with the selective extraction findings that suggest little of the uranium in the sediments is found in readily water or cation exchangeable (leachable) fractions. Although only a small $\%$ of the total uranium is readily leachable, the resulting dissolved uranium levels are large compared to the proposed drinking water level of $30 \mu \mathrm{g} / \mathrm{L}$, and the leachate concentrations remain high for many pore volumes of leaching.

Flow to the columns was stopped for a period of approximately five weeks in an attempt to determine the residence time required to reach steady state leachate concentrations. The first leachate sample collected from the B11494 column after flow was resumed (represented by the open symbol in Figure 4.7) contained nearly $50 \%$ less uranium than the last sample collected before flow was stopped. During the no-flow period, uranium was re-sorbing or re-precipitating onto the sediment. This is in sharp contrast to the data collected for first sample of B11495 leachate collected after the no-flow condition (represented by the open symbol in Figure 4.7), which had an immediate increase in uranium solution concentration when flow was resumed. 
Figure 4.7: Leach Test Data for the 300 Area North Process Pond Samples

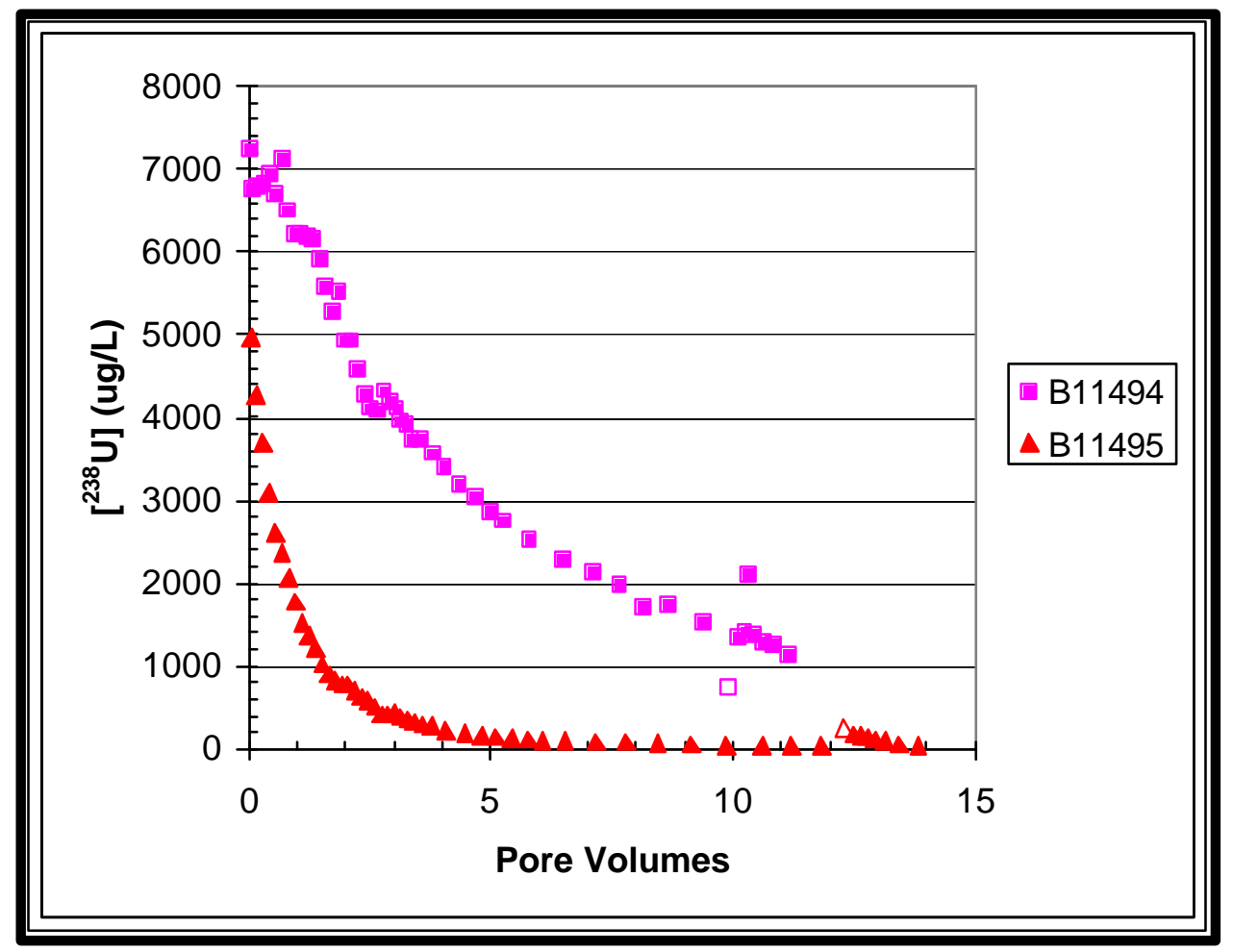

Thermodynamic modeling of the solution data from both columns using the geochemical code MINTEQ (Allison et al., 1991) does not lead us to believe that the leachates are consistently oversaturated or in equilibrium with respect to discrete uranium solids for which thermodynamic solubility products are known. Therefore, the observed decrease in uranium solution concentration during the five week no-flow condition in sample B11494 leachate may represent slow readsorption.

Figure 4.8 shows the leach characteristics of the three sediment samples collected in the vicinity of the 303-K building (B11BY4-B11BY6). Sample B11BY4, the first of two samples taken from the same sampling location, contains $563 \mathrm{mg} / \mathrm{Kg}$ of total uranium. Very high concentrations of uranium are found in the leachates in the first pore volume (41,500 to 17,000 $\mu \mathrm{g} / \mathrm{L}$ ). Even after 10 pore volumes of leaching, the uranium concentration remains close to $1,000 \mu \mathrm{g} / \mathrm{L}$. There is a rapid decrease in uranium concentration in the first two pore volumes; after 4 pore volumes, the rate of decrease slows considerably. After 10 pore volumes of leachate collection, less than $1.5 \%$ of sample B11BY4's uranium has been leached by the simulated rain water.

The leachate data for sample B11BY6, the second sample collected from the same location as sample B11BY4, is also shown in Figure 4.8. Sample B11BY6 contained the highest concentration of total uranium in this study, $989 \mathrm{mg} / \mathrm{Kg}$. In a consistent fashion, this sample also showed the highest concentrations of uranium in the leachate and a rapid decrease versus pore volume of leachate collected. The starting leachate uranium concentration was $66,000 \mu \mathrm{g} / \mathrm{L}$, but rapidly dropped off to $24,000 \mu \mathrm{g} / \mathrm{L}$ after one pore volume. Even after 9 pore volumes of fluid 
percolated through the sediment, the leachate uranium concentration is in excess of 1,400 $\mu \mathrm{g} / \mathrm{L}$. After more than 12 pore volumes of leaching, sample B11BY6 has released $1 \%$ of the total uranium in the sediment. The shape of the leach curve for these two samples from the same location are quite similar, and after the first four aliquots (approximately 0.4 pore volumes), the absolute values of the concentration of uranium in solution are nearly identical. This suggests that the type of uranium in the sediments is also similar as was found using laser fluorescence spectroscopy (Appendix U). The selective extraction results in section 4.1.7 also suggest that the type of uranium is quite similar in the two samples.

Flow to the $303 \mathrm{~K}$ sample columns was also stopped for a period of approximately five weeks (represented by the open symbols in Figure 4.8) about two-thirds of the way through the experiment. Similar to sample B11495, leachate solutions for samples B11BY4 and B11BY6 appear to be under-saturated with respect to known uranium compounds, and an increase in uranium leachate concentrations was seen in the subsequent samples after flow was resumed. The no-flow conditions suggest that the kinetics of uranium leaching is quite slow and that equilibrium was not reached at residence times of one to five weeks. The five-week no-flow condition had little to no effect on B11BY5 uranium leachate concentrations.

Figure 4.9 shows the leach characteristics of the uranium from sample B11BY5, which contains $287 \mathrm{mg} / \mathrm{Kg}$ total uranium. Unlike all the other contaminated samples, very little uranium is leached. The leachates collected over the first 3 pore volumes contain a fairly constant uranium concentration of about 45 to $55 \mu \mathrm{g} / \mathrm{L}$. With the exception of sample 34, see Sheet B11BY5 Daily's in Appendix L, the solution uranium concentration drops to $10 \mu \mathrm{g} / \mathrm{L}$ or less after 4.5 pore volumes. The spike seen at sample 34 appears to be real (the uranium value was confirmed in an

Figure 4.8: Leach Test Data for the 303-K Environ Samples

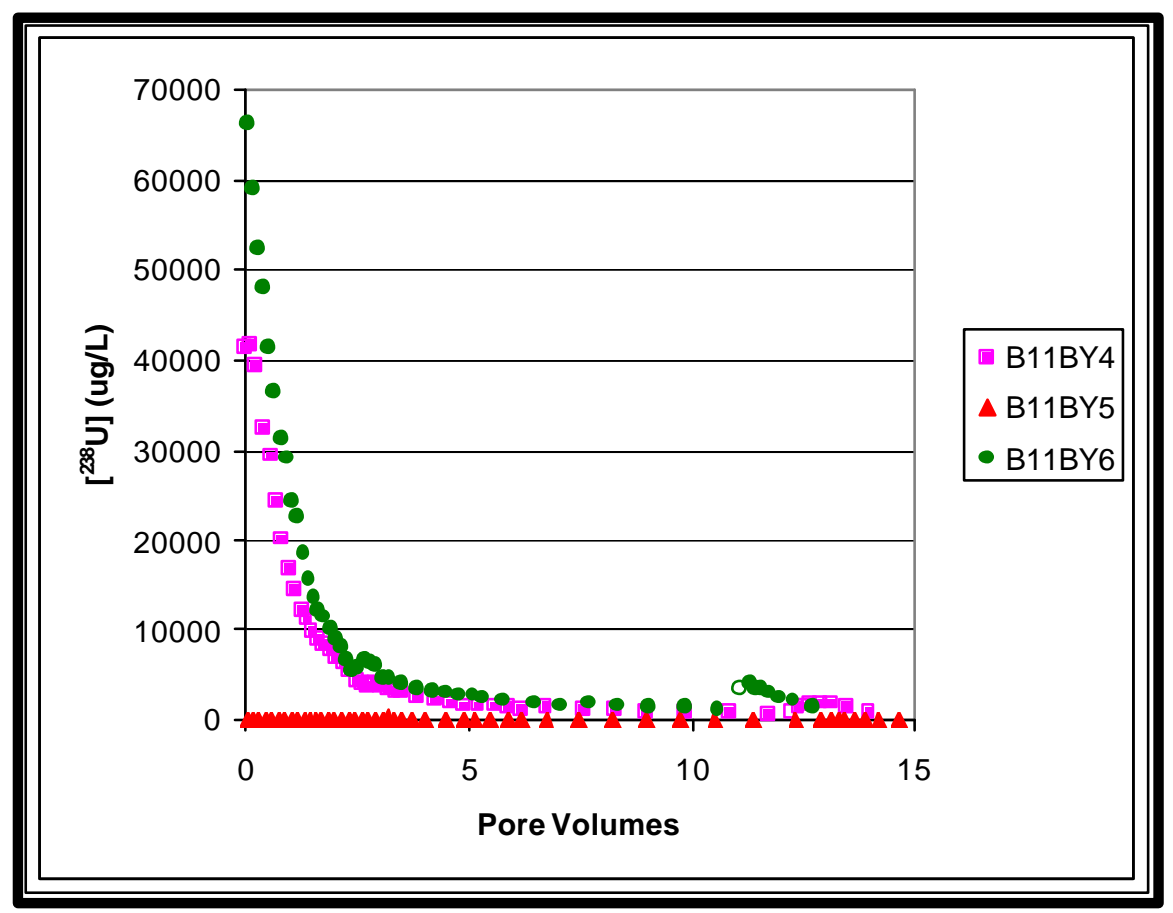


alternate run) and is apparently due to the dissolution of a higher activity particle in the column or the presence of a uranium-bearing colloid in the filtered effluent. Despite having $287 \mathrm{mg} / \mathrm{Kg}$ total uranium, sample B11BY5 leaches only slightly more uranium than the background sediment, which contains $5.1 \mathrm{mg} / \mathrm{Kg}$ total uranium. Sample B11BY5 contains more organic carbon than the other sediments and the leachate solution contained elevated dissolved iron (an indication of reducing conditions; although Eh measurements for the B11BY5 leachates were not significantly lower than for the other column leachates). There were also obvious signs of biological growth in the B11BY5 packed column and leachates in this test. Some of the other columns show slight indications of biological growth (perhaps fungal), but column B11BY5 was the most affected.

Figure 4.9 and Sheet B11493 Daily's in Appendix Lalso shows that the background sediment leaches some uranium and in fact, the first sample collected contains $30 \mu \mathrm{g} / \mathrm{L}$, equal to the current drinking water standard. As shown, the effluent uranium concentration for the background sediment dropped to $5 \mu \mathrm{g} / \mathrm{L}$ within the first pore volume, dropped to $2 \mu \mathrm{g} / \mathrm{L}$ after about 1.5 pore volumes, and drops below $1 \mu \mathrm{g} / \mathrm{L}$ before two pore volumes are collected. There is one leachate sample, \#37, with an anonymously high value of $6.4 \mu \mathrm{g} / \mathrm{L}$. In general, the uranium concentration in the background sediment leachate monotonically decreases with each aliquot collected. The amount leached in each aliquot and the total amount of uranium that leaches from the background sediment is extremely small $(<0.1 \%)$. This suggests that almost all of the uranium is present in a rather inert form, which is similar to the selective extraction results (see section 4.1.7) that showed approximately 95 percent of the uranium was not removed by any

Figure 4.9: Leach Test Data for the Background Material and Sample B11BY5

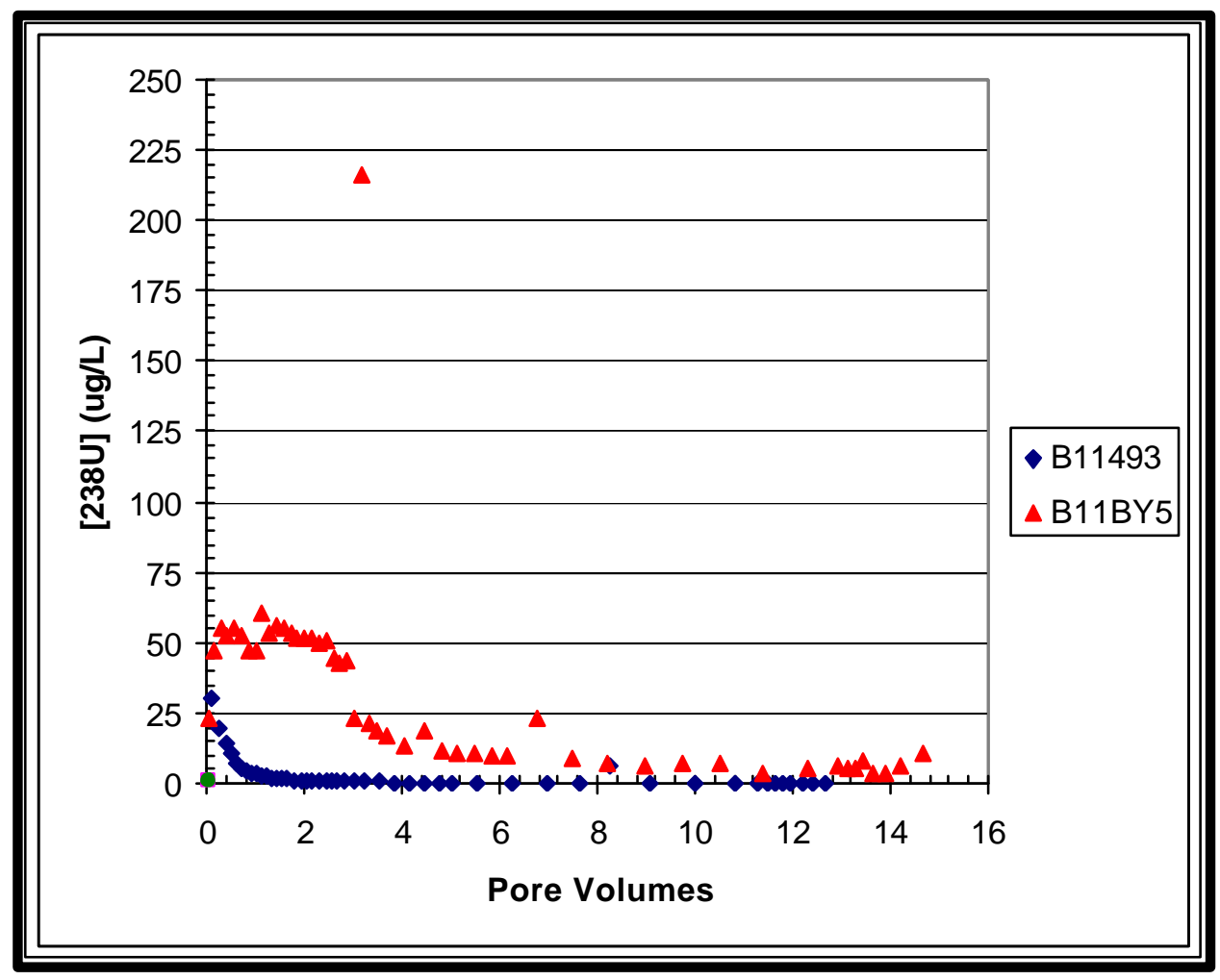


reagent. However, as shown with the first aliquot collected, it is quite easy to reach the proposed drinking water limit upon contacting the background sediment, which contains $5.1 \mathrm{mg} / \mathrm{Kg}$ total uranium (Table 4.10), with a small volume of water.

Major cations and anions were also monitored during the course of the large column leach tests. The total dissolved salt concentrations in all the column leachates showed the same shape as the uranium curves in that high values were seen in the first few aliquo ts and then concentrations dropped systematically to lower values. The only notable observance to report was a slight increase in dissolved iron and manganese solution concentrations for sample B11BY5. The increase became evident after the first pore volume had been collected, when dissolved manganese solution concentrations slowly increased by a factor of three, and dissolved iron solution concentrations slowly increased by approximately a factor of 15 . The elevated solution concentrations were short-lived, returning to initial solution concentration levels by the time the fourth pore volume was collected (see Cations in App. L).

Figure 4.10 shows the total percent of uranium leached versus pore volumes of leachate collected. In all cases, only about one percent or less of the total uranium in the sediments leaches from the highly contaminated sediments. At most, 3.7 percent of the uranium leaches from the moderately contaminated B11495 sediment.

Figure 4.10: Percentage of Total Uranium in the Sediment That Leaches vs. Pore Volumes

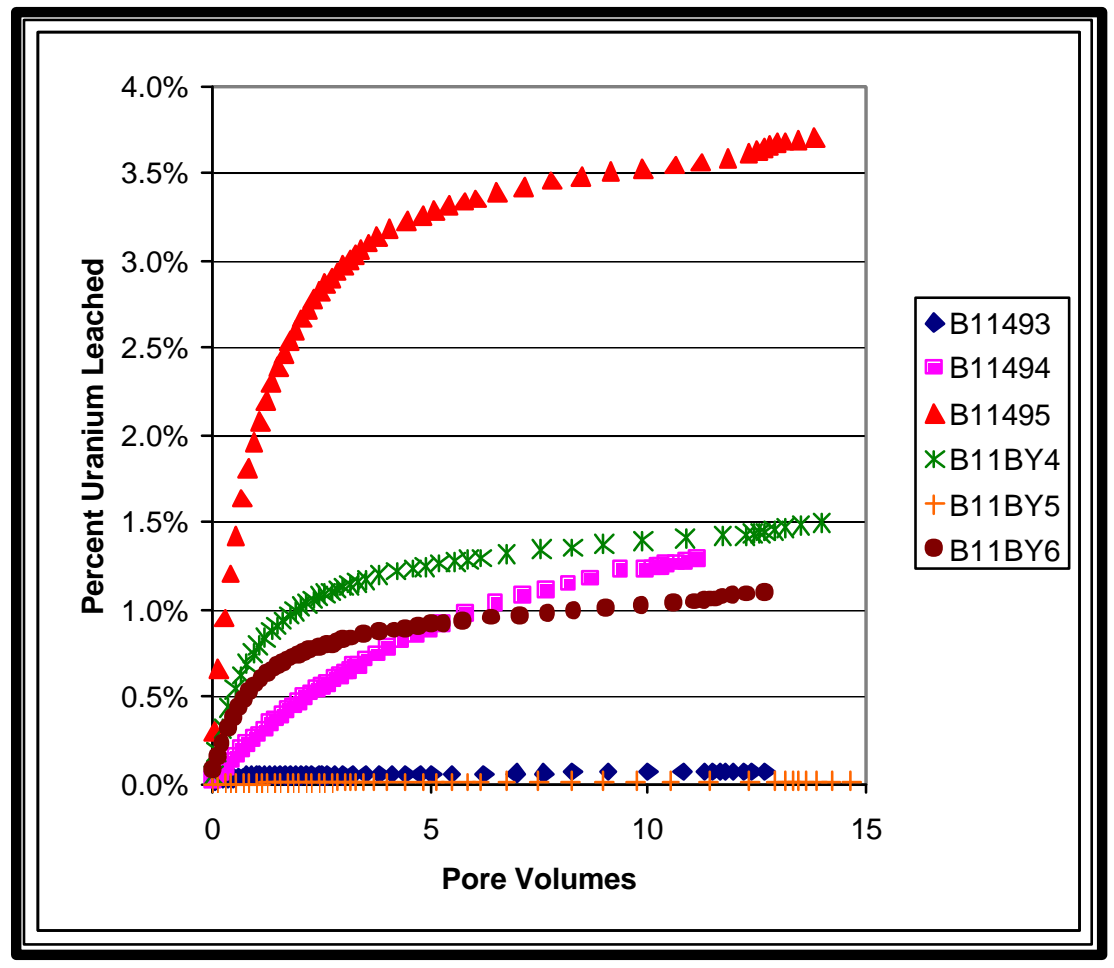


PNNL-14022 300 Area U Leach/Adsorption Study for ERC Final Report Chapter 4. Results and Discussion

\subsection{2. $\quad$ Scouting Adsorption Studies}

The results of the scouting batch adsorption $\mathrm{K}_{\mathrm{d}}$ tests are shown in Table 4.13. In the batch tests, the background sediment and two composite leachates (as described in Section 3.3) were used to investigate the sorption of uranium onto the 300 Area background sediment. Three sediment to solution ratios were used in order to get an indication of whether the amount of uranium loaded onto the sediment influences the observed $\mathrm{K}_{\mathrm{d}}$ value. This is equivalent to checking whether the linear isotherm construct that is ASSUMED TO BE VALID for using constant $\mathrm{K}_{\mathrm{d}}$ values in fate and transport predictions is valid. We also measured the batch $\mathrm{K}_{\mathrm{d}}$ for uranium at two contact times to see if uranium adsorption is being influenced/controlled by slow-kinetics.

As discussed in EPA 1999, the batch $\mathrm{K}_{\mathrm{d}}$ methodology is not very useful for determining the adsorption of constituents that show very low adsorption. These scouting tests are a good example of the poor results that are often found. In general, the $\mathrm{K}_{\mathrm{d}}$ data in Table 4.13 for the B11494 composite leachate show negative values. This is caused by the fact that there is little or no adsorption and one is seeing the measurement error in analyzing essentially the same solution (the soil effluents and the blank "influent") numerous times and taking the difference. This difference then gets divided by the effluent value and multiplied by the solution to solid ratio, which is a large number. The batch methodology is only useful for constituents that show significant adsorption and ideally one should strive to have the effluent concentrations drop to $50 \%$ of the influent values to get good measurements of $\mathrm{K}_{\mathrm{d}}$. For the B11494 tests, there was no

Table 4.13 Calculated $K_{d}$ Value From Batch Adsorption Experiments

\begin{tabular}{||r|c|c|c|r|r|}
\hline Leachate & Wt of Soil $(\mathrm{g})$ & \multicolumn{5}{l|}{ Vol of Soln $(\mathrm{mL})$} & Time $(\mathrm{hr})$ & $\mathrm{U}$ in Soln $(\mathrm{ug} / \mathrm{L}$ & $\mathrm{K}_{\mathrm{d}}(\mathrm{mL} / \mathrm{g})$ \\
\hline \multicolumn{5}{|c|}{$\mathrm{B} 11494$} \\
\hline tube \#1 & 0.37 & 40 & 95 & $6.66 \mathrm{E}+03$ & -4.93 \\
\hline tube \#3 & 1.52 & 40 & 95 & $6.46 \mathrm{E}+03$ & -1.91 \\
\hline tube \#5 & 7.13 & 40 & 95 & $6.49 \mathrm{E}+03$ & -2.37 \\
\hline tube \#7 & blank & 40 & 95 & $6.34 \mathrm{E}+03$ & \\
\hline tube \#1 & 0.37 & 38 & 187 & $6.01 \mathrm{E}+03$ & -2.84 \\
\hline tube \#3 & 1.52 & 38 & 187 & $5.54 \mathrm{E}+03$ & 6.05 \\
\hline tube \#5 & 7.13 & 38 & 187 & $6.38 \mathrm{E}+03$ & -8.98 \\
\hline tube \#7 & blank & 38 & 187 & $5.85 \mathrm{E}+03$ & \\
\hline & & B11BY6 & & & \\
\hline tube \#2 & 0.34 & 40 & 95 & $2.26 \mathrm{E}+04$ & 1.56 \\
\hline tube \#4 & 1.54 & 40 & 95 & $2.03 \mathrm{E}+04$ & 3.33 \\
\hline tube \#6 & 7.22 & 40 & 95 & $2.06 \mathrm{E}+04$ & 0.62 \\
\hline tube \#8 & blank & 40 & 95 & $2.29 \mathrm{E}+04$ & \\
\hline tube \#2 & 0.34 & 38 & 187 & $2.23 \mathrm{E}+04$ & -7.52 \\
\hline tube \#4 & 1.54 & 38 & 187 & $2.20 \mathrm{E}+04$ & -1.35 \\
\hline tube \#6 & 7.22 & 38 & 187 & $2.01 \mathrm{E}+04$ & 0.18 \\
\hline tube \#8 & blank & 38 & 187 & $2.08 \mathrm{E}+04$ & \\
\hline
\end{tabular}


drop in uranium concentration (no significant adsorption onto the sediments). Even the test with $7 \mathrm{~g}$ of sediment did not show measurable adsorption. Qualitatively, this result is consistent with the column experiment results (Appendix V) that showed very low adsorption of uranium from the B11494 leachate. It was possible to measure a small amount of adsorption that was occurring in the column tests because the soil to solution ratio was much larger (approximately $4.6 \mathrm{~g} / \mathrm{mL})$ than that used in the batch tests $(0.01$ to $0.18 \mathrm{~g} / \mathrm{mL})$.

For the other leachate, B11BY6, the batch adsorption data vacillate versus contact time with some apparent adsorption after approximately 4 days and no adsorption after about 8 days. The batch test with the most sediment present shows a small $\mathrm{K}_{\mathrm{d}}$ for both time periods. However, the overall data set is not useful. It can be seen in Table 4.13 that the blank test tubes seem to be adsorbing some uranium as contact time increases. This is a common problem but in this case may not be real. Analytical measurement error for uranium in the solutions may be occurring. If further batch tests are used to study the adsorption of uranium in the leachates onto the Hanford background sediment, much larger masses of sediment will be required or the uranium solution concentration will have to be significantly reduced to see if we have swamped out the adsorption sites. The choice of containers should also be made judiciously to minimize container wall adsorption artifacts.

\subsubsection{Batch Leach Test}

As discussed in Section 3.3, long-term static leach tests were conducted on residual sediment from the FY 2001 column leach tests. After it was discovered that only a small portion $(<4 \%)$ of the total uranium in the sediments was leaching during the flow through tests, a different strategy was devised to address the leaching of the remainder of the uranium. The simple fate and transport code utilized by the ERC staff can utilize a desorption $\mathrm{K}_{\mathrm{d}}$ release model. Thus, it was decided to develop, if possible, empirical data for a steady state desorption $\mathrm{K}_{\mathrm{d}}$. The five large flow-through leach columns were dismantled and 100 gram aliquots of sediment from the influent ends were placed in batch reactors and leached with either deionized water, groundwater collected from the Hanford Patrol Training Facility, or a simulated vadose zone porewater (see Section 3.5 for solution composition). Samples were collected every 2-6 weeks and analyzed for $\mathrm{pH}, \mathrm{EC}$, and ${ }^{238} \mathrm{U}$. Selected aliquots were also analyzed for major cations and trace metals using ICP-OES, anions using IC, and alkalinity by titration. The results of the long-term leach tests are presented in Tables 4.14-4.16 and Figures 4.11-4.13.

\subsubsection{1. $\quad$ Deionized Water Leach Test}

Figure 4.11 is a plot of uranium leach $K_{d}$ values, in deionized water, as a function of time for the five contaminated near-surface sediment samples. The $\mathrm{K}_{\mathrm{d}}$ values were calculated using the linear isotherm model, in which $\mathrm{K}_{\mathrm{d}}=$ the concentration of uranium present in the sediment $\left(\mathrm{C}_{\mathrm{A}}\right)$ divided by the concentration in equilibrating solution $\left(\mathrm{C}_{\mathrm{L}}\right)$ (See the equations embedded in the Excel file: Appendix M). In four of the five samples tested (B11494, B11495, B11BY4, and B11BY6), there is a decrease in uranium leach or desorption $K_{d}$ values with time, as would be expected if uranium was slowly leaching out of the solid. The one exception to this 
PNNL-14022 300 Area U Leach/Adsorption Study for ERC Final Report

Chapter 4. Results and Discussion

Table 4.14 Batch Leach Test Data: Deionized Water

\begin{tabular}{|c|c|c|c|}
\hline $\begin{array}{c}\text { Sample } \\
\text { ID }\end{array}$ & $\begin{array}{c}\text { U 238 } \\
\text { (ug/L) }\end{array}$ & $\begin{array}{c}\text { Kd } \\
\text { (mL/g) })\end{array}$ & $\begin{array}{c}\text { U-238 Removed } \\
\text { Cum. \% of Total }\end{array}$ \\
\hline B11494-DI-14 & 322 & 1646 & 0.596 \\
\hline B11494-DI-28 & 441 & 1197 & 0.826 \\
\hline B11494-DI-49 & 541 & 975 & 1.02 \\
\hline B11494-DI-77 & 628 & 838 & 1.20 \\
\hline B11494-DI-119 & 628 & 838 & 1.22 \\
\hline B11494-DI-154 & 747 & 703 & 1.42 \\
\hline B11495-DI-14 & 77.6 & 476 & 2.06 \\
\hline B11495-DI-28 & 93.3 & 394 & 2.50 \\
\hline B11495-DI-49 & 104 & 354 & 2.81 \\
\hline B11495-DI-77 & 118 & 311 & 3.22 \\
\hline B11495-DI-119 & 126 & 289 & 3.49 \\
\hline B11495-DI-154 & 138 & 263 & 3.80 \\
\hline B11BY4-DI-14 & 470 & 1169 & 0.848 \\
\hline B11BY4-DI-28 & 488 & 1127 & 0.892 \\
\hline B11BY4-DI-49 & 593 & 925 & 1.09 \\
\hline B11BY4-DI-77 & 817 & 669 & 1.51 \\
\hline B11BY4-DI-119 & 983 & 554 & 1.84 \\
\hline B11BY4-DI-154 & 1300 & 416 & 2.40 \\
\hline B11BY5-DI-14 & 49.1 & 5842 & 0.171 \\
\hline B11BY5-DI-28 & 43.9 & 6535 & 0.155 \\
\hline B11BY5-DI-49 & 22.4 & 12817 & 0.083 \\
\hline B11BY5-DI-77 & 19.2 & 14955 & 0.073 \\
\hline B11BY5-DI-119 & 14.4 & 19934 & 0.057 \\
\hline B11BY5-DI-154 & 13.4 & 21456 & 0.054 \\
\hline B11BY6-DI-14 & 836 & 1160 & 0.855 \\
\hline B11BY6-DI-28 & 736 & 1318 & 0.766 \\
\hline B11BY6-DI-49 & 785 & 1235 & 0.827 \\
\hline B11BY6-DI-77 & 981 & 987 & 1.04 \\
\hline B11BY6-DI-119 & 1259 & 766 & 1.34 \\
\hline B11BY6-DI-154 & 1465 & 657 & 1.55 \\
\hline
\end{tabular}

trend is sample B11BY5, which exhibits an increase in uranium desorption $\mathrm{K}_{\mathrm{d}}$ values over the course of the experiment. The loss of uranium in solution in sample B11BY5 is particularly intriguing, and is potentially an artifact of biological reduction.

Uranium desorption $\mathrm{K}_{\mathrm{d}}$ values versus leach time ranged from $712 \mathrm{~mL} / \mathrm{g}$ to $274 \mathrm{~mL} / \mathrm{g}$ for samples B11494, B11495, B11BY4, and B11BY6, with an additional 1.5 to $3.8 \%$ of the total uranium originally present being removed during the 154 day experiment. During the initial large column leach test these sediments leached from $<1 \%$ to a maximum of $3 \%$ so that the total amount leached by simulated rain water was $\sim 2.5 \%$ to $6 \%$. Conversely, the uranium leach $\mathrm{K}_{\mathrm{d}}$ value was greater than $20,000 \mathrm{~mL} / \mathrm{g}$ for sample B11BY5, with less than $0.1 \%$ of the remaining uranium present going into solution during the 154 day experiment. The data from the extended leach test further supports the data collected from the column leach studies, which showed that very little uranium leaches into deionized or "rainwater" type solutions. 
Figure 4.11 Uranium Leach $K_{d}$ as a Function of Time for the Five Contaminated NearSurface Sediment Samples in Deionized Water

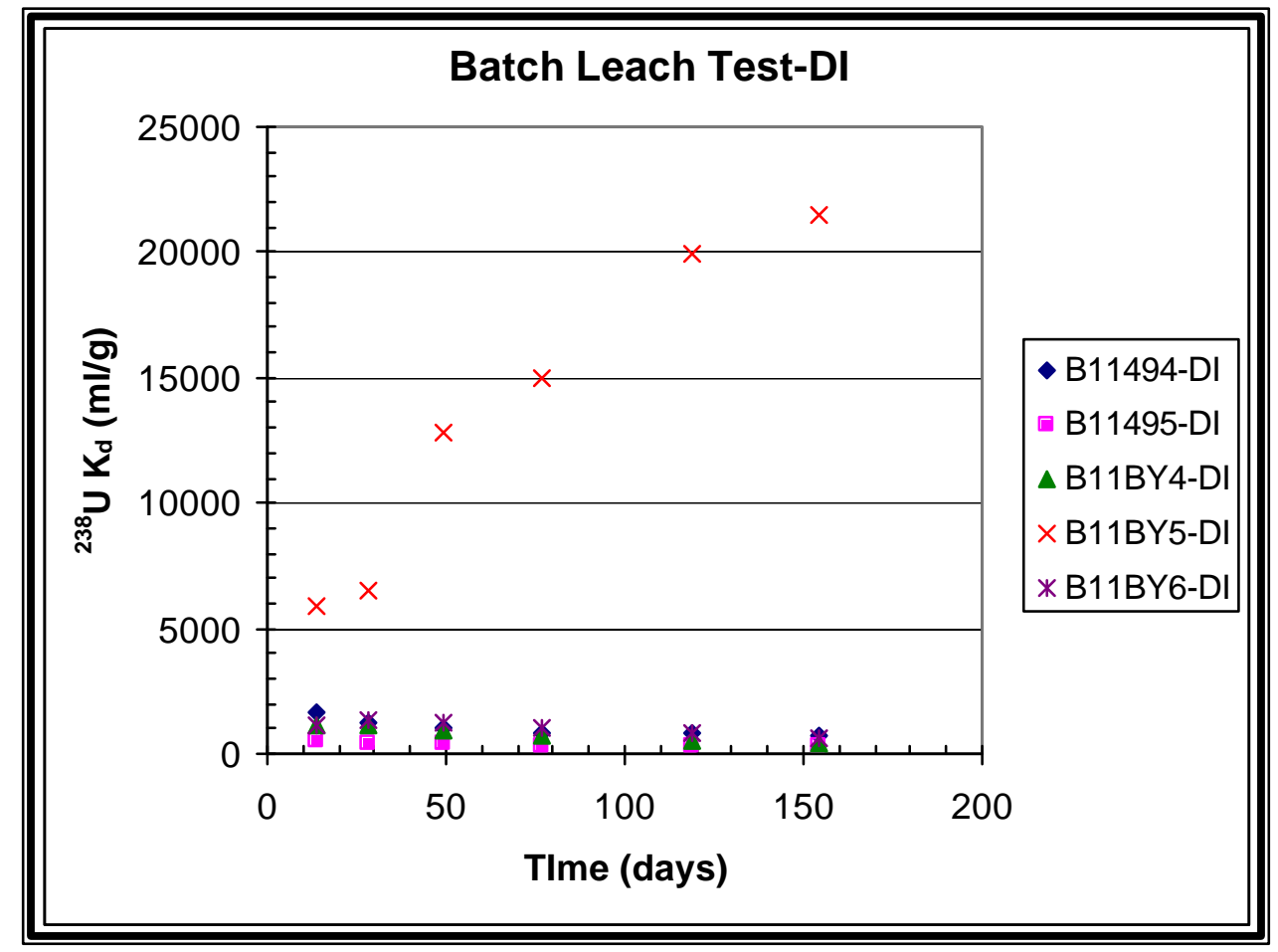

\subsubsection{Groundwater Leach Test}

Figure 4.12 is a plot of uranium desorption $\mathrm{K}_{\mathrm{d}}$ values, in groundwater collected from the Hanford Patrol Training Facility, as a function of time for the five contaminated near-surface sediment samples. The $\mathrm{K}_{\mathrm{d}}$ values were again calculated using the linear isotherm model. (See the equations embedded in the Excel file: Appendix M). In four of the five contaminated samples tested (B11494, B11495, B11BY4, and B11BY6), there is a decrease in uranium leach $\mathrm{K}_{\mathrm{d}}$ values with time. The one exception to this trend is sample B11BY5, which exhibits an increase in uranium $\mathrm{K}_{\mathrm{d}}$ values over the course of the experiment. Again, the loss of uranium in solution in sample B11BY5 is particularly intriguing, and is potentially an artifact of biological reduction.

Uranium leach or desorption $\mathrm{K}_{\mathrm{d}}$ values ranged from $446 \mathrm{~mL} / \mathrm{g}$ to $91 \mathrm{~mL} / \mathrm{g}$ for samples B11494, B11495, B11BY4, and B11BY6, with an additional 2.3 to $10 \%$ of the total uranium present being removed during the 154 day experiment. Conversely, the uranium leach $\mathrm{K}_{\mathrm{d}}$ value was greater than $9,000 \mathrm{~mL} / \mathrm{g}$ for sample B11BY5, with a little more than $0.1 \%$ of the remaining uranium present going into solution during the 154 day experiment. 
PNNL-14022 300 Area U Leach/Adsorption Study for ERC Final Report Chapter 4. Results and Discussion

Table 4.15 Batch Leach Test Data: Groundwater

\begin{tabular}{|c|c|c|c|}
\hline $\begin{array}{c}\text { Sample } \\
\text { ID }\end{array}$ & $\begin{array}{c}\text { U 238 } \\
\text { ug/L }\end{array}$ & $\begin{array}{c}\text { Kd } \\
\text { (mL/g) }\end{array}$ & $\begin{array}{c}\text { U-238 Removed } \\
\text { Cum. \% of Total }\end{array}$ \\
\hline B11494-GW-14 & 1060 & 493 & 1.96 \\
\hline B11494-GW-28 & 1161 & 449 & 2.17 \\
\hline B11494-GW-49 & 1201 & 434 & 2.28 \\
\hline B11494-GW-77 & 1197 & 435 & 2.30 \\
\hline B11494-GW-119 & 1158 & 450 & 2.26 \\
\hline B11494-GW-154 & 1183 & 440 & 2.29 \\
\hline B11495-GW-14 & 182 & 197 & 4.82 \\
\hline B11495-GW-28 & 214 & 166 & 5.73 \\
\hline B11495-GW-49 & 226 & 156 & 6.14 \\
\hline B11495-GW-77 & 239 & 148 & 6.55 \\
\hline B11495-GW-119 & 231 & 153 & 6.44 \\
\hline B11495-GW-154 & 252 & 139 & 7.01 \\
\hline B11BY4-GW-14 & 1946 & 275 & 3.50 \\
\hline B11BY4-GW-28 & 2770 & 190 & 5.04 \\
\hline B11BY4-GW-49 & 3454 & 150 & 6.34 \\
\hline B11BY4-GW-77 & 4123 & 124 & 7.64 \\
\hline B11BY4-GW-119 & 5027 & 100 & 9.38 \\
\hline B11BY4-GW-154 & 5567 & 89 & 10.4 \\
\hline B11BY5-GW-14 & 225 & 1265 & 0.782 \\
\hline B11BY5-GW-28 & 192 & 1487 & 0.678 \\
\hline B11BY5-GW-49 & 80.3 & 3568 & 0.300 \\
\hline B11BY5-GW-77 & 48.2 & 5950 & 0.193 \\
\hline B11BY5-GW-119 & 35.2 & 8147 & 0.150 \\
\hline B11BY5-GW-154 & 29.6 & 9679 & 0.131 \\
\hline B11BY6-GW-14 & 2326 & 411 & 2.38 \\
\hline B11BY6-GW-28 & 3494 & 270 & 3.62 \\
\hline B11BY6-GW-49 & 4427 & 211 & 4.63 \\
\hline B11BY6-GW-77 & 5320 & 174 & 5.61 \\
\hline B11BY6-GW-119 & 6469 & 141 & 6.87 \\
\hline B11BY6-GW-154 & 7170 & 126 & 7.61 \\
\hline \hline & & & \\
\hline
\end{tabular}

\subsubsection{3. $\quad$ Simulated Porewater Leach Test}

Figure 4.13 is a plot of uranium leach $\mathrm{K}_{\mathrm{d}}$ values, in simulated vadose zone porewater, as a function of time for the five contaminated near-surface sediment samples. Once again, the $\mathrm{K}_{\mathrm{d}}$ values were calculated using the linear isotherm model. (See the equations embedded in the Excel file: Appendix M). For the first time, all five of the contaminated sediment samples show a decrease in uranium leach or desorption $\mathrm{K}_{\mathrm{d}}$ values over time. This trend is what would be expected in a system that has not reached equilibrium with respect to uranium solution concentration (where uranium continues to slowly leach out of the sediments). The process or 
Figure 4.12 Uranium Leach $K_{d}$ as a Function of Time for the Five Contaminated NearSurface Sediment Samples in Groundwater

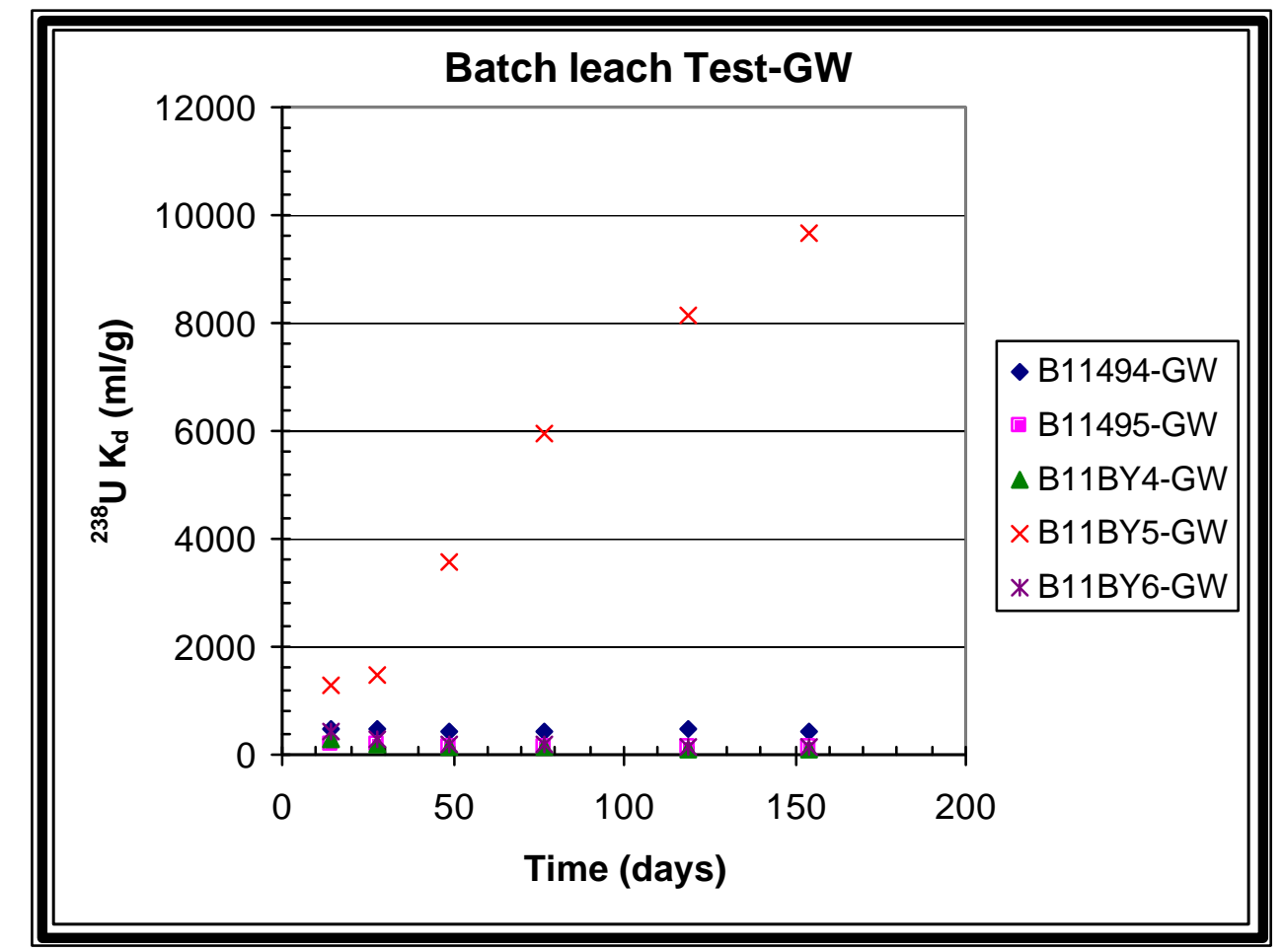

effect responsible for the loss of uranium from solution for the preceding two low ionic strength solutions for sample B11BY5 was not experienced in the simulated porewater.

Uranium leach or desorption $\mathrm{K}_{\mathrm{d}}$ values ranged from $213 \mathrm{~mL} / \mathrm{g}$ to $26 \mathrm{~mL} / \mathrm{g}$ for the five uraniumcontaminated near-surface sediment samples in contact with simulated porewater, with an additional 4.6 to $29 \%$ of the total uranium present being removed during the 154 day experiment.

\subsubsection{Summary of Batch Leach Test Results}

The results of the extended batch leach tests show that solution composition has a dramatic effect on uranium desorption $\mathrm{K}_{\mathrm{d}}$ values. As expected, uranium from the contaminated sediment samples was most soluble/desorbable in the simulated porewater solution. This is most likely caused by the high carbonate solution concentration $(10 \mathrm{mM})$, which induces the formation of soluble anionic uranyl-carbonate complexes. The groundwater collected from the Hanford Patrol Training Facility was effective at removing uranium in four of the five samples tested, with as much as $10 \%$ of the remaining uranium going into solution. Deionized water was the least effective leaching solution, removing less than $4 \%$ of the total uranium present. Although the data has been calculated and plotted as desorption $\mathrm{K}_{\mathrm{d}}$ values, it is important to note that steadystate uranium concentrations were not measured in most of the reactors after six months of static contact time. 
PNNL-14022 300 Area U Leach/Adsorption Study for ERC Final Report Chapter 4. Results and Discussion

Table 4.16 Batch Leach Test Data: Simulated Porewater

\begin{tabular}{|c|c|c|c|}
\hline $\begin{array}{c}\text { Sample } \\
\text { ID }\end{array}$ & $\begin{array}{c}\text { U 238 } \\
\text { ug/L }\end{array}$ & $\begin{array}{c}\text { Kd } \\
\text { (mL/g) }\end{array}$ & $\begin{array}{c}\text { U-238 Removed } \\
\text { Cum. \% of Total }\end{array}$ \\
\hline B11494-PW-14 & 1787 & 288 & 3.30 \\
\hline B11494-PW-28 & 2021 & 254 & 3.78 \\
\hline B11494-PW-49 & 2129 & 240 & 4.04 \\
\hline B11494-PW-77 & 2371 & 214 & 4.55 \\
\hline B11494-PW-119 & 2335 & 218 & 4.55 \\
\hline B11494-PW-154 & 2415 & 210 & 4.65 \\
\hline B11495-PW-14 & 313 & 111 & 8.26 \\
\hline B11495-PW-28 & 370 & 92 & 9.86 \\
\hline B11495-PW-49 & 398 & 85 & 10.8 \\
\hline B11495-PW-77 & 452 & 73 & 12.4 \\
\hline B11495-PW-119 & 425 & 78 & 11.8 \\
\hline B11495-PW-154 & 482 & 68 & 13.3 \\
\hline B11BY4-PW-14 & 7556 & 63 & 13.7 \\
\hline B11BY4-PW-28 & 10466 & 43 & 19.1 \\
\hline B11BY4-PW-49 & 13049 & 32 & 24.1 \\
\hline B11BY4-PW-77 & 15348 & 26 & 28.6 \\
\hline B11BY4-PW-119 & 17884 & 21 & 33.6 \\
\hline B11BY4-PW-154 & 14407 & 28 & 27.5 \\
\hline B11BY5-PW-14 & 3511 & 72 & 12.3 \\
\hline B11BY5-PW-28 & 4324 & 56 & 15.3 \\
\hline B11BY5-PW-49 & 4674 & 51 & 16.8 \\
\hline B11BY5-PW-77 & 4841 & 49 & 17.6 \\
\hline B11BY5-PW-119 & 5099 & 46 & 18.7 \\
\hline B11BY5-PW-154 & 5134 & 45 & 18.8 \\
\hline B11BY6-PW-14 & 8433 & 106 & 8.62 \\
\hline B11BY6-PW-28 & 14166 & 59 & 14.6 \\
\hline B11BY6-PW-49 & 17633 & 45 & 18.3 \\
\hline B11BY6-PW-77 & 20690 & 37 & 21.7 \\
\hline B11BY6-PW-119 & 25525 & 28 & 27.0 \\
\hline B11BY6-PW-154 & 27281 & 25 & 28.9 \\
\hline \hline
\end{tabular}

An intriguing result of the extended batch leach tests was the loss of uranium in solution for sample B11BY5 in both the deionized water and groundwater leaching solutions. Sample B11BY5 had the highest organic carbon content (approximately $3 \%$ ), so it is possible that this re-adsorption/precipitation of uranium is a result of biological reduction of uranium. However, a subset of samples was analyzed for major cations and anions (Cations and Anions in Appendix $\mathrm{M}$ ), and little evidence was found to support the idea of biological reduction, such as increases in dissolved iron and manganese. Perhaps uranium is re-sorbing or re-precipitating in the deionized and groundwater solution matrices. 
Figure 4.13 Uranium Leach $K_{d}$ Data as a Function of Time for the Five Contaminated Near-Surface Sediment Samples in Simulated Porewater

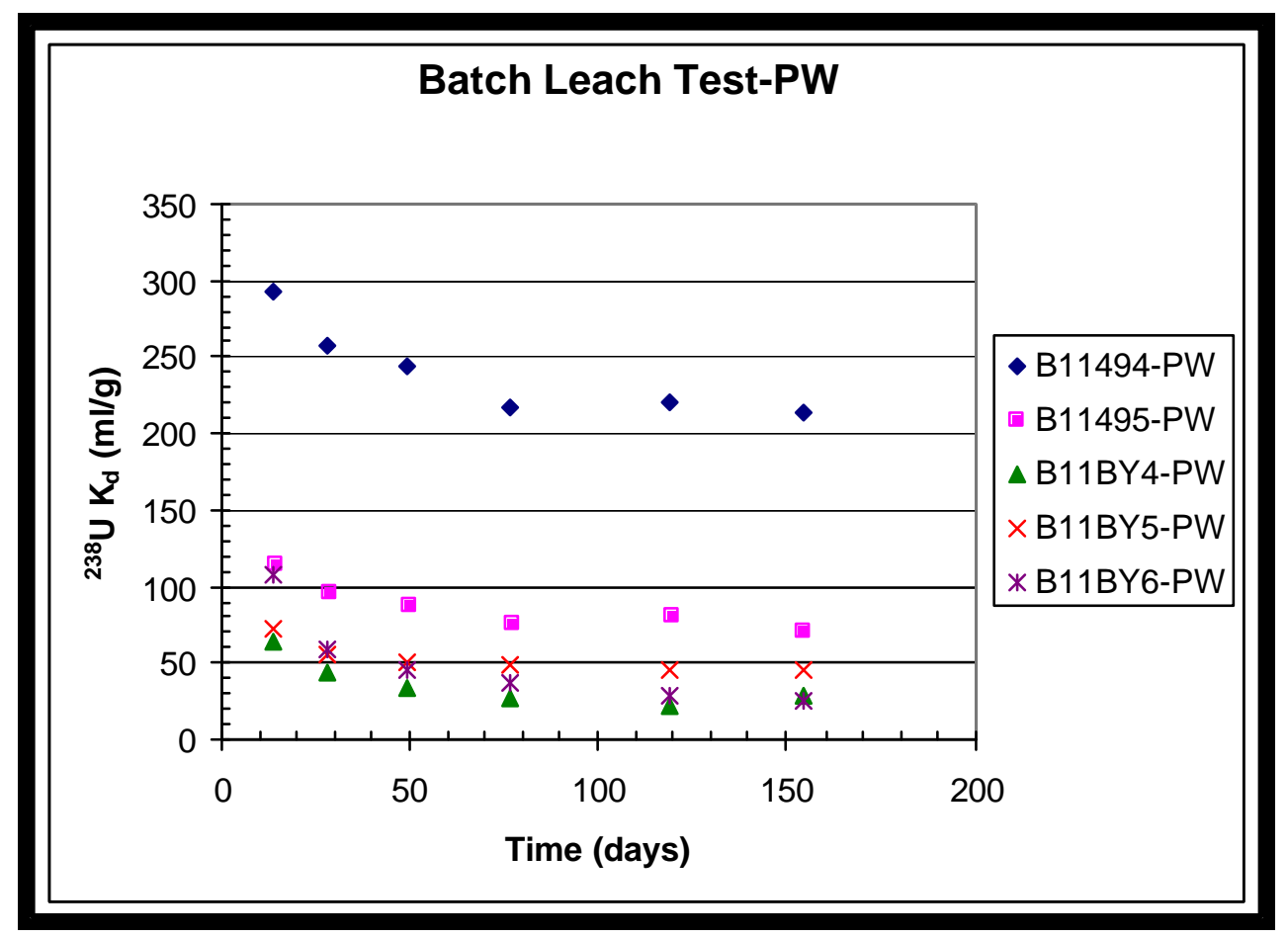

\subsubsection{Batch Adsorption Test: Variable Uranium Solution Concentration}

The first batch adsorption test conducted in FY 2002 examined the effect of uranium solution concentration on uranium $\mathrm{K}_{\mathrm{d}}$ values. As discussed in Sections 3.5-3.7, batch reactors were used to assess the sorption of uranium onto the background sediment in both a low and high ionic strength solution over a starting uranium concentration range of $0.05 \mathrm{mg} / \mathrm{L}$ to $5 \mathrm{mg} / \mathrm{L}$. The results of this experiment are presented in Tables $4.17 \& 4.18$ and Figures $4.14 \& 4.15$.

As seen in Figure 4.14, a plot of the adsorbed concentration $\left(C_{A}\right.$ in $\left.\mu g / g\right)$ versus the uranium concentration remaining in solution $\left(\mathrm{C}_{\mathrm{L}}\right.$ in $\left.\mu \mathrm{g} / \mathrm{mL}\right)$ yields a linear relationship across the entire range tested $(0.05 \mathrm{mg} / \mathrm{L}$ to $\sim 4 \mathrm{mg} / \mathrm{L})$. Linear regression of the data yields a line with an $\mathrm{R}^{2}$ value of 0.997 . The uranium adsorption $\mathrm{K}_{\mathrm{d}}$ value for the background sediment in the low ionic strength solution is $3.2 \mathrm{~mL} / \mathrm{g}$, the slope of the regression line.

Appendix $\mathrm{N}$ contains data collected after the reactors were allowed to sit for approximately six months. It is interesting to see that the calculated $\mathrm{K}_{\mathrm{d}}$ value decreases with time (from $3.2 \mathrm{~mL} / \mathrm{g}$ to $2.1 \mathrm{~mL} / \mathrm{g}$ ). This could be an artifact of the system attempting to reach equilibrium, resulting in additional leaching or dissolution of uranium from the sediment. 
PNNL-14022 300 Area U Leach/Adsorption Study for ERC Final Report

Chapter 4. Results and Discussion

Table 4.17 Batch Adsorption Data for the Low Ionic Strength Solution

\begin{tabular}{|c|c|c|c|}
\hline Sample & {$[238 \mathrm{U}](\mathrm{ug} / \mathrm{l})$} & $\begin{array}{c}\mathbf{K d} \\
(\mathrm{mL} / \mathrm{g})\end{array}$ & $\begin{array}{c}\text { Kd } \\
\text { Avg } \\
(\mathrm{mL} / \mathrm{g})\end{array}$ \\
\hline ISO-1 (50 ppb) & 33.2 & 5.04 & \multirow{2}{*}{4.48} \\
\hline ISO-2 (50 ppb) & 35.9 & 3.92 & \\
\hline ISO-3 (500 ppb) & 340 & 4.72 & \multirow{2}{*}{4.50} \\
\hline ISO-4 (500 ppb) & 350 & 4.28 & \\
\hline ISO-13 (1500 ppb) & 1147 & 3.57 & \multirow{2}{*}{3.45} \\
\hline ISO-14 (1500 ppb) & 1157 & 3.34 & \\
\hline ISO-15 (3000 ppb) & 2295 & 3.27 & \multirow{2}{*}{3.13} \\
\hline ISO-16 (3000 ppb) & 2329 & 2.99 & \\
\hline ISO-5 (5000 ppb) & 3703 & 3.50 & \multirow{2}{*}{3.27} \\
\hline ISO-6 (5000 ppb) & 3836 & 3.03 & \\
\hline
\end{tabular}

Figure 4.14: Plot of $C_{A}$ vs. $C_{L}$ for the Low Ionic Strength Solution

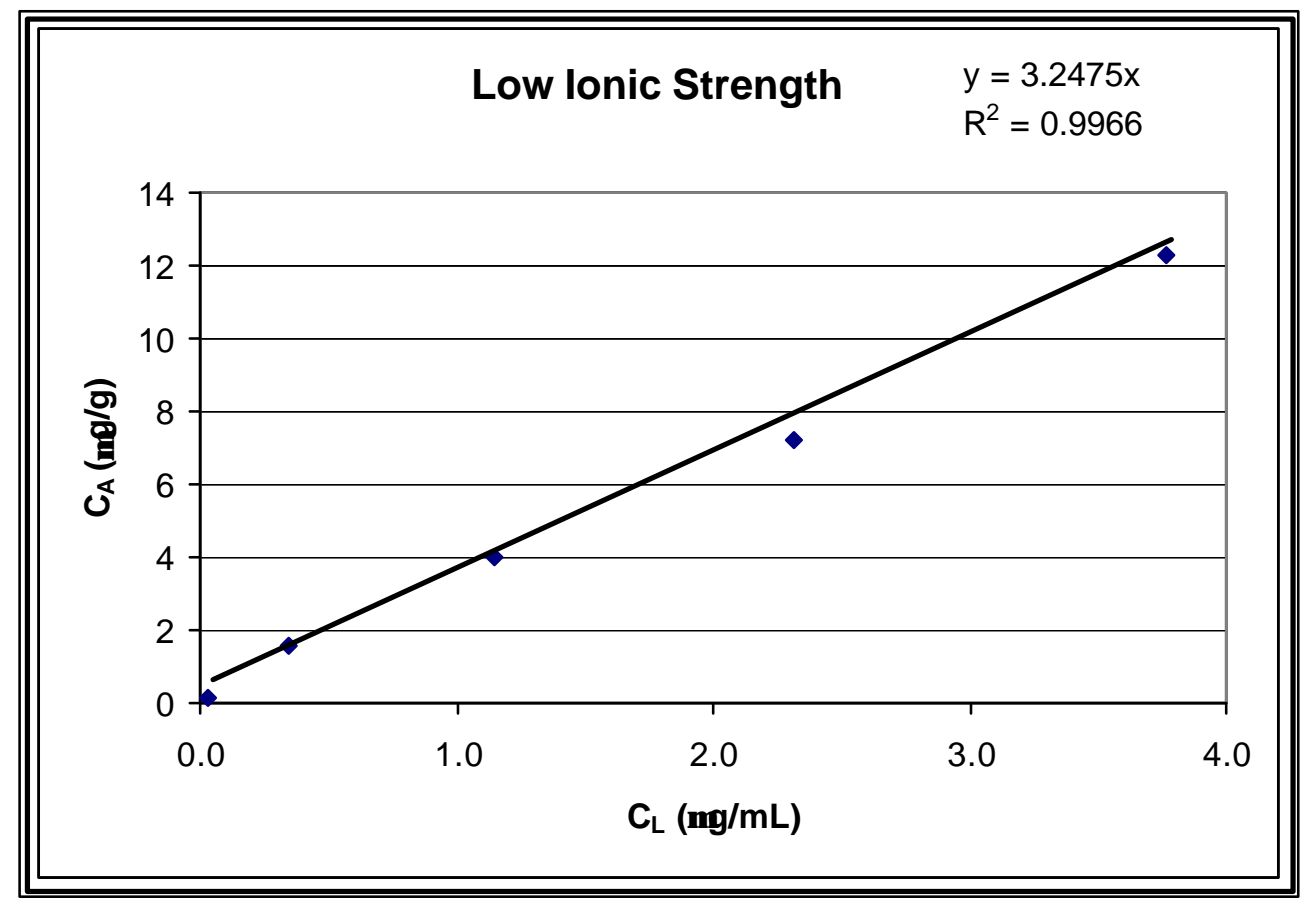


PNNL-14022 300 Area U Leach/Adsorption Study for ERC Final Report

Chapter 4. Results and Discussion

Table 4.18 Batch Adsorption Data for the High Ionic Strength Solution

\begin{tabular}{|c|c|c|c|}
\hline Sample & {$[238 \mathrm{U}](\mathrm{ug} / \mathrm{l})$} & $\begin{array}{c}\mathrm{Kd} \\
(\mathrm{mL} / \mathrm{g})\end{array}$ & $\begin{array}{c}\mathrm{Kd} \\
\text { Avg } \\
(\mathrm{mL} / \mathrm{g})\end{array}$ \\
\hline B11493-1 (50 ppb) & 32 & 0.36 & \multirow{2}{*}{0.28} \\
\hline B11493-2 (50 ppb) & 35 & 0.20 & \\
\hline B11493-3 (250 ppb) & 180 & 0.54 & \multirow{2}{*}{0.43} \\
\hline B11493-4 (250 ppb) & 198 & 0.32 & \\
\hline B11493-5 (500 ppb) & 338 & 0.58 & \multirow{2}{*}{0.56} \\
\hline B11493-6 (500 ppb) & 346 & 0.55 & \\
\hline B11493-7 (750 ppb) & 499 & 0.49 & \multirow{2}{*}{0.45} \\
\hline B11493-8 (750 ppb) & 524 & 0.40 & \\
\hline B11493-9 (1500 ppb) & 985 & 0.55 & \multirow{2}{*}{0.53} \\
\hline B11493-10 (1500 ppb) & 993 & 0.51 & \\
\hline B11493-11 (3000 ppb) & 1995 & 0.45 & \multirow{2}{*}{0.44} \\
\hline B11493-12 (3000 ppb) & 2014 & 0.43 & \\
\hline B11493-13 (5000 ppb) & 3442 & 0.35 & \multirow{2}{*}{0.35} \\
\hline B11493-14 (5000 ppb) & 3467 & 0.36 & \\
\hline
\end{tabular}

Figure 4.15: Plot of $C_{A}$ vs. $C_{L}$ for the High Ionic Strength Solution

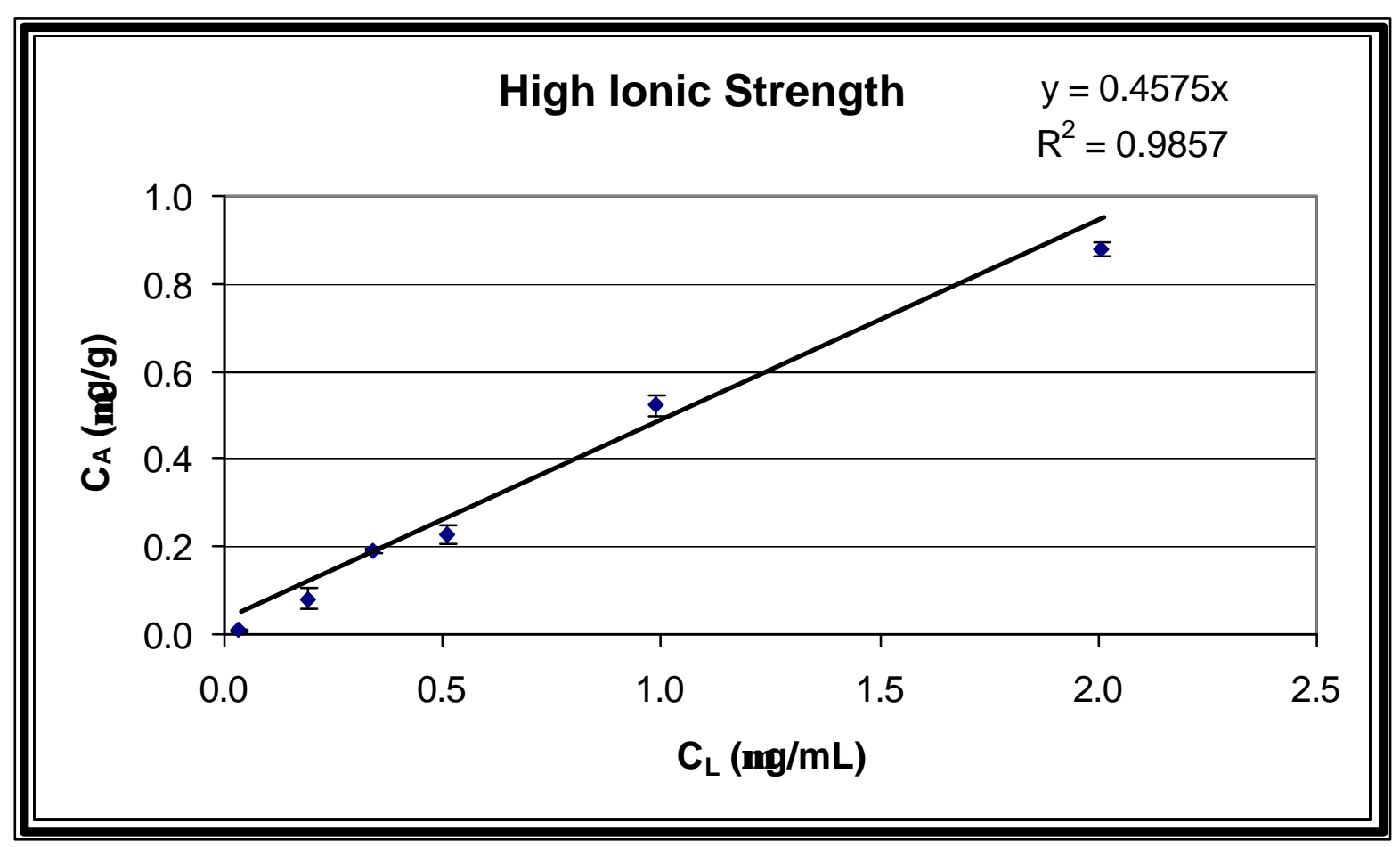

As seen in Figure 4.15, a plot of the adsorbed concentration $\left(C_{A}\right.$ in $\left.\mu g / g\right)$ versus the uranium concentration in solution $\left(\mathrm{C}_{\mathrm{L}}\right.$ in $\left.\mu \mathrm{g} / \mathrm{mL}\right)$ in the high ionic strength solution yields a linear 
relationship across the entire range plotted $(0.05 \mathrm{mg} / \mathrm{L}$ to $\sim 2 \mathrm{mg} / \mathrm{L})$. Linear regression of the data yields a line with an $\mathrm{R}^{2}$ value of 0.986 . The uranium adsorption $K_{d}$ value for the background sediment in the high ionic strength solution is $0.46 \mathrm{~mL} / \mathrm{g}$ as evidenced by the slope of the line.

Appendix $\mathrm{N}$ contains data collected after the reactors were allowed to sit for approximately six months. It is interesting to see that the calculated $\mathrm{K}_{\mathrm{d}}$ value increases with time (from $0.46 \mathrm{~mL} / \mathrm{g}$ to $1 \mathrm{~mL} / \mathrm{g}$ ). This suggests that the mechanism controlling sorption of uranium onto the sediment is kinetically controlled and that 72 hours of contact time was not adequate to reach maximum sorption.

The data presented in this section shows that uranium $\mathrm{K}_{\mathrm{d}}$ values are linear across a broad range of uranium solution concentrations, $0.05 \mathrm{mg} / \mathrm{L}$ to $\sim 4 \mathrm{mg} / \mathrm{L}$ in the low ionic strength solution and $0.05 \mathrm{mg} / \mathrm{L}$ to $2 \mathrm{mg} / \mathrm{L}$ in the high ionic strength solution. It appears that the relationship becomes slightly less linear above $3 \mathrm{mg} / \mathrm{L}$ (i.e. in the $5 \mathrm{mg} / \mathrm{L}$ test solution) in the high ionic strength solution. A slightly more complicated model, such as the Freundlich isotherm, might be needed to model the system when uranium solution concentrations exceed 3 to $4 \mathrm{mg} / \mathrm{L}$. This does not pose a significant problem when modeling uranium mobility in the 300 Area unconfined aquifer, since uranium concentrations in the aquifer are not expected to reach values even close to 3 $\mathrm{mg} / \mathrm{L}$. Uranium solution concentrations in the 300 Area unconfined aquifer have not exceeded $0.5 \mathrm{mg} / \mathrm{L}$ in the past ten years (Hartman et al., 2002). However, concentrations of uranium in the vadose zone porewater may be higher than $3 \mathrm{mg} / \mathrm{L}$ based on the column leach data shown in Section 4.2.1, but field data are not available.

Based on the results from the FY 2001 large column leach tests (where uranium desorption never reached equilibrium or steady-state concentrations), the FY 2002 SAP was revised to allow for the collection of data that could be used to generate $\mathrm{K}_{\mathrm{d}}$ values based on the range of conditions expected in the 300 Area. The two solutions used for this experiment (the low ionic strength simulated Columbia River water and the high ionic strength simulated vadose zone porewater) represent the least and most saline solutions or conditions expected in the 300 Area. Calculated uranium adsorption $\mathrm{K}_{\mathrm{d}}$ values varied significantly based on the ionic strength of the test solution ( $3.2 \mathrm{~mL} / \mathrm{g}$ in the low ionic strength solution vs. $0.46-1 \mathrm{~mL} / \mathrm{g}$ in the high ionic strength solution). This variability in $\mathrm{K}_{\mathrm{d}}$, caused by changes in solution composition results in a factor of $12-20$ difference in retardation rates in the saturated aquifer based on which type of solution the uranium is being transported in. In the vadose zone, the retardation factor also varies with moisture content as well as the value of the $\mathrm{K}_{\mathrm{d}}$ chosen. Therefore, the retardation may be even more variable than the factor of 20 calculated for the aquifer.

\subsubsection{Batch Adsorption Test: Variable Solution pH}

The second set of batch adsorption tests performed in FY 2002 involved varying the solution $\mathrm{pH}$. As discussed in Section 3.6, batch reactors were used to assess the sorption of uranium onto the background sediment in both a low and high ionic strength solution at starting uranium solution concentrations of $0.5 \mathrm{mg} / \mathrm{L}$ and $3 \mathrm{mg} / \mathrm{L}$. The $\mathrm{pH}$ range tested in the low ionic strength solution was from 6.5 to 8.5 ; the $\mathrm{pH}$ range tested in the high ionic strength solution was from 6.5 to 8.0. Results of this experiment are presented in Tables $4.19 \& 4.20$ and Figures $4.16 \& 4.17$. 
Table 4.19 Batch pH Adsorption Data for the Low Ionic Strength Solution

\begin{tabular}{|c|c|c|c|}
\hline Sample & [238U] $(\mathbf{u g} / \mathbf{L})$ & $\mathbf{K}_{\mathbf{d}}(\mathbf{m L} / \mathbf{g})$ & $\mathbf{p H}$ \\
\hline Low I.S.-1 $(500 \mathrm{ppb})$ & 41.3 & 121 & 6.37 \\
\hline Low I.S.-2 $(500 \mathrm{ppb})$ & 65.6 & 72.5 & 6.61 \\
\hline Low I.S.-3 (500 ppb) & 258 & 10.5 & 7.31 \\
\hline Low I.S.-4 $(500 \mathrm{pbb})$ & 326 & 6.32 & 7.41 \\
\hline Low I.S.-5 (500 ppb) & 408 & 2.95 & 8.21 \\
\hline Low I.S.-6 (500 ppb) & 428 & 2.43 & 8.16 \\
\hline & & & \\
\hline Low I.S.-7 $(3000 \mathrm{ppb})$ & 333 & 82.8 & 6.31 \\
\hline Low I.S.-8 $(3000 \mathrm{ppb})$ & 641 & 38.2 & 6.74 \\
\hline Low I.S.-9 $(3000 \mathrm{ppb})$ & 2042 & 5.23 & 7.32 \\
\hline Low I.S.-10 $(3000 \mathrm{ppb})$ & 1989 & 5.61 & 7.47 \\
\hline Low I.S.-11 $(3000 \mathrm{ppb})$ & 2383 & 2.71 & 8.25 \\
\hline Low I.S.-12 $(3000 \mathrm{ppb})$ & 2456 & 2.56 & 8.53 \\
\hline
\end{tabular}

Table 4.20 Batch pH Adsorption Data for the High Ionic Strength Solution

\begin{tabular}{|c|c|c|c|}
\hline Sample & {$[238 \mathrm{U}](\mathrm{ug} / \mathrm{L})$} & $K_{d}(m L / g)$ & pH \\
\hline High I.S.-1 (500 ppb) & 4.58 & 137.83 & 6.26 \\
\hline High I.S.-2 (500 ppb) & 62.5 & 8.63 & 6.77 \\
\hline High I.S.-3 (500 ppb) & 340 & 0.31 & 7.49 \\
\hline High I.S.-4 (500 ppb) & 328 & 0.36 & 7.36 \\
\hline High I.S.-5 (500 ppb) & 405 & -0.09 & 7.93 \\
\hline High I.S.-6 (500 ppb) & 375 & -0.07 & 7.97 \\
\hline High I.S.-7 (3000 ppb) & 501 & 6.09 & 6.53 \\
\hline High I.S.-8 (3000 ppb) & 750 & 3.93 & 6.68 \\
\hline High I.S. -9 (3000 ppb) & 2125 & 0.16 & 7.26 \\
\hline High I.S.-10 (3000 ppb) & 1985 & 0.20 & 7.11 \\
\hline High I.S.-11 (3000 ppb) & 2507 & 0.02 & 7.9 \\
\hline High I.S.-12 (3000 ppb) & 2623 & 0.03 & 7.89 \\
\hline
\end{tabular}

Note: The adsorbed concentration used in the $\mathrm{K}_{\mathrm{d}}$ calculation was calculated by subtracting the total amount of uranium in solution from the initial uranium starting solution concentration. Therefore, negative $\mathrm{K}_{\mathrm{d}}$ values are possible but should be considered to equal $0 \mathrm{~mL} / \mathrm{g}$. 
PNNL-14022 300 Area U Leach/Adsorption Study for ERC Final Report Chapter 4. Results and Discussion

Figure 4.16: Uranium Adsorption as a Function of pH

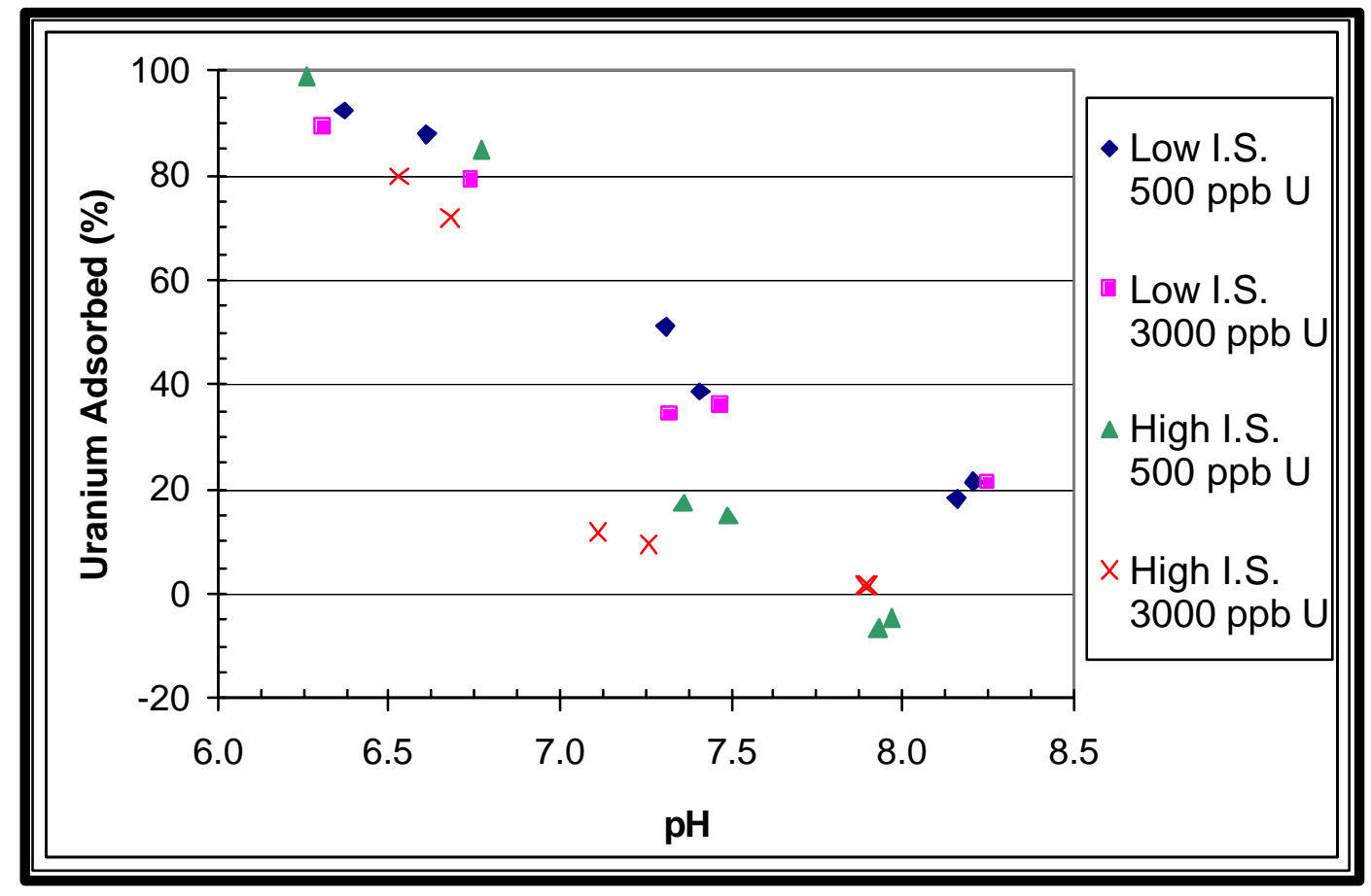

Figure 4.17: Uranium $K_{d}$ as a Function of $\mathbf{p H}$

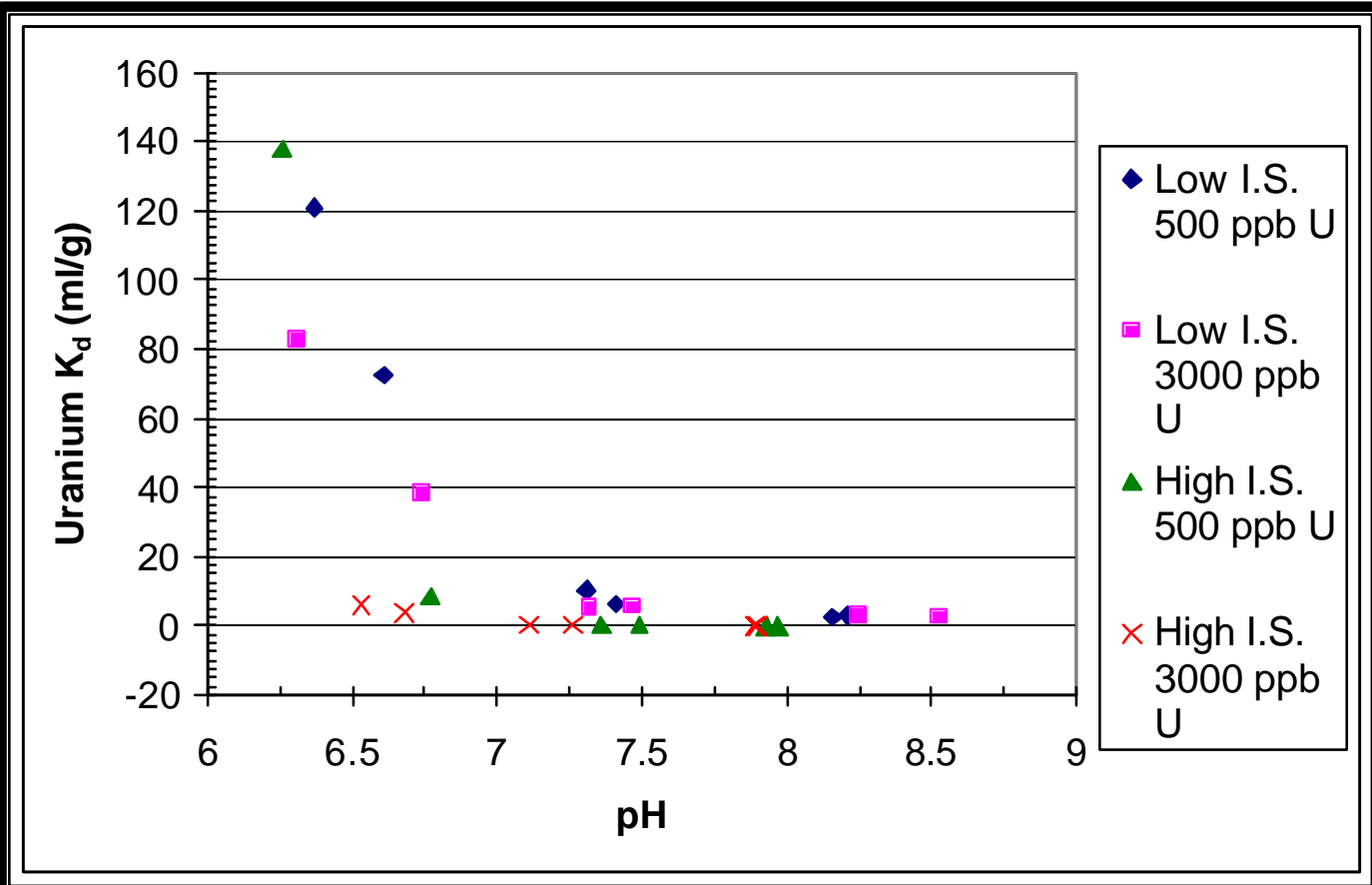


As seen in Figure 4.16, a plot of uranium adsorption onto the background sediment as a function of $\mathrm{pH}$, nearly all of the uranium is sorbed to the sediment around $\mathrm{pH} 6.5$ in both solutions tested. As the solution $\mathrm{pH}$ was increased, the percentage of sorbed uranium decreased, but in different proportions for the low vs. high ionic strength solutions. Around $\mathrm{pH} 7.5$, approximately $20 \%$ of the total uranium was still sorbed to the sediment in the high ionic strength matrix vs. $40 \%$ in the low ionic strength matrix. This divergence is also seen at the highest $\mathrm{pH}$ tested in both solutions, $\mathrm{pH} 8$ for the high ionic strength solution and $\mathrm{pH} 8.5$ for the low ionic strength solution, with $0 \%$ and $20 \%$ sorption, respectively.

When this same data is plotted as uranium adsorption $\mathrm{K}_{\mathrm{d}}$ values as a function of $\mathrm{pH}$, Figure 4.17, the differences due to the two solution matrices become clearer. For the low ionic strength solution, uranium adsorption $\mathrm{K}_{\mathrm{d}}$ values ranged from about $100 \mathrm{~mL} / \mathrm{g}$ at $\mathrm{pH} 6.5$ to $2 \mathrm{~mL} / \mathrm{g}$ at $\mathrm{pH}$ 8.5. In the high ionic strength solution, uranium adsorption $\mathrm{K}_{\mathrm{d}}$ values ranged from $6.1 \mathrm{~mL} / \mathrm{g}$ at $\mathrm{pH} 6.5$ to $0 \mathrm{~mL} / \mathrm{g}$ at $\mathrm{pH} 8$.

The data presented in this section shows that uranium $\mathrm{K}_{\mathrm{d}}$ values vary considerably based on solution $\mathrm{pH}$ and ionic strength of solution. The effect of solution $\mathrm{pH}$ is a classic example of the formation of anionic uranyl carbonate species that increase the solubility of uranium and increases the negative charge on the uranyl carbonate complexes as the solution $\mathrm{pH}$ increases. For a given solution composition, uranium solution concentrations below $3 \mathrm{mg} / \mathrm{L}$ appear to yield linear isotherms (i.e., have no effect on uranium $\mathrm{K}_{\mathrm{d}}$ values), which agrees quite well with the data presented in Section 4.2.4. There is some variability seen in the data, but it is generally within the experimental/analytical error associated with this experiment.

To relate the above data to the specific problem in the 300 Area, we first must define the $\mathrm{pH}$ parameters expected in the 300 Area. As seen in the FY 2001 column leach tests, Section 4.2.1, the sediment tends to dominate the system, ultimately keeping the solution $\mathrm{pH}$ between $\mathrm{pH}$ 7.5-8. The anticipated primary recharge input to the 300 Area North Process Pond will be rainfall, so it is unlikely that the in-situ field conditions will deviate much from the laboratory findings. Based on this, expected uranium $\mathrm{K}_{\mathrm{d}}$ values could be narrowed down to between 0 and $2 \mathrm{~mL} / \mathrm{g}$ (based on values calculated in the HIS matrix between $\mathrm{pH} 7.5$ and 8) in the vadose zone region, and between 2 and $6 \mathrm{~mL} / \mathrm{g}$ (based on values calculated in the LIS matrix between $\mathrm{pH} 7.5$ and 8) in the up gradient groundwater dominated aquifer.

\subsubsection{Batch Adsorption Test: Variable Bicarbonate Solution Concentration}

The final set of batch adsorption tests performed in FY 2002 involved varying the initial inorganic carbon (bicarbonate) solution concentration. As discussed in Section 3.7, batch reactors were used to assess the sorption of uranium onto the background sediment in both a low and high ionic strength solution at initial uranium solution concentrations of $0.5 \mathrm{mg} / \mathrm{L}$ and 3 $\mathrm{mg} / \mathrm{L}$. The bicarbonate solution concentration ranged from 0.5 to $2 \mathrm{mM}$ in the low ionic strength solution and from 2 to $16 \mathrm{mM}$ in the high ionic strength solution. Results of this experiment are presented in Tables $4.21 \& 4.22$ and Figures $4.18 \& 4.19$. The solution uranium analysis was performed using a kinetic phosphorescence analyzer (KPA) instead of ICP-MS because the ICPMS was inoperative for several weeks. 
Table 4.21 Batch Carbonate Adsorption Data for the Low Ionic Strength Solution

\begin{tabular}{|c|c|c|c|c|}
\hline Sample & $\begin{array}{c}{\left[\mathrm{HCO}_{3}\right]} \\
(\mathrm{mM})\end{array}$ & $\begin{array}{l}\left.{ }^{238} \mathrm{U}\right] \\
\text { (ug/L) }\end{array}$ & $\begin{array}{c}\mathrm{Kd} \\
(\mathrm{mL} / \mathrm{g})\end{array}$ & $\begin{array}{l}\text { Kd } \\
\text { Avg }\end{array}$ \\
\hline Low l.S.-1 (500 ppb) & 0.863 & 318 & 6.54 & \multirow{2}{*}{6.80} \\
\hline Low I.S.-2 (500 ppb) & 0.868 & 309 & 7.05 & \\
\hline Low I.S.-3 (500 ppb) & 1.56 & 421 & 2.24 & \multirow{2}{*}{1.93} \\
\hline Low I.S.-4 (500 ppb) & 1.39 & 444 & 1.62 & \\
\hline Low I.S.-5 (500 ppb) & 2.44 & 456 & 1.25 & \multirow{2}{*}{1.32} \\
\hline Low I.S.-6 (500 ppb) & 2.34 & 468 & 1.39 & \\
\hline Low I.S.-7 (3000 ppb) & 1.06 & 1753 & 7.03 & \multirow{2}{*}{7.15} \\
\hline Low I.S.-8 (3000 ppb) & 1.04 & 1688 & 7.28 & \\
\hline Low I.S.-9 (3000 ppb) & 1.29 & 2115 & 3.71 & \multirow{2}{*}{4.30} \\
\hline Low I.S.-10 (3000 ppb) & 1.09 & 1944 & 4.89 & \\
\hline Low I.S.-11 (3000 ppb) & 2.08 & 2254 & 2.58 & \multirow{2}{*}{2.13} \\
\hline Low I.S.-12 (3000 ppb) & 2.01 & 2440 & 1.67 & \\
\hline
\end{tabular}

Table 4.22 Batch Carbonate Adsorption Data for the High Ionic Strength Solution

\begin{tabular}{|c|c|c|c|c|}
\hline Sample & $\begin{array}{c}{\left[\mathrm{HCO}_{3}\right]} \\
(\mathrm{mM})\end{array}$ & $\begin{array}{l}\left.{ }^{238} \mathrm{U}\right] \\
\text { (ug/L) }\end{array}$ & $\begin{array}{c}\mathrm{Kd} \\
(\mathrm{mL} / \mathrm{g})\end{array}$ & $\begin{array}{c}\text { Kd } \\
\text { Avg } \\
\end{array}$ \\
\hline High I.S.-1 (500 ppb) & 2.57 & 354 & 0.38 & \multirow{2}{*}{0.35} \\
\hline High I.S.-2 (500 ppb) & 2.47 & 371 & 0.32 & \\
\hline High I.S.-3 (500 ppb) & 6.46 & 447 & 0.08 & \multirow{2}{*}{0.06} \\
\hline High I.S.-4 (500 ppb) & 6.18 & 443 & 0.05 & \\
\hline Hiah I.S.-5 (500 ppb) & 14.8 & 630 & -0.47 & \multirow{2}{*}{$-0.4 \mathrm{~S}$} \\
\hline High I.S.-6 (500 ppb) & 12.3 & 590 & -0.51 & \\
\hline High I.S.-7 (3000 ppb) & 2.66 & 1812 & 0.22 & \multirow{2}{*}{0.20} \\
\hline High I.S.-8 (3000 ppb) & 2.63 & 1900 & 0.17 & \\
\hline High I.S.-9 (3000 ppb) & 6.49 & 2193 & 0.16 & \multirow{2}{*}{0.15} \\
\hline High I.S.-10 (3000 ppb) & 5.83 & 2102 & 0.14 & \\
\hline High I.S.-11 (3000 ppb) & 12.42 & 2374 & 0.03 & \multirow{2}{*}{0.05} \\
\hline High I.S.-12 (3000 ppb) & 12.02 & 2012 & 0.07 & \\
\hline
\end{tabular}

Note: The adsorbed concentration used in the $\mathrm{K}_{\mathrm{d}}$ calculation was calculated by subtracting the total amount of uranium in solution from the initial uranium starting solution concentration. Therefore, negative $\mathrm{K}_{\mathrm{d}}$ values are possible but should be considered to equal $0 \mathrm{~mL} / \mathrm{g}$. 
PNNL-14022 300 Area U Leach/Adsorption Study for ERC Final Report Chapter 4. Results and Discussion

Figure 4.18: Uranium Adsorption as a Function of Bicarbonate Concentration

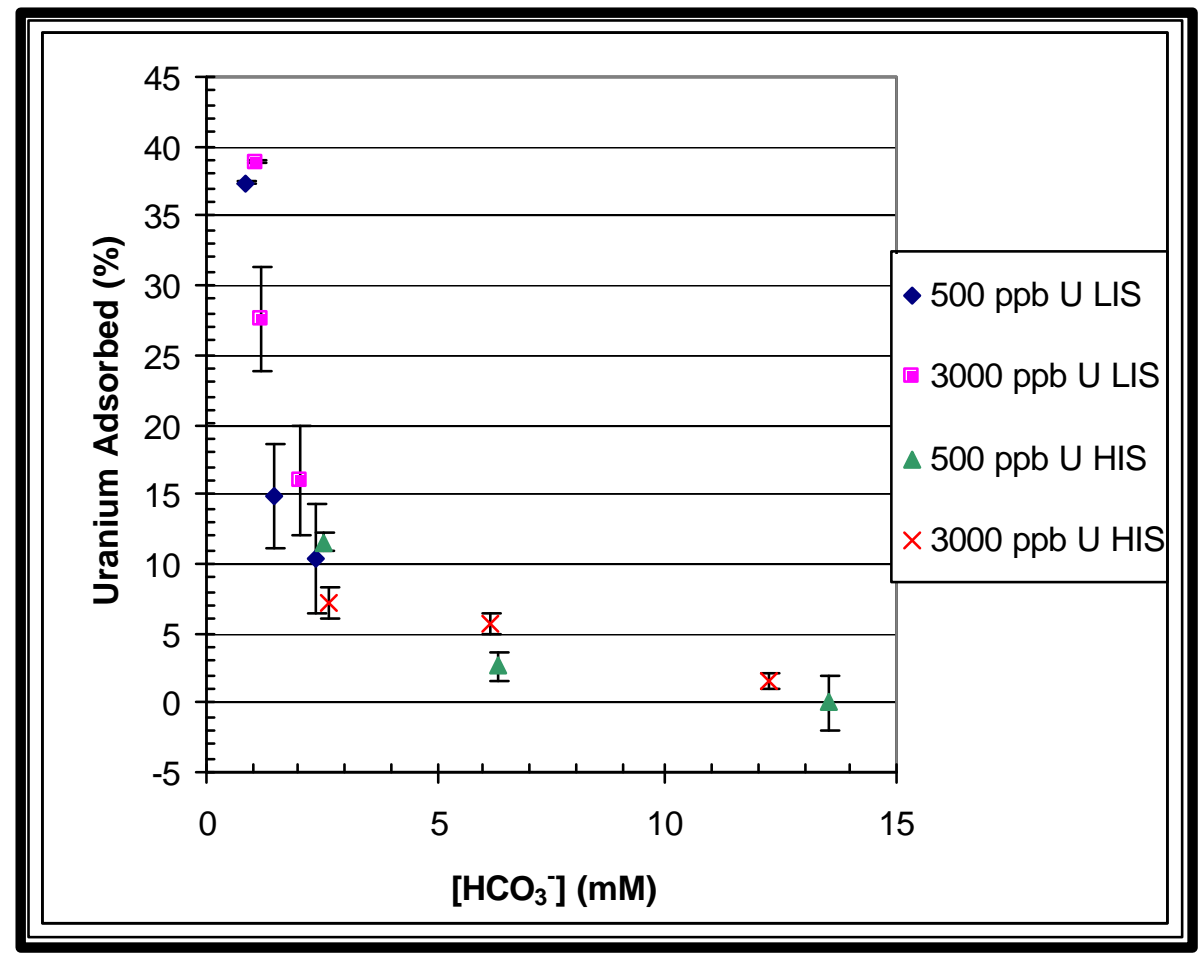

Figure 4.19: Uranium Kd as a Function of Bicarbonate Concentration

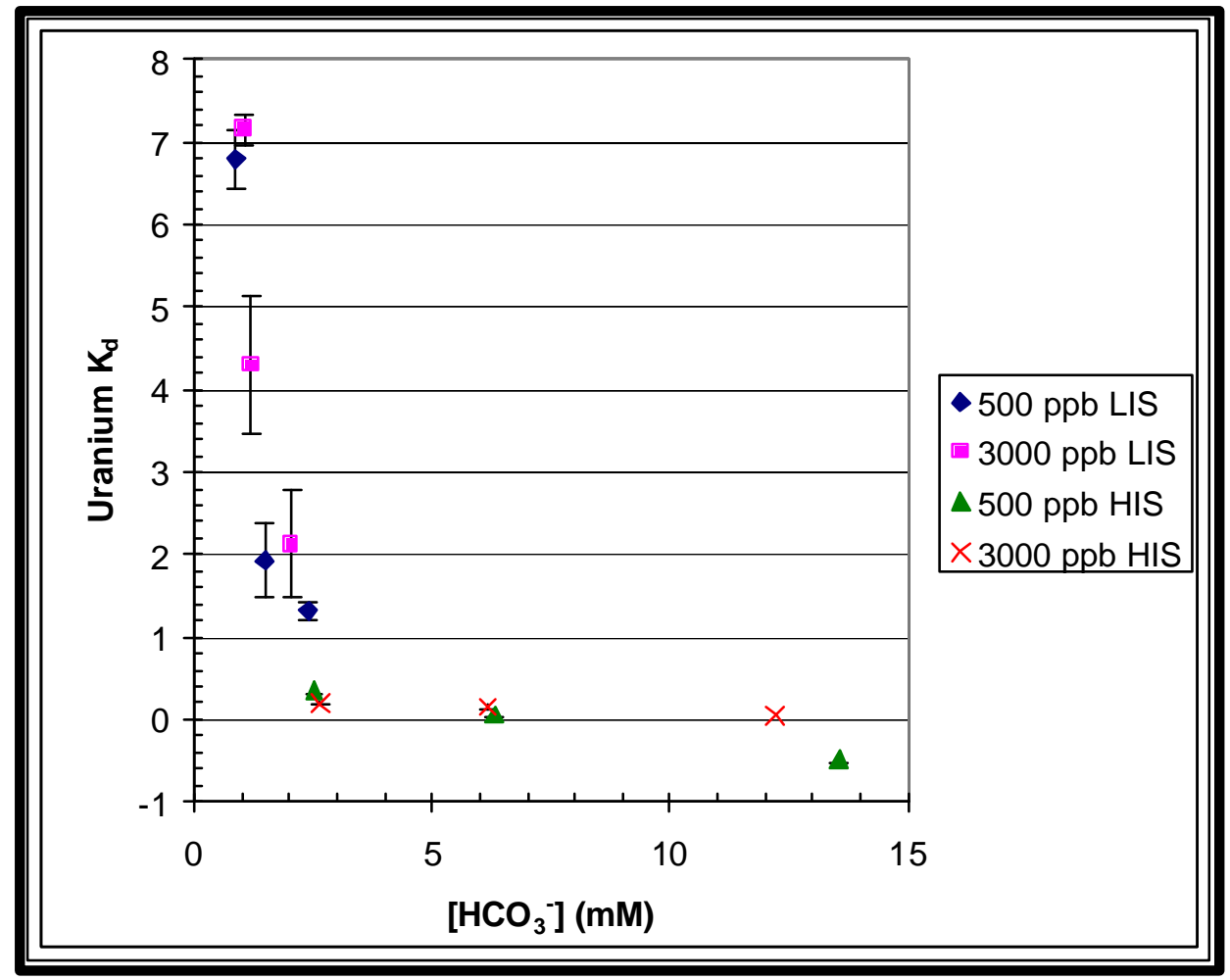


As seen in Figure 4.18, a plot of the percentage of total uranium adsorption onto the background sediment as a function of bicarbonate solution concentration, curves with very different slopes versus bicarbonate concentration exist for the two ionic strength solution matrices tested. Uranium adsorption onto the background sediment ranges from about $40 \%$ at $0.9 \mathrm{mM} \mathrm{HCO}_{3}{ }^{-}$to $12 \%$ at $2.2 \mathrm{mM} \mathrm{HCO}_{3}{ }^{-}$in the low ionic strength solution. Considerably less sorption is seen in the high ionic strength solution, with a range of about $7 \%$ at $2.5 \mathrm{mM} \mathrm{HCO}_{3}{ }^{-}$to $0 \%$ at $13 \mathrm{mM}$ $\mathrm{HCO}_{3}{ }^{-}$.

When this same data is plotted as uranium adsorption $\mathrm{K}_{\mathrm{d}}$ values as a function of bicarbonate concentration, Figure 4.19, the differences due to the two solution matrices become clearer. For the low ionic strength solution, uranium adsorption $K_{d}$ values range from 7 to $2 \mathrm{~mL} / \mathrm{g}$ over a bicarbonate range of 0.9 to $2.2 \mathrm{mM}$. Adsorption $\mathrm{K}_{\mathrm{d}}$ values ranged from 0.3 to $0 \mathrm{~mL} / \mathrm{g}$ over a bicarbonate range of 2.5 to $13 \mathrm{mM}$ in the high ionic strength solution.

The data presented in this section show that uranium $\mathrm{K}_{\mathrm{d}}$ values vary significantly based on the bicarbonate concentration in solution. This is particularly evident in the low ionic strength solution, where the uranium $\mathrm{K}_{\mathrm{d}}$ value decreases by a factor of three with a factor of two increase in bicarbonate solution concentration. Uranium $\mathrm{K}_{\mathrm{d}}$ values were quite low in the high ionic strength solution, $<0.4 \mathrm{~mL} / \mathrm{g}$, and were generally unaffected by bicarbonate concentrations above $6 \mathrm{meq} / \mathrm{L}$. As seen in the other batch adsorption tests, Sections 4.2.4 and 4.2.5, uranium solution concentration appears to have no effect on uranium $\mathrm{K}_{\mathrm{d}}$ values, a requirement for the use of the linear adsorption isotherm or $\mathrm{K}_{\mathrm{d}}$ construct. There is some variability seen in the data, but it is generally within the experimental/analytical error associated with this experiment.

To relate the above data to the specific problem in the 300 Area aquifer plume, we first must define the inorganic carbon parameters expected in the 300 Area. The Columbia River has a total inorganic carbon concentration around $0.5 \mathrm{mM}$, groundwater in the 300 Area has a inorganic carbon concentration between 1 and $2 \mathrm{mM}$, and the vadose zone porewater may have (based on our lab leach tests) an inorganic carbon concentration in excess of $10 \mathrm{mM}$ (see Appendix L carbonate data). Based on this, expected uranium $\mathrm{K}_{\mathrm{d}}$ values could be narrowed down to between 0 and $1 \mathrm{~mL} / \mathrm{g}$ in the vadose zone region and between 2 and $4 \mathrm{~mL} / \mathrm{g}$ in the aquifer. Although not studied in detail, the $\mathrm{K}_{\mathrm{d}}$ values for the aquifer sediments that are close to the Columbia River may range above $6 \mathrm{~mL} / \mathrm{g}$ during periods when dilute River water is present. These $K_{d}$ values are slightly different than those given in the previous section (Section 4.2.5); they are based solely on the information collected during the bicarbonate adsorption experiments. A final $\mathrm{K}_{\mathrm{d}}$ range will be provided in the conclusions section that takes into account all of the batch adsorption data.

\subsubsection{Column Flow-through Test: Adsorption/Desorption Study}

The final laboratory studies performed in FY 2002 were column flow-through experiments to test the adsorption of uranium onto the background sediment (B11493) using a dilute (low ionic strength) and saline (high ionic strength) solution (See Section 3.8 for additional details). Results of this experiment are presented in Figures $4.20 \& 4.21$.

Figure 4.20 is a plot of uranium breakthrough versus pore volumes collected for the low ionic strength solution. The red data point represents the point where uranium $(1 \mathrm{mg} / \mathrm{L})$-spiked 
solution was introduced to the column. As seen in Figure 4.20, it takes more than two pore volumes of injection before detectable uranium is found in the effluent. This delay in uranium breakthrough is due to the ability of the sediment to remove uranium from solution. The pink data point represents the time where the uranium-spiked solution was replaced with the original low ionic strength solution without uranium (flushing solution). The plateau in uranium solution concentration seen in Figure 4.20 between approximately 11 and 13 pore volumes is intriguing, perhaps it indicates the precipitation of a uranium bearing mineral.

An adsorption partition coefficient can be calculated for the system once 50\% breakthrough (the effluent uranium concentration is equal to $50 \%$ of the influent uranium concentration) is achieved. The $\mathrm{K}_{\mathrm{d}}$ can be calculated using the following equation:

$$
R=1+\left(\rho_{b} / \theta\right) \bullet K_{d} .
$$

Where $\rho_{b}$ is the dry bulk density of the sediment in the column and $\theta$ is the water content [or for saturated systems the porosity of the packed column].

The retardation factor $(\mathrm{R})$ is the pore volume at which the uranium breakthrough curve $\mathrm{C} / \mathrm{C}_{0}\left[\mathrm{C}=\right.$ concentration in solution, $\mathrm{C}_{0}=$ starting concentration $]$ reaches a value of 0.5 . The other two parameters were directly measured and are listed in Appendix Q.

Using the above equation results in an adsorption $\mathrm{K}_{\mathrm{d}}$ value of $1.85 \mathrm{~mL} / \mathrm{g}$, which corresponds quite well with the LIS matrix extended time data $\left(\mathrm{K}_{\mathrm{d}}=2.08 \mathrm{~mL} / \mathrm{g}\right)$ observed in Appendix N.

Figure 4.20 Adsorption Column Data: Low Ionic Strength Solution

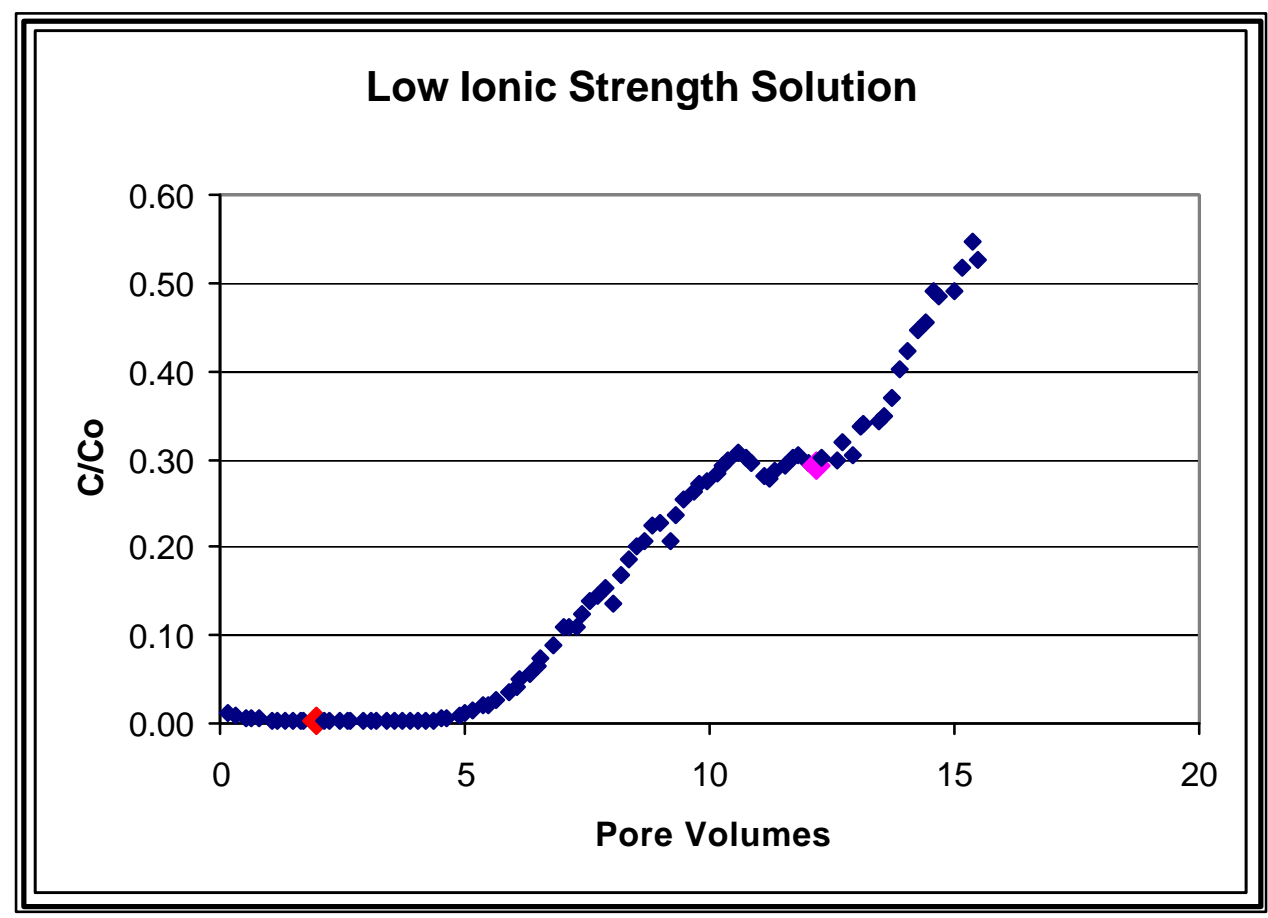


Figure 4.21 is a plot of uranium breakthrough versus pore volumes collected for the high ionic strength solution contacting the background sediment. The red data point represents the point where uranium $(1 \mathrm{mg} / \mathrm{L})$-spiked solution was introduced. The green data point represents the point where a second batch of uranium solution $(1 \mathrm{mg} / \mathrm{L})$ was introduced to the system (additional solution had to be made to continue the experiment). As seen in Figure 4.21, it takes approximately one pore volume of injection before measurable uranium effluent concentration is observed. The quicker uranium breakthrough seen in the high ionic strength tests when compared to the low ionic strength test (shown in Figures 4.20 and 4.21) is most likely due to the higher carbonate solution concentration (although increased ionic strength and potentially a higher solution $\mathrm{pH}$ could also be affecting the system).

It is apparent upon inspection of Figure 4.21 that uranium breakthrough in the high ionic strength system is not following a typical Gaussian or "bell-shaped" distribution. It appears that the sediment becomes more effective at removing uranium from solution as the experiment progressed. This is most likely the result of loading the sediment with enough calcium to initiate the precipitation of a calcium-bearing uranium mineral, such as uranophane or the removal of carbonate from solution by precipitation of calcite. The second uranium bearing solution injected into the column inadvertently had a lower calcium solution concentration (calcite or calcium carbonate may have precipitated out of the solution). The lower calcium, may have allowed the sediment to dissolve some calcite (releases carbonate) that releases previously bound uranium (as is evident by the large spike in uranium solution concentration at approximately 13 pore volumes).

Using the same equation listed earlier in this section to calculate an adsorption $\mathrm{K}_{\mathrm{d}}$ yields a value of $0.86 \mathrm{~mL} / \mathrm{g}$, which is consistent with our assessment of uranium adsorption $\mathrm{K}_{\mathrm{d}}$ values $(0-1$ $\mathrm{mL} / \mathrm{g}$ ) in the unsaturated vadose zone. The calculated $\mathrm{K}_{\mathrm{d}}$ value also corresponds quite well with the extended time HIS matrix data $\left(\mathrm{K}_{\mathrm{d}}=1.01\right)$ found in Appendix $\mathrm{N}$. 
PNNL-14022 300 Area U Leach/Adsorption Study for ERC Final Report Chapter 4. Results and Discussion

Figure 4.21 Adsorption Column Data: High Ionic Strength Solution

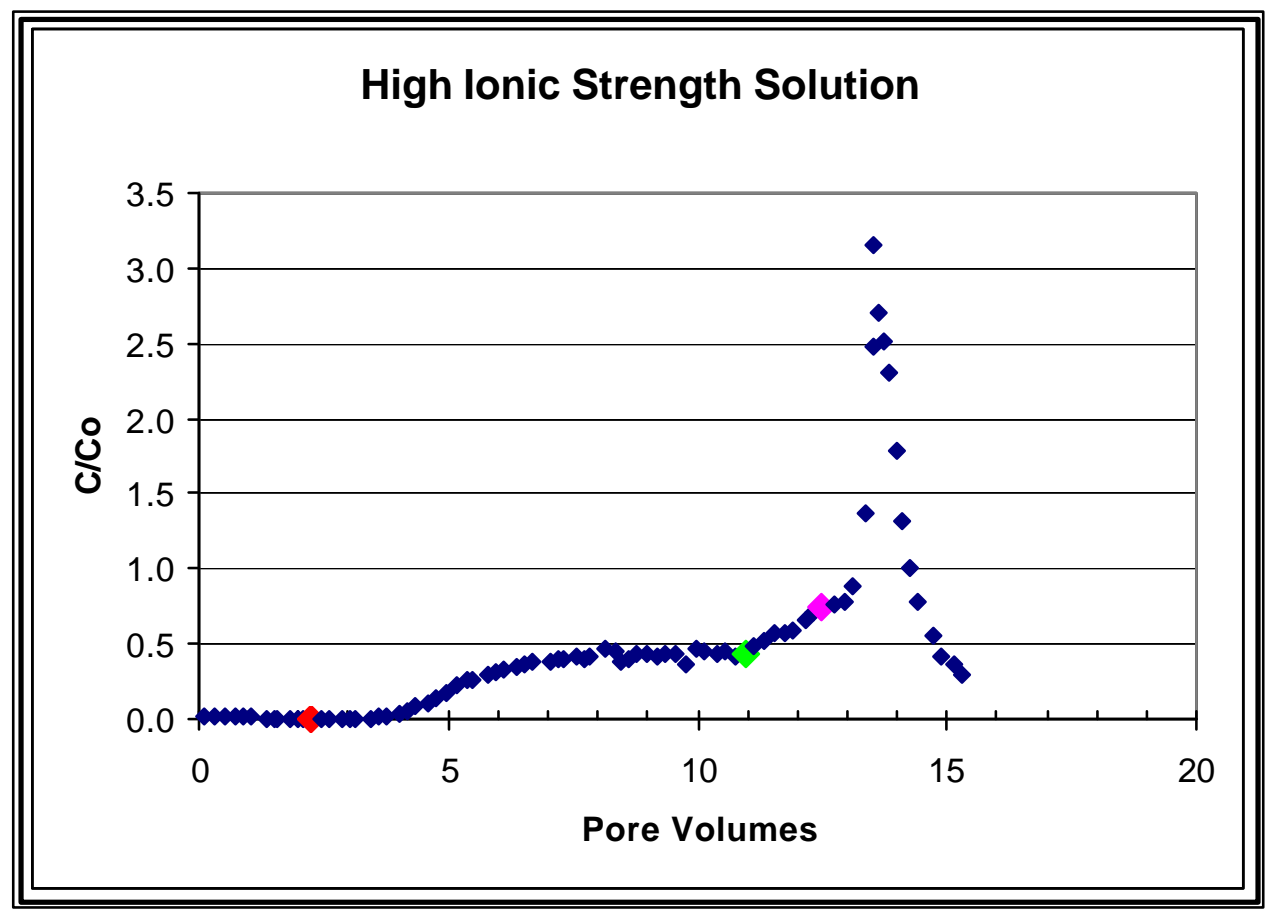


PNNL-14022 300 Area U Leach/Adsorption Study for BHI FY 2001 Progress Report

Chapter 5. Conclusions

\subsection{CONCLUSIONS}

Six near-surface sediment samples were subjected to a series of mineralogical and geochemical measurements. The samples were found to be composed primarily of coarse-grained sands with some gravel (sample B11494 contained slightly more silt and fine grained material). The organic carbon content of the samples was typical for Hanford soils $(<1 \%)$, with the exception of sample B11BY5, which contained almost $3 \%$ by weight organic carbon.

The total chemical composition of the near-surface sediments shows that sample B11B494, from the bottom of the N Process Pond, has elevated concentrations of many metals including: arsenic, chromium, copper, lead, molybdenum, nickel, silver, uranium, zinc, zirconium, as well as phosphorous (likely phosphate), nitrate, and sulfur (sulfate). Sample B11BY5 shows elevated concentrations of chromium, copper, lead, nickel, uranium, and zinc as well as sulfate compared to the background sediment. Sample B11BY6 shows elevated concentrations of lead, molybdenum, and the highest concentration of uranium in all the sediments. Sample B11B495 contains the least uranium and other signs of Hanford fuel processing activities. After contact with water at a one-to-one ratio, the water extracts of the sediments show that the pond sediments, especially B11B494, extract considerably more nitrate, sulfate, calcium, magnesium, sodium, uranium, and the trace metals chromium, copper, and zinc than the background sediment. The three samples from around 303-K building do not leach any constituents, except uranium and perhaps calcium, at higher concentrations than the background sediment. The water leachate from the background sediment had a $\mathrm{pH}$ value tightly buffered to values between 7.65 to 7.75. The five contaminated sediments had water extract $\mathrm{pH}$ values that ranged between 7.13 and 7.8 .

Overall, the bulk sediments appear to be dominated by quartz, with lesser amounts of feldspar and hornblende. Sodium-rich feldspar (albite) appears more abundant than the potassium-rich feldspar (orthoclase) in all the sediments. Minor amounts of clay minerals (chlorite and mica) were detected in each bulk sample. XRD patterns of known crystalline U-oxide compounds were checked against the patterns and no matches were observed. Furthermore, one sample containing high amounts of $\mathrm{Cu}$ from the 300 Area North Process Pond (B11494) was checked for crystalline $\mathrm{Cu}$-bearing minerals and none were detected. XRD is not ultra-sensitive for detection of crystalline phases, which typically requires one to five weight percent concentrations. Therefore, crystalline solids could be present at trace levels and not be detected by XRD. The uranium concentrations, although elevated, are still low (in the $0.1 \mathrm{wt}$. percent range). Also, the $\mathrm{U}$ and $\mathrm{Cu}$ (in sediment $\mathrm{B} 11494$ ) could be present as amorphous solids that do not have crystalline structures that can be observed via X-ray diffraction.

The background sample (B11493) contains typical clay minerals commonly found on the Hanford site. The background sample clay fraction is dominated by illite, with lesser amounts of smectite and chlorite, and trace amounts of kaolinite. Minor concentrations of non-clay minerals (quartz, feldspars, and an amphibole) were also identified in the clay-sized separate from the background sediment. Two clay separates collected from the $303 \mathrm{~K}$ Building environs samples (B11BY4 and B11BY5) produced similar XRD tracings to the background sample. All 303K clay sized separates have sediment dominated by smectite. In comparison, clay sized separates collected from the 300 Area North Processing Pond (B11494 and B11495) did not contain 
significant quantities of clay minerals. Trace amounts of illite and chlorite were detected in both samples, but with very low intensities compared to samples collected from the $303-\mathrm{K}$ Building environs. Furthermore, the pond samples were comprised of very little crystalline material, which is evident by the lack of reflections on the XRD tracings. Oxides of Fe, Ti, Cr, and $\mathrm{Mn}$ were also observed to be present in the clay fractions of the 300 Area North Processing Pond samples.

Two SEM images from the $303 \mathrm{~K}$ environs contaminated sediment samples suggest that uranium is likely present as co-precipitates and/or discrete uranium particles. State-of-the-art molecular probe techniques also confirm the presence of crystalline discrete uranium bearing phases in the sediments from around the $303 \mathrm{~K}$ building. The crystalline material in the two samples from $303 \mathrm{~K}$ environs is the same mineral. The nature of the uranium in the sediments from the 300 Area N Process Pond is less certain. One technique suggests the presence of the same crystalline compounds in the 300 Area North Process Pond sediments as in the 303 -K sediments and another technique suggests that the uranium in the Process Pond sediments is less crystalline and predominately more amorphous than the uranium in the $303-\mathrm{K}$ sediments. In all contaminated sediments studied, the uranium is present as oxidized uranium (uranyl [U(VI)]). The molecular probe data collected to date suggests that the crystalline uranium is most likely clarkeite ( $\mathrm{Na}$, $\left.\mathrm{Ca}, \mathrm{Pb})\left(\mathrm{UO}_{2}\right) \mathrm{O}(\mathrm{OH})^{*} 0-1\left(\mathrm{H}_{2} \mathrm{O}\right)\right)$ or uranophane $\left(\mathrm{Ca}\left(\mathrm{UO}_{2}\right)_{2} \mathrm{SiO}_{3}(\mathrm{OH})^{*} 5\left(\mathrm{H}_{2} \mathrm{O}\right)\right)$. The EXAFS data further suggests that the discrete crystalline U(VI) bearing phases may likely be phosphates and or silicates based on the interatomic distances between uranium atoms in crystalline structures. However, laser fluorescence spectroscopy suggests that the sediments do not contain uranyl phosphates, which conflicts with the EXAFS findings. The two lead investigators are working on resolving this conflict using pure uranyl bearing minerals and collecting additional spectra using all the techniques.

Semi-selective extraction analysis of the six near-surface sediment samples showed that the bulk of the extractable uranium in the contaminated sediments was associated with weak acid dissolvable phases (perhaps discrete uranyl compounds or associated with alkaline earth carbonates) and amorphous hydrous iron and aluminum oxides, and that very little (a few percent or less) of the uranium is water-soluble or cation-exchangeable (anion exchange was not investigated).

The characterization data suggests that the release of uranium from the near-surface contaminated sediments is more likely dominated by dissolution of discrete uranium minerals or uranium containing co-precipitates as opposed to desorption reactions from uranium adsorbed to surface exchange sites.

Results from large column leach tests showed that uranium leaching did not follow a constant solubility paradigm. Four of the five contaminated near-surface sediments showed a large near instantaneous release of a few percent of the total uranium (readily leachable) followed by a slower continual release of recalcitrant uranium. Steady-state uranium leachate concentrations were never observed and leaching characteristics and trends were not consistent among the samples. Dissolution kinetics were slow, and the measured leach curves most likely represent a slow kinetically controlled dissolution paradigm. Very little uranium was leached from sample B11BY5 from near the 303-K building. This sediment contained the highest organic carbon 
content of all the sediments obtained and the leach test showed signs of biological activity. However, no confirmation for reducing conditions that convert soluble U(VI) to insoluble U(IV) were evident. We measured effluent Eh and looked for dissolved iron and manganese, but found no signs of reducing conditions. The cause for the entirely different leaching trends for sample B11BY5 remains unexplained at this time. Based on the atypical nature of sample B11BY5, it was generally excluded from the assessments used to calculate the final desorption $\mathrm{K}_{\mathrm{d}}$ values presented in this report.

Results from the preliminary column and batch adsorption experiments showed that uranium sorption onto the uncontaminated sediment was highly variable, and that sorption was dependent on the uranium solution concentration, perhaps because very high uranium solution concentrations from the initial flow through column leach tests were used. Concentrations of uranium in the preliminary adsorption tests exceeded $20 \mathrm{mg} / \mathrm{L}$, which may have been beyond the range where the adsorption isotherm is linear.

The laboratory work performed during fiscal year (FY) 2002 was changed to enable a more accurate prediction of uranium partition coefficients based on conditions expected in the 300 Area. The sampling and analysis plan (SAP) was amended to allow for long-term batch leach tests (to provide equilibrium desorption $\mathrm{K}_{\mathrm{d}}$ values) and numerous batch uranium adsorption studies (to investigate the sensitivity of the adsorption $\mathrm{K}_{\mathrm{d}}$ to key variables such as $\mathrm{pH}$, total inorganic carbon and uranium solution concentrations, and total ionic strength). These FY 2002 batch adsorption tests were used to complement column flow-through adsorption/desorption tests.

Long-term batch leach tests were used to investigate the effect of static contact on uranium leaching. Sediment from the leach columns was subjected to three leaching solutions (deionized water, uncontaminated groundwater, and simulated vadose zone porewater) to determine how much of the recalcitrant uranium could be removed over a six-month period. Results from the batch leach test showed that less than four percent of the remaining uranium mass was removed by deionized water, a simulate for rainwater. The groundwater solution was slightly more effective, leaching as much as $10 \%$ of the recalcitrant uranium. The simulated vadose zone porewater solution was the most effective at leaching uranium, removing almost $30 \%$ of the residual total uranium mass in two out of the five contaminated samples.

Three suites of batch adsorption experiments were performed to investigate the effect of uranium solution concentration, $\mathrm{pH}$, and inorganic carbon solution concentration on uranium adsorption onto the uncontaminated sediment. Uranium adsorption $\mathrm{K}_{\mathrm{d}}$ values ranged from $0 \mathrm{~mL} / \mathrm{g}$ to more than $100 \mathrm{~mL} / \mathrm{g}$ depending on which solution parameter was being adjusted. Results of the experiments showed that inorganic carbon solution concentration has the greatest impact on uranium adsorption onto the 300 Area background sediment. Solution $\mathrm{pH}$ was shown to be important in laboratory tests; however, the sediment will dominate the field $\mathrm{pH}$ (i.e., buffer $\mathrm{pH}$ to a nearly constant value) and minimize its overall effect in the 300 Area sediments. Results from the batch adsorption tests also showed that if one fixes the $\mathrm{pH}$, carbonate concentration and all other solution concentrations, the resulting sorption follows the linear adsorption isotherm model through $4 \mathrm{mg} / \mathrm{L}$ uranium solution concentration in the LIS solution and through $2 \mathrm{mg} / \mathrm{L}$ uranium solution concentrations in the HIS matrix, which is well above the dissolved uranium values 
found in the upper unconfined aquifer. However, the natural vadose zone porewater and groundwater chemical composition in the 300 Area are not constant. Inorganic carbon, $\mathrm{pH}$, and other constituents vary in space and time because of evapotranspiration and transient rainfall/snow events. Fluctuations of the River stage cause groundwater and River water to mix at different proportions at different times of year, and even different times of day when the dams are dominating the River flow. Therefore, the linear $K_{d}$ model, but not the constant $K_{d}$ model, is defensible in predicting the fate of uranium in the 300 Area aquifer plume.

Column adsorption tests were performed to assess the sorption, or loading, of uranium onto the background, or uncontaminated sediment. This test most closely predicts the fate of uranium contaminated solutions once they come into contact with "clean" or uncontaminated sediment. Uranium adsorption $\mathrm{K}_{\mathrm{d}}$ values ranged from $1.85 \mathrm{~mL} / \mathrm{g}$ in the low ionic strength solution matrix to $0.86 \mathrm{~mL} / \mathrm{g}$ in the high ionic strength solution matrix.

The large column leach tests that were performed as part of this study have shown that less than $4 \%$ of the existing uranium in the contaminated near-surface sediments readily leaches into "simulated" rainwater. Based on our current understanding of the episodic natural recharge at the 300 Area, we would assume that the system is still within this $4 \%$ release phase. Note that the fast leaching of a small fraction of the total uranium occurred during the constant percolation of water into the sediments over a period of about one pore volume. In the real world, there will be episodic wetting and drying of the sediments so that these "steady-state" recharge tests are very simplified. Now that we understand the extreme sensitivity of uranium leaching to the carbonate content of the water in contact with the contaminated sediments, it is clear that the real world leach rates will also vary with time. A key need is to understand the seasonal variations of the chemical composition of water in the contaminated sediments and the depth at which seasonal variations dominate or conversely, the depth at which a constant steady state environment can be assumed. The traditional soil physics conceptual model for the near-surface environment relies on the assumption that there is a depth somewhere at or below the root zone where the seasonal variations in water content and chemical composition cease. Below this zone, one can use simplified steady-state conceptual models for both water flux and chemical composition of porewaters. It is plausible that our leach data after the washing out of the first pore volume could be used to represent the simplified steady-state condition for contaminated sediments below the zone where seasonal evapotranspiration dynamic conditions dominate. At this time, we are not certain how to deal with the "transient" near-surface zone.

The following equation can be extrapolated based on a simple estimate that the water we added in seven days (one pore volume) represents the recharge rate:

\section{Time $(\mathrm{yrs})=$ Pore Volume $\left(\mathrm{cm}^{3}\right) /(($ Column Area-cm² $) *($ Recharge rate $-\mathrm{cm} / \mathbf{y r}))$.}

Dependent on the chosen recharge rate, each pore volume in our large column leach tests can be considered to represent from several hundred to a thousand years of steady state conditions. However, this is very simplified and does not address the seasonal variations in chemical composition of the water in the "transient" near-surface zone. Once again, we are not certain how to deal with the "transient" near-surface zone at this time. 
PNNL-14022 300 Area U Leach/Adsorption Study for BHI FY 2001 Progress Report Chapter 5. Conclusions

Uranium sorption onto uncontaminated 300 Area sediment has been shown to be highly variable and dependent upon solution conditions. Therefore, predicted $\mathrm{K}_{\mathrm{d}}$ values based on site specific conditions expected in the 300 Area range from 0 to $1 \mathrm{~mL} / \mathrm{g}$ in the near-surface vadose zone and from 2 to $4 \mathrm{~mL} / \mathrm{g}$ in deeper steady-state vadose zone and in the unconfined aquifer. Although not studied in detail, adsorption $\mathrm{K}_{\mathrm{d}}$ values for Columbia River water diluted solutions reach values at least as high as $7 \mathrm{~mL} / \mathrm{g}$. 
PNNL-14022 300 Area U Leach/Adsorption Study for ERC Final Report

Chapter 6. References

\subsection{REFERENCES}

Allison, J. D., D. S. Brown, and K. J. Novo-Gradac. 1991. MINTEQA2/PRODEFA2, A Geochemical Assessment Model for Environmental Systems: Version 3.0 User's Manual. EPA/600/3-91/021, U.S. Environmental Protection Agency, Athens, Georgia.

(ART) Alternative Remediation Technologies, Inc. 1994. 300-FF-1 Operable Unit Physical Separation of Soils Pilot Plant Study. WHC-SD-EN-TI-277, Westinghouse Hanford Company, Richland, Washington.

ASTM. 1985. Standard Practice for Dry Preparation of Soil Samples for Particle-Size Analysis and Determination of Soil Constants. D 421-85, American Society for Testing and Materials, West Conshohocken, Pennsylvania.

ASTM. 1972. Particle-Size Analysis of Soils. D 422-63, American Society for Testing and Materials, West Conshohocken, Pennsylvania.

ASTM. 1971. Amount of Material in Soils Finer than the No 200 (75m) Sieve. D 1140-54, American Society for Testing and Materials, West Conshohocken, Pennsylvania.

DOE-RL. 2000a. Proposed Plan for the 300-FF-2 Operable Unit. DOE/RL-99-53, Rev.0, U.S. Department of Energy, Richland Operations Office, Richland, Washington.

DOE-RL. 2000b. Sampling and Analysis Plan for the 300 Area Uranium Leach/Kd Study. DOE/RL-2000-75, Rev.2, U.S. Department of Energy, Richland Operations Office, Richland, Washington.

EPA, Ecology, and DOE. 1996. Declaration of the Record of Decision: USDOE Hanford 300 Area - 300-FF-1 and 300-FF-5 Operable Units. Washington State Department of Ecology, U.S. Environmental Protection Agency, and U.S. Department of Energy, Olympia, Washington.

EPA. 1999a. Understanding Variation in Partition Coefficient, Kd, Values: Volume I. The Kd Model, Methods of Measurement, and Application of Chemical Reaction Codes. EPA 402-R-99. 004A, U.S. Environmental Protection Agency, Washington, D.C. prepared by K. M. Krupka, D. I. Kaplan, G. Whelan, R. J. Serne and S. V. Mattigod at the Pacific Northwest National Laboratory, Richland, Washington (approx 300 pages).

EPA. 1999b. Understanding Variation in Partition Coefficient, Kd, Values: Volume II. Review of Geochemistry and Available Kd Values for Cadmium, Cesium, Chromium, Lead, Plutonium, Radon, Strontium, Thorium, Tritium (3H), and Uranium. EPA 402-R-99-004B, U.S. Environmental Protection Agency, Washington, D.C. prepared by K. M. Krupka, D. I. Kaplan, S. V. Mattigod, and R. J. Serne at the Pacific Northwest National Laboratory, Richland, Washington (approx. 400 pages). 
PNNL-14022 300 Area U Leach/Adsorption Study for ERC Final Report Chapter 6. References

Hartman, M. J., L. F. Morasch, and W.D. Webber. 2002. Hanford Site Groundwater Monitoring for Fiscal Year 2001. PNNL-13788, Pacific Northwest National Laboratory, Richland, Washington.

Hsi, C. D., and D. Langmuir. 1985. Adsorption of Uranyl onto Ferric Oxyhydroxides: Application of the Surface Complexation Site-binding Model. Geochimca et Cosmochimica Acta 49, 1931-1941.

Jury, W. A., W. R. Gardner, and W. H. Gardner. 1991. Soil Physics. John Wiley, New York.

Kaplan, D. I., T.L. Gervais, and K.M. Krupka. 1998. Uranium(VI) Sorption to Sediments Under High pH and Ionic Strength Conditions. Radiochimica Acta 225, 1-11.

Kaplan, D.I., and R. J. Serne. 1999. Geochemical Data Package for the Hanford Immobilized Low-Activity Tank Waste Performance Assessment (ILAW-PA). PNNL-13037, Pacific Northwest National Laboratory, Richland, Washington.

Relyea, J. F., R. J. Serne and D. Rai. 1980. Methods for Determining Radionuclide Retardation Factors: Status Report. PNL-3349, Richland, Washington.

Sanders, R.; Legore, V. 2000. Energy Dispersive X-Ray Fluorescence Spectroscopy Using the BEP Approach With the Kevex 770/8000 System. PNNL Operating Procedure AGG-RAL-XRF1, Pacific Northwest National Laboratory, Richland, Washington.

Serne, RJ, CW Lindenmeier, PK Bhatia, and VL LeGore. 1992. Contaminant Concentration vs. Particle Size for 300 Area North Process Pond Samples. WHC-SD-EN-TI-049, Westinghouse Hanford Company, Richland, Washington.

Serne, R.J., H.T. Schaef, B.N. Bjornstad, B.A. Williams, D.C. Lanigan, D.G. Horton, R.E. Clayton, V.L. LeGore, M.J. O’Hara, C.F. Brown, K.E. Parker, I.V. Kutnyakov, J.N. Serne, A.V. Mitroshkov, G.V. Last, S.C. Smith, C.W. Lindenmeier, J.M. Zachara, and D.S. Burke. 2002a. Characterization Of Uncontaminated Sediments From The Hanford Reservation-RCRA Borehole Core And Composite Samples. PNNL-13757-1, Pacific Northwest National Laboratory, Richland, Washington.

Serne, R.J., G.V. Last, G.W. Gee, H.T. Schaef, D.C. Lanigan, C.W. Lindenmeier, R.E. Clayton, V.L. LeGore, R.D. Orr, M.J. O'Hara, C.F. Brown, D.S. Burke, A.T. Owen, I.V. Kutnyakov, and T.C. Wilson. 2002b. Geologic And Geochemical Data Collected From Vadose Zone Sediments From Borehole SX 41-09-39 In The S/SX Waste Management Area And Preliminary Interpretations. PNNL-13757-3, Pacific Northwest National Laboratory, Richland, Washington.

Serne, R.J., H.T. Schaef, B.N. Bjornstad, D.C. Lanigan, G.W. Gee, C.W. Lindenmeier, R.E. Clayton, V.L. LeGore, M.J. O’Hara, C.F. Brown, R.D. Orr, G.V. Last, I.V. Kutnyakov, D.S. Burke, T.C. Wilson, and B.A. Williams. 2002c. Geologic And Geochemical Data Collected From Vadose Zone Sediments From Borehole 299 W23-19 (SX -115) In The S/SX Waste 
PNNL-14022 300 Area U Leach/Adsorption Study for ERC Final Report Chapter 6. References

Management Area And Preliminary Interpretations. PNNL-13757-2, Pacific Northwest National Laboratory, Richland, Washington.

Serne, R.J., G.V. Last, H.T. Schaef, D.C. Lanigan, C.W. Lindenmeier, C.C. Ainsworth, R.E. Clayton, V.L. LeGore, M.J. O’Hara, C.F. Brown, R.D. Orr, I.V. Kutnyakov, T.C. Wilson, K.B. Wagnon, B.A. Williams and D.S. Burke. 2002d. Geologic And Geochemical Data Collected From Vadose Zone Sediments From The Slant Borehole Under SX-108 In The S/SX Waste Management Area And Preliminary Interpretations. PNNL-13757-4, Pacific Northwest National Laboratory, Richland, Washington.

Tessier, A., P.G.C. Campbell, and M. Bisson. 1979. "Sequential Extraction Procedure for the Speciation of Particulate Trace Metals." Anal. Chem. 51, 844-850.

Waite, T. D., J. A. Davis, T. E. Payne, G. A. Waychunas, and N. Xu. 1994. Uranium (VI) Adsorption to Ferrihydrite: Application of a Surface Complexation Model Geochimica et Cosmochimica Acta 58, 5465-5478. 


\subsection{APPENDICES}

\section{A. Leach Column Set-up}

This is a Microsoft Excel file containing the column volumes, sediment sample weights, and additional measured and calculated parameters needed to re-construct the column flow-through leach tests.

\section{B. FY01 Batch and Column Ads $K_{d}$ Set-up}

This is a Microsoft Excel file containing the column volumes, sediment sample weights, and additional measured and calculated parameters needed to re-construct the column flow-through and batch adsorption leach tests.

\section{Sediment Moisture Content}

This is a Microsoft Excel file containing the sediment sample weights and additional measured parameters needed to re-construct the air-dried sediment moisture content analysis/calculations.

\section{Water Extracts}

This is a Microsoft Excel file containing the 1:1 water extract sample set-up information, as well as the results from numerous analyses (i.e. uranium, anions, and cations).

\section{E. Carbon Analysis}

This is a Microsoft Excel file containing the sample set- up information, as well as the results (i.e. organic carbon, total carbon) from the carbon analyses of the near-surface sediment samples.

\section{F. BET Surface Area Data}

This is a Microsoft Excel file containing surface area analysis data for sample B11493.

\section{G. Oxide Calculations and GEA Data}

This is a Microsoft Excel file containing gamma energy analysis data, raw x-ray fluorescence data, as well as the calculations performed to convert the raw data to total oxide percentages. 
PNNL-14022 300 Area U Leach/Adsorption Study for ERC Final Report

Chapter 7. Appendices

\section{H. Particle Size vs. Activity Data}

This is a Microsoft Excel file containing the sample weights and raw gamma energy analysis data used to determine the total uranium activity for the various sediment particle size fractions.

\section{Particle Size Data}

This is a Microsoft Excel file containing the measurements and weights needed to reconstruct the particle size analysis of the eight 300 Area near-surface samples.

\section{J. SEM EDS Files}

This is a Microsoft Excel file containing the Energy Dispersive Spectra from the scanning electron analysis of two particle size fractions from sample B11BY6.

\section{K. Semi-Selective Extraction Data}

This is a Microsoft Excel file containing the sample weights, data, and calculations required to reproduce the semi-selective extraction analysis.

\section{Leach Column Data}

This is a Microsoft Excel file containing the daily sampling information, as well as the results of the analyses of the various aliquots of leachate.

\section{Batch Leach Test Set-up and Data}

This is a Microsoft Excel file containing the sample weights, data, and calculations required to reproduce the extended-time batch leach test data.

\section{N. Batch Adsorption Test Variable Uranium}

This is a Microsoft Excel file containing the sample weights, data, and calculations required to reproduce the batch adsorption $\mathrm{K}_{\mathrm{d}}$ test utilizing varying uranium solution concentrations.

\section{O. Batch Adsorption Variable pH}

This is a Microsoft Excel file containing the sample weights, data, and calculations required to reproduce the batch adsorption $\mathrm{K}_{\mathrm{d}}$ test utilizing varying solution $\mathrm{pHs}$. 
PNNL-14022 300 Area U Leach/Adsorption Study for ERC Final Report

Chapter 7. Appendices

\section{P. Batch Adsorption Variable Carbonate}

This is a Microsoft Excel file containing the sample weights, data, and calculations required to reproduce the batch adsorption $\mathrm{K}_{\mathrm{d}}$ test utilizing varying carbonate solution concentrations.

\section{Q. Adsorption-Desorption Columns}

This is a Microsoft Excel file containing the column volumes, sediment sample weights, and additional measured and calculated parameters needed to re-construct the column flow-through adsorption-desorption tests.

\section{R. Experiment Key}

This is a Microsoft Excel file outlining the solutions used in the various tests that were performed as part of this study.

\section{S. Mineralogy}

This is a Microsoft Word write-up of the mineralogy work that was performed as part of this study.

\section{T. SEM Write-up}

This is a Microsoft Word write-up of the scanning electron microscopy work that was performed as part of this study.

\section{U. Molecular Probe Write-up}

This is a Microsoft Word write-up of the molecular probe analysis that was performed as part of this study.

\section{Scouting Column Adsorption Write-up}

This is a Microsoft Word write-up of the scouting adsorption column work that was performed as part of this study. 
PNNL-14022 300 Area U Leach/Adsorption Study for ERC Final Report

Chapter 7. Appendices

\section{W. Activity vs. Grain Size Write-up}

This is a Microsoft Word write-up of the activity vs. grain size investigation that was performed as part of this study. 